\title{
صور التعدي على المعلومات التجارية السرية "دراسة تحليلية مقارنة بين النظام السعودي والتشريعات الدولية" تهية
}

\author{
shel \\ د.اعلي بن صالج الزهراني

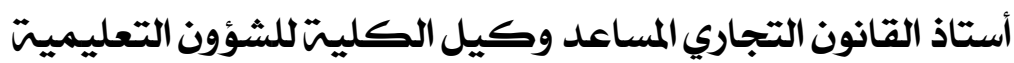

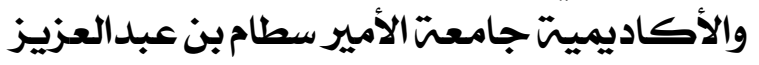 \\ قسم القانون - كليتَ إدارة الأعمال
}


عالجت هـذه الاراسـة موضـوع صـور الاسـتذذام المشـروع وغير المششروع

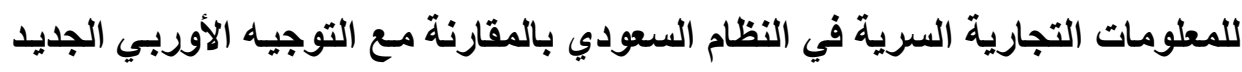

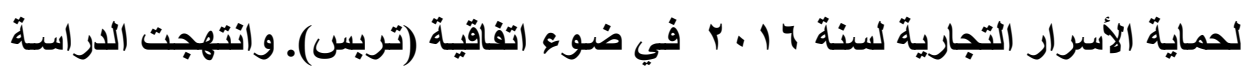

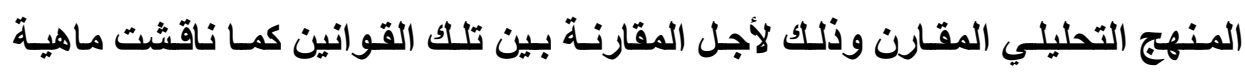

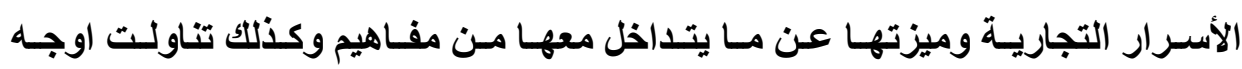

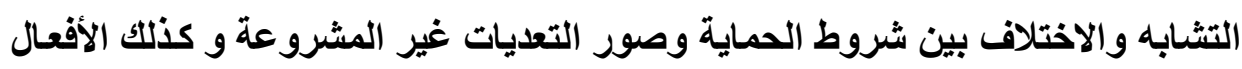

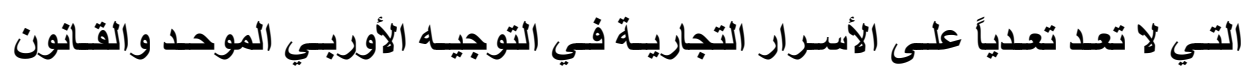

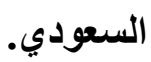

وخلصت الاراسة إلى ان شروط حمايـة المطلومـات التجارية السرية في النظام

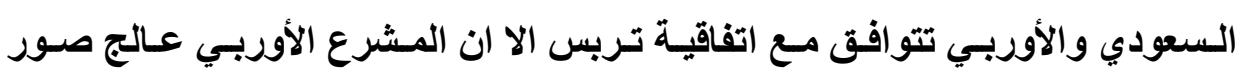

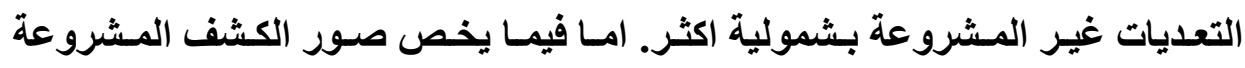

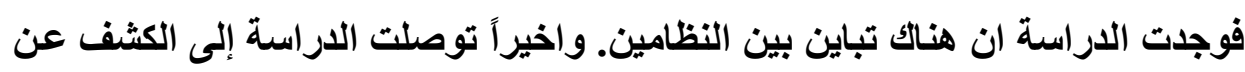

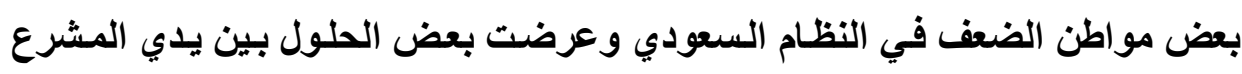
لتبنيها مستقبلاً. 


\section{Abstract:}

This study has addressed the issue that what kind of practices are considered to be infringement of the trade secret and what practices are considered to lawful in the Saudi Trade Secret Law comparing with the new Trade Secret Directive of the EU (2016) in the light of the (TRIPS) Agreement. The study adopted a comparative and analytical method in order to compare between the two Trade Secret Laws. The study has discussed the definition of trade secrets and has clearly distinguished it from the other concepts which interfere with it. Also, it has dealt with the similarities and differences found between the requirements for the protection and infringements and non-infringements types in both laws.

The study concluded that the requirements for the protection of secrets in Saudi Arabia and the European system both are consistent with the TRIPS agreement, but the European Draft addressed the issue of non-infringements more comprehensively. As for the issues of legitimate disclosure are concerned, the study has found that there is inconsistency between the two law. Finally, the study detected some weaknesses in the Saudi law and offered some solutions for the government to adopt in the future. 
تعد حماية حقوق الملكية الفكرية من التوجهات الديثة في التشريعات المقارنة التي جاعت استجابة للتطور التجاري والاقتصادي والصناعي وازدهاره بين دول المجتمع الدولي الحديث. إلا أنها كاتت معروفة بصورة بدائية بثكل أو بآخر لاى الأمم السابقة فقد عرفت في الحضارة الفرعونية وحضارة بلاد ما بين النهرين والحضارة

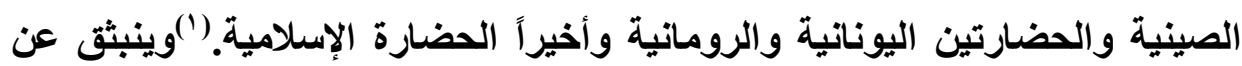

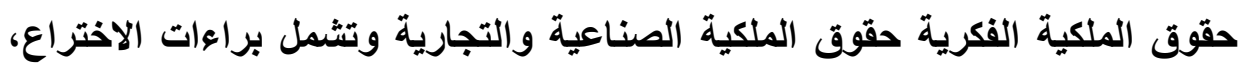
والرسوم والنماذج الصناعية، والعلامات التجارية، والمؤشرات الجغرافية والأسرار

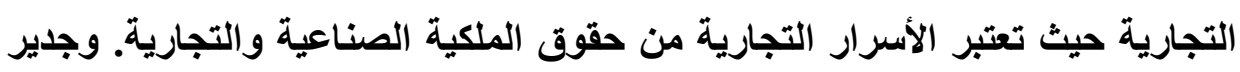
بالذكر أن هذه النوعية من الحقوق تسمى بتسميات مختلفة في التشريعات والاتفاقات الدولية فتاره نجدها باسم الأسرار التجارية Trade secret وتارة باسم المعلومات غير المفصح عنها Undisclosed information وتارة باسم المعلومات التجارية السرية Secret commercial information كما هو الحال في التشريع

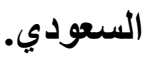

وتعتبر الأسرار التجاريـة كأحد أهم أنواع حقوق الملكية الصناعية والتجاريـة

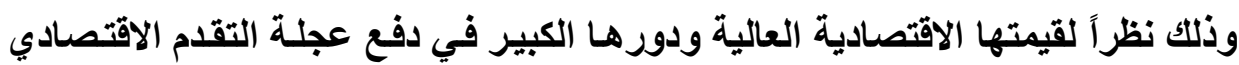

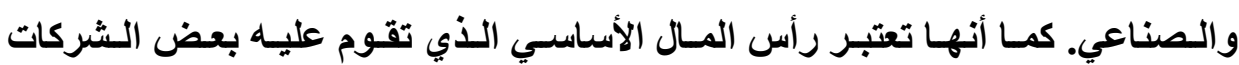
التجارية في استثماراتها. ولم تعترف بها كثير من التشريعات الحديثة إلا بعد إقرارها ضمن اتفاقية الجوانب المتصلة بالتجارة من حقوق الملكية الفكرية (تربس) (TRIPS) (1) انظر د.خالد ممدوح إبراهيم ، حقوق الملكية الفكرية ،الملكية الصناعية ــ الملكية الأدبية والفنية.

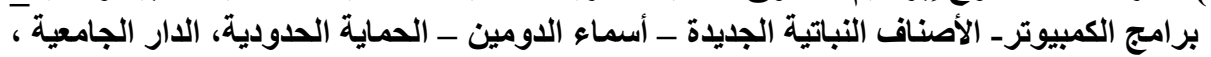

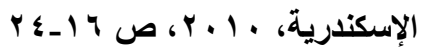


Agreement on Trade-Related Aspects of Intellectual Property Rights (') حيث ألزمت الاتفاقية الدول الأعضاء في المنظـة بتبني قوانين لحمايـة حقوق الملكية الفكرية بما يتو افق مع أحكام الاتفاقية. وكان الهـف من إقرار الاتفاقية لهذا النوع من الحماية هو إسباغ الحماية الدولية عليها نظراً لتنامي التجارة الدولية التهاية العابرة للقارات التي تقوم في استثمار|تها على هذه الحقوق وذلك كاستثناء على مبلدأ إقليمية القوانين.

تعد اتفاقية (تربس) من أهم وأشمل الاتفاقيات الدولية المتعقة بحقوق الملكية الفكرية حيث تضمنت قواعد قانونية لحماية كافة أنواع حقوق الملكية الفكرية(") بما فيها الأسرار التجارية وقد فرضت على الأعضاء حداً أدنى من معايير الحماية يجب

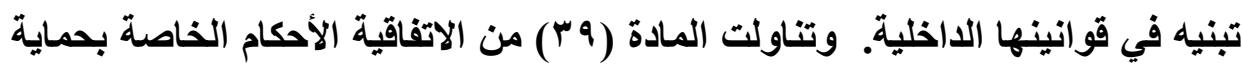
المعلومات التجارية السرية تحت مسمى " المعلومات غير المفصح عنها"، Undisclosed Information حماية قانونية على الأسرار التجارية.(") ووفقاً لأحكام هذه الاتفاقية فإن الأحكام الواردة

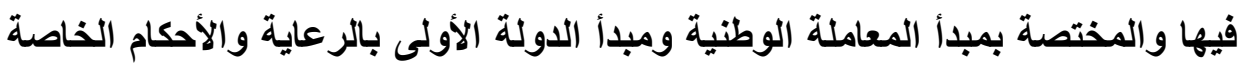

(1)Agreement on Trade-Related Aspects of Intellectual Property Rights, The TRIPS Agreement is Annex 1C of the Marrakesh Agreement Establishing the World Trade Organization, signed in Marrakesh, Morocco on 15 April 1994.

(2)See in general, Justin Malbon, Charles Lawson, Mark Davison, The WTO Agreement on Trade-related Aspects of Intellectual Property Rights: A Commentary, (Edward Elgar Publishing, 2014).

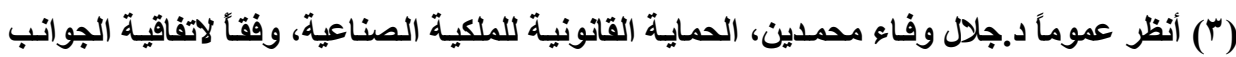
المتصلة بالتجارة من حقوق الملكية الفكريـة (تريبس)، دار الجامعة الجديدة للنشر، الإسكندرية 
باكتساب الحقوق وإنفاذها والأحكام الخاصة بالمنازعات جميعها تسري أيضاً على المعلومات غير المفصح عنها. كما أن المادة (؛ () من اتفاقية (تربس) ألزمت الدول

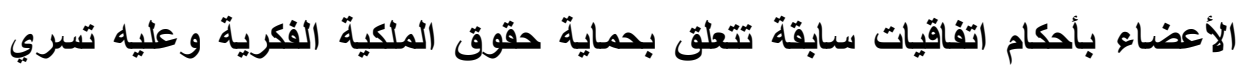
الأحكام الخاصة الواردة بقمع المنافسة غير المشروعة وتطبيقاتها الواردة في المواد

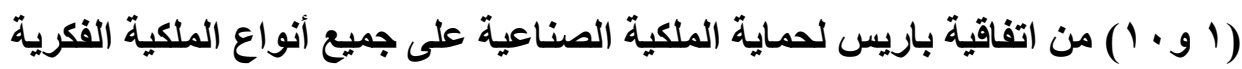

$$
\text { التي وردت في اتفاقية (تربس). (') }
$$

وقد سارعت المملكة العربية السعودية كغيرها من الدول الأعضاء في منظمة

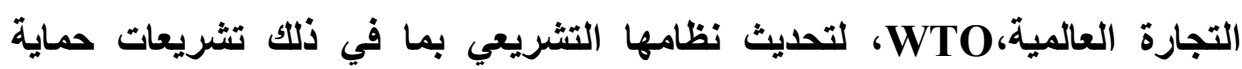

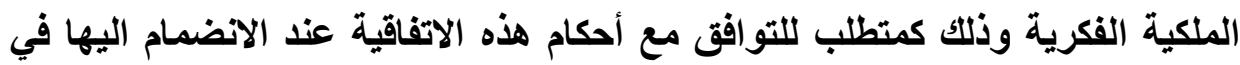

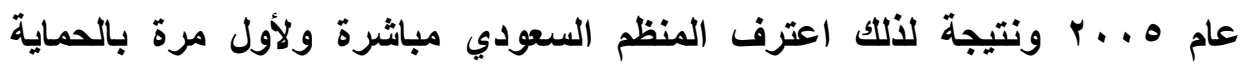
القانونية للأسرار التجارية،حيث صدرت لائحة خاصة بحكم الأسرار التجارية باسم

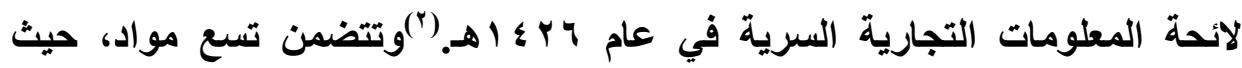

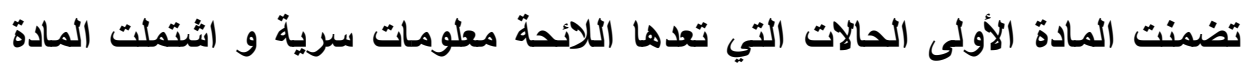

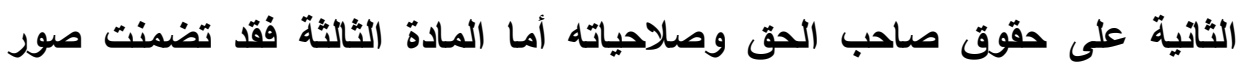

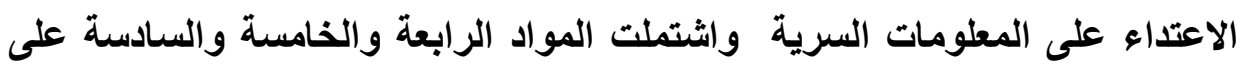

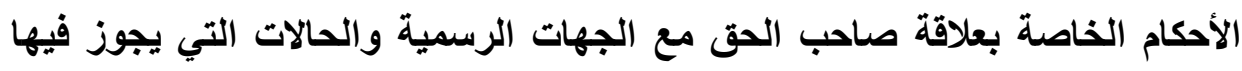

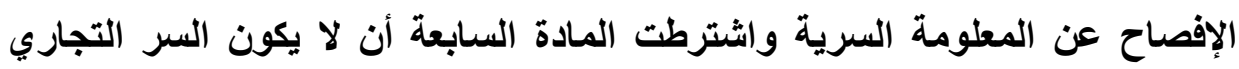

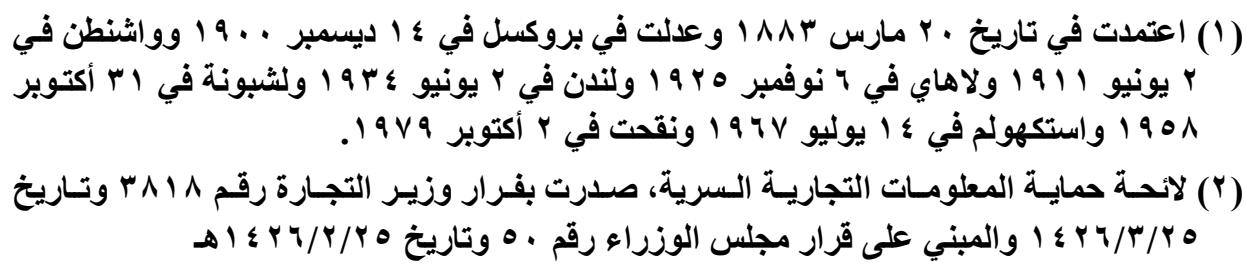




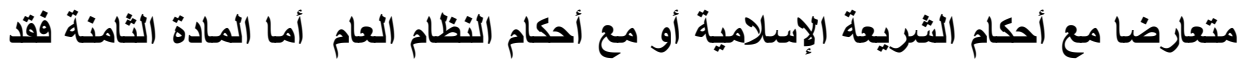

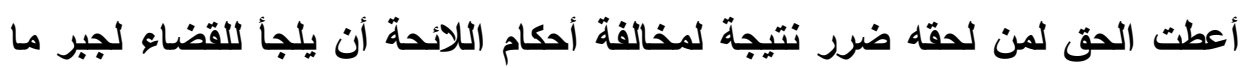

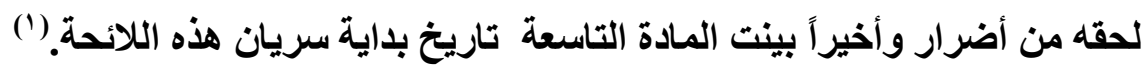

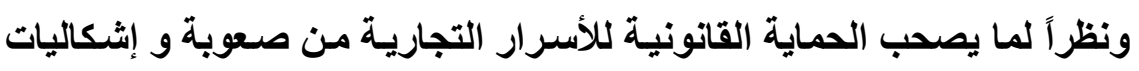
قانونية متعددة في كثير من دول العالم فقد عمدت كثير من هذه الدول(") إلى إدخال تعديلات جوهرية على قوانينها في هذا المجال وكان أخرها التطور التشريعي في دول

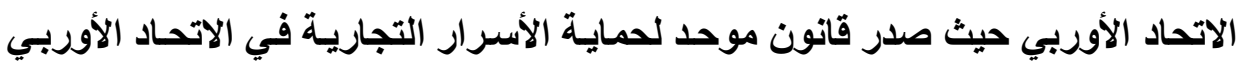
Y 14 بU Trade Secrets Directive of 2016

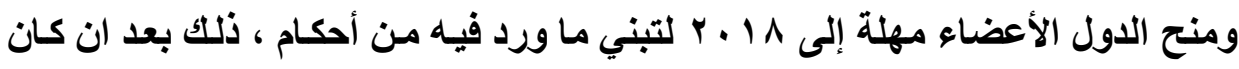
الأمر متروكاً للاول الأعضاء لتوفير حماية وطنية داخلية للأسرار(

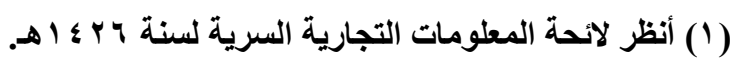

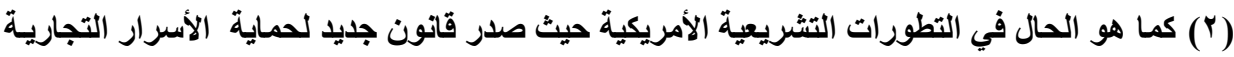

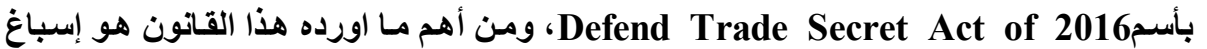

$$
\text { الحماية القدرالية على الأسرار التجارية. }
$$

(3)Directive (EU) 2016/943 of the European Parliament and of the Council of 8 June 2016 on the protection of undisclosed know-how and business information (trade secrets) against their unlawful acquisition.

كلمة Directive تغني احد اشكال التشريعات التي تفرض على الدول الأعضاء في الاتحساد الأوربي

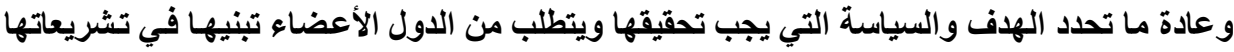

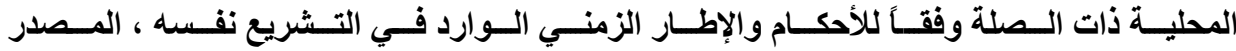
http://www.europeanlawmonitor.org/what-is-guide-to-key-eu-terms/eulegislation-what-is-an-eu-directive.html

(4)See , Torremans, Paul L. C, The road towards the harmonisation of trade secrets law in the European Union, Revista La PropiedadInmaterial,, Issue 20,(2015) P24 also see, David T. Keeling, $=$ 
عنه تباين في مستوى الحماية الموفرة بين الأعضاء وتسببه في كثير من الإثكاليات القانونية والاقتصادية وخصوصاً في ازدياد حالات المنافسة غير المشروعة في الدول الأعضاء.(')وقد صدر التوجيه الأوربيك استجابة لعدد من التقارير التي قيمت وضع

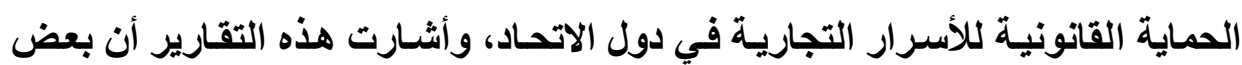
الاول لا يوجد بها قانون خاص للأسرار التجارية وإنما توفر لها الحماية تحت قوانين المسؤولية المدنية والجنائية، ووجدت التقارير أيضاً ان حتى في الدول التي يوجد بها قوانين للأسرار التجارية فهي بحاجة للتطوير والتحديث وقد خلصت هذه التقارير إلى

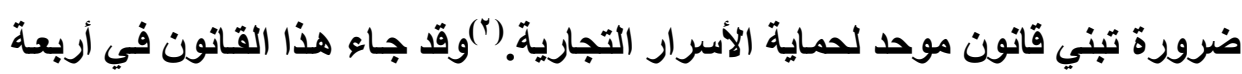
Subject Matter فصول رئيسية، تضمن الفصل الأول نطاق القانون وموضوعيه and Scope ، Acquisition, use and disclosure of the trade secret للأسرار التجاريـة

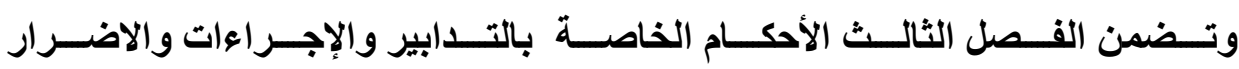
وجبر هابeasures, procedures and Remedies ، اما الفصل الرابع فقد تناول

Intellectual Property Rights in EU Law Volume I: Free Movement and Competition Law: 1 (OUP Oxford, 2004), p.30

(1) Tanya Aplin, A critical evaluation of the proposed EU Trade Secrets Directive, King's College London Dickson Poon School of Law Legal Studies Research Paper Series, paper no. 2014-25, (2014) p. 3-4.

(2) See, Baker \& Mackenzie, Study on Trade Secrets and Confidential Business Information in the Internal Market, MARKT/2011/128/D (2013) (B\&M Report). Also see, Hogan Lovells International, Study on Trade Secrets and Parasitic Copying (Look-alikes), MARKT/2010/20/D: Report on Trade Secrets for the European Commission (2012) (Hogan Lovells Report). 
Sanction, reporting الأحكام الخاصة بالعقوبات و التقارير ويعض الأحكام الختامية الاعضاء.and final provisions

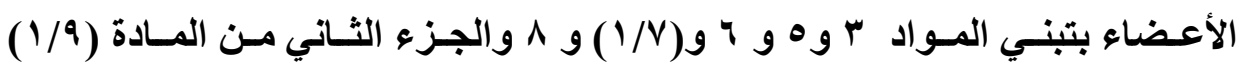

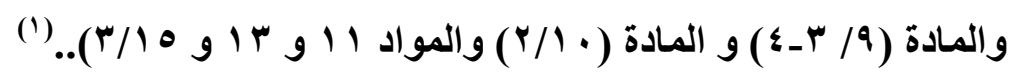
أهمية البحث

تعد حماية الأسرار التجارية من الظواهر الاقتصادية والقانونية التي تقوم عليها

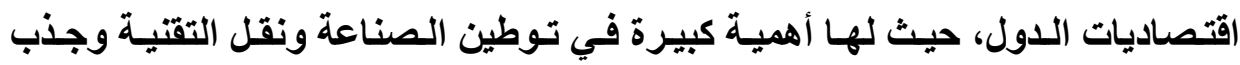

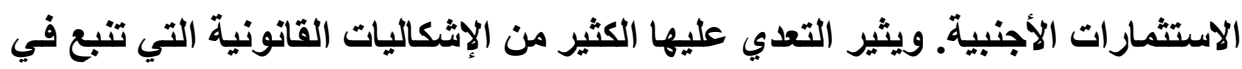

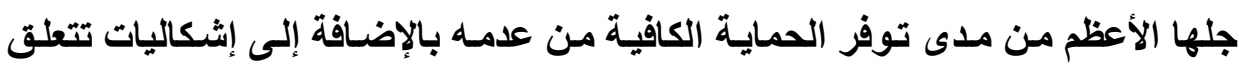
بطريقة تكييف الأسس القانونية التي تؤسس عليها الحماية القانونية للأسرار التجارية

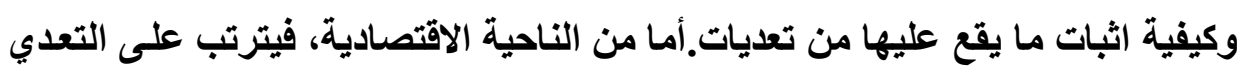

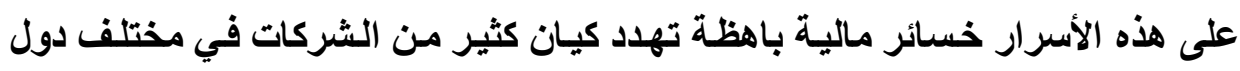
العالم.(") نظراً للتطورات التثريعية الأوروبية الجديدة في هذا المجال، جاعت فكرة هذان

(1) Article (1/1 states as follow: "This Directive lays down rules on the protection against the unlawful acquisition, use and disclosure of trade secrets. Member States may, in compliance with the provisions of the TFEU, provide for more far-reaching protection against the unlawful acquisition, use or disclosure of trade secrets than that required by this Directive, provided that compliance with Articles 3, 5, 6, Article 7(1), Article 8, the second subparagraph of Article 9(1), Article 9(3) and (4), Article 10(2), Articles 11, 13 and Article 15(3) is ensured."

(2)Fitzpatrick, William M; DiLullo, Samuel A., International Trade Secret Protection: Global Issues and Responses, Competition Forum 11.2 (2013), P 21. 
البحث لمقارنة النظام السعودي لحمايـة الأسرار التجارية بأحلث التطورات في مجاله والنظر في مدى مسايرته لتك التطورات بالكثف عن مزاياه وعيويه وتقديم المقترحات اللازمة للارتقاء به بما يحقق الهدف المنشود من وجوده. وتظهر أهمية هذا البحث ايضاً في أنه سيسلط الضوء على التطورات القانونية

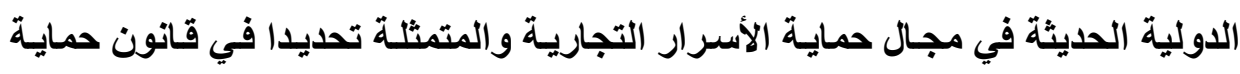

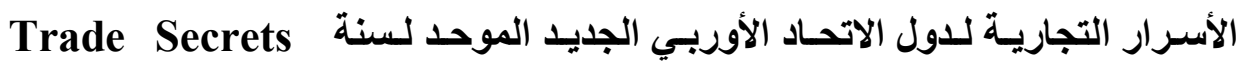
Directive 2016 صور التعدي غير المشروع وكذلك على صور الكثف التي يعتبرها القانون مشروعة ،

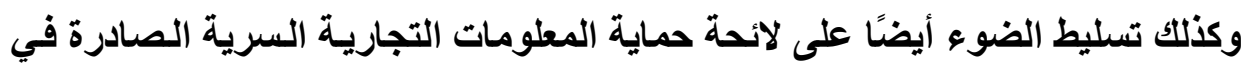

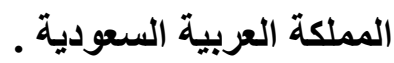

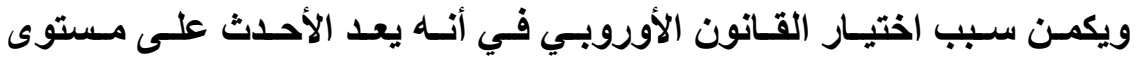

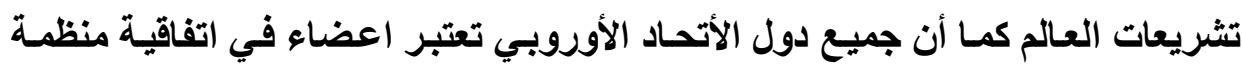
التجـارة الاوليـة المتعقة بحقوق الملكيـة الفكريـة وذلكت الحسال تعتبر المملكة العربيـة

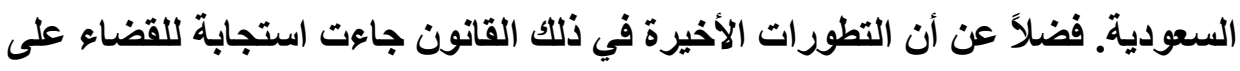

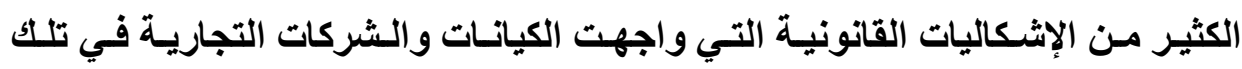
البلدان وخصوصا أنها تعتبر من أكبر اقتصاديات العالم، وكذلك الحال بالنسبة للاقتصاد

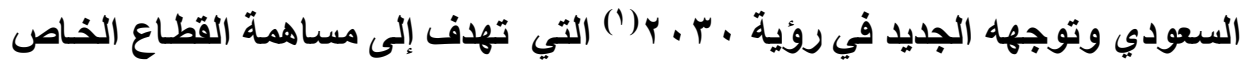

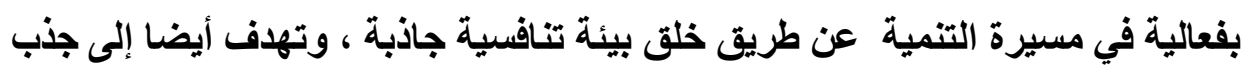

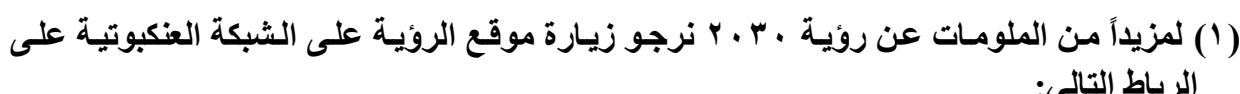
http://vision2030.gov.sa/ 
مزيداً من الاستثمارات الأجنبية والانتقال بحجم الاقتصاد المحلي إلى مراتب عالمية متقدمة.

ونحو تحقيق هذا الهدف كان لا بـ من جعل دول الاتحاد الأوروبي لمـا للديها

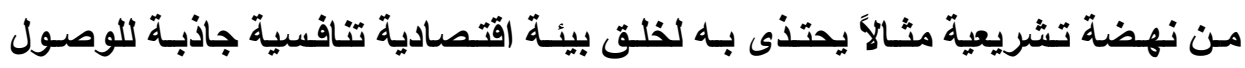

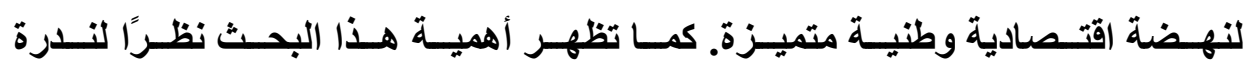
الأبحاث المتخصصة التي تتناول هذا الموضوع، ليس في المملكة العربية السعودية

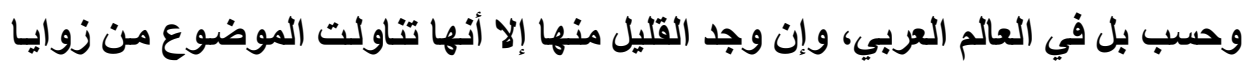
مختلفة عن هذا البحث حيث ركز جلها الأعظم على الحماية القانونية للأسرار التجارية.

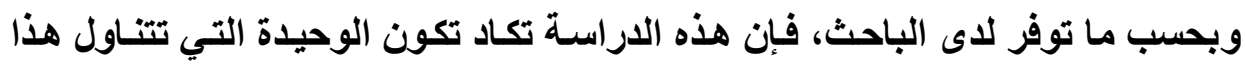
الموضوع.

\section{أهداف الدراسة}

ويناء على الأهمية السابقة لموضوع البحث فإنه يهاف إلى التالي:

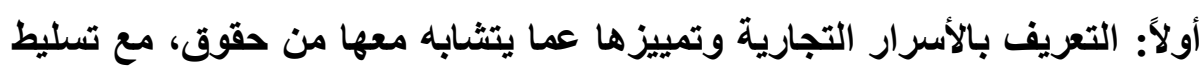

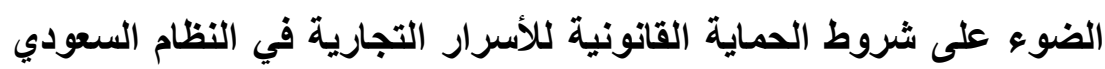

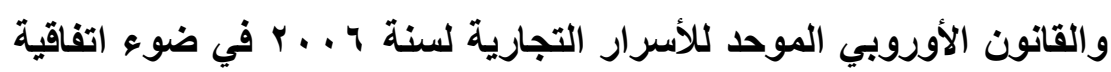

$$
\text { (تربس). }
$$

ثانياً: الكثف والمقارنة بين ما يعد في القانونين من صور التعديات غير المشروعة على الأسرار التجارية في ضوء اتفاقية (تربس). ثالثاً: الكثف والمقارنة بين ما يعد في القانونين من صور كثف الأسرار التجارية المشروعة على ضوء اتفاقية (تربس). 
رابعاً: النظر في مدى كفاية ما أورده المنظم السعودي من صور مـا يعد ومـا لا يعد

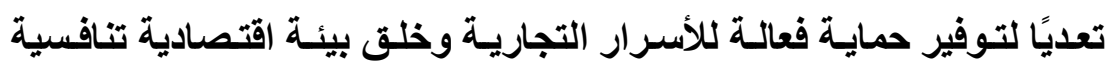

$$
\text { جاذبة. }
$$

خامسـاً: التعـرف علـى مـواطن القـصور التــي غفـل عنهـــا المـنظم فـي لاتحــة حماية المعلومات التجارية السرية واقتراح ما يمكن لسد الفراغ التشريعي إن

\section{وجد. \\ أسئلة البحث}

تهدف هذه الاراسة إلى الإجابة عن الأسئلة التالية:

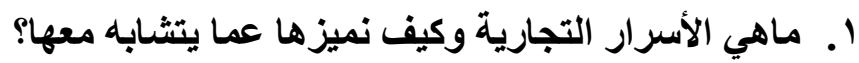

r. ماهي الثروط المتطلبة للحماية في النظام السعودي وفي القانون الأوروبي

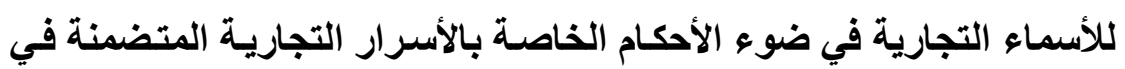

$$
\text { اتفاقية (تربس)؟ }
$$

r. مـاهي صـور التعديات غير المششروعة على الأسـرار التجاريـة في القـانون

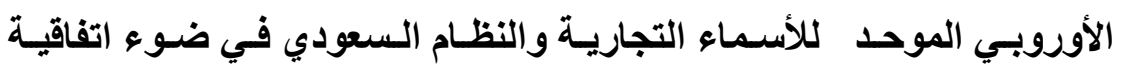

$$
\text { (تربس) }
$$

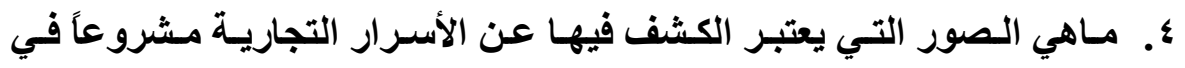

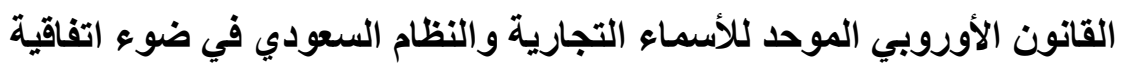

$$
\text { (تربس) }
$$

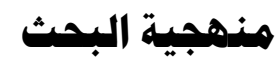

يتبع هذا البحث الأسلوب التحليلي المقارن عن طريق مناقشة النظام القانوني لحمايـة المعلومـات السرية في المملكة وقانون دول الاتحـاد الأوروبي الموحد الجديد 
لسنة 17 ـ ب م، و النظر في مدى تو افقـه مع اتفاقيـة منظمـة التجارة العالمية المتعلقة

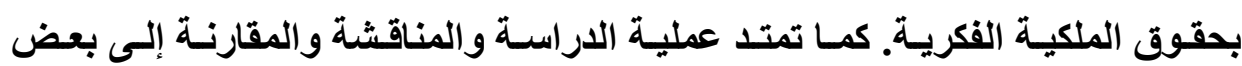
التثريعات العربية والأجنبية متى ما أمكن ذلك. واخيراً تهلف عملية التحليل والمقارنة إلى كثف مواطن الظلل والقصور في النظام السعودي وتقديم الحلول القانونية لها.

\section{عوائق البحث}

من أبرز الإثكاليات التي واجهت الباحث هي ندرة المراجع التي تتناول موضوع البحث، حيث لا يوجد منها فيما يتطلق بالنظام السعودي إلا عدد محدود جداً يتناول الموضوع من جوانب مختلفة عن موضوع البحث حيث تناول البحث الجوانب القانونية لحماية الأسرار التجاريـة إضـافة إلى إلى استعرض القانون الأوروبي الموحد، الأمر

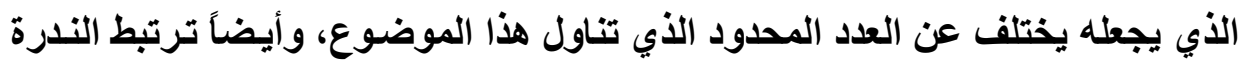

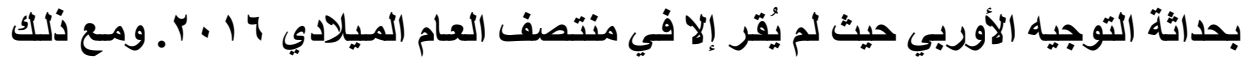

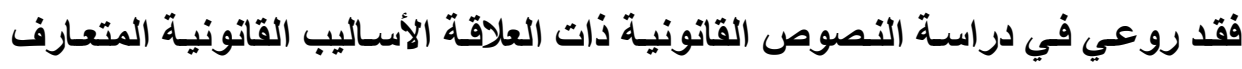

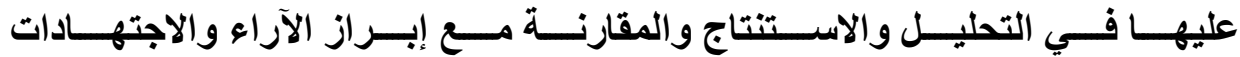
الققهيـة والقضائية متى مـا أمكن ذلكت بمـا يضمن الوصسول لإجابـات شـافية لأسئلة

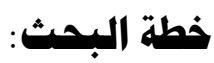

المبحث الأول: ماهية المعلومات التجارية السرية

المبحث الثاني: الاستخدام المشروع للمعلومات التجارية السرية

المبحث الثاث: التعدي علي المطلومات التجارية السرية 


\section{المبحث الأول \\ هاهية المعلوهات التجارية السرية}

تقتضي دراسـة الحمايـة القانونيـة للأسرار التجاريـة أن نحدد المقصود بهـا

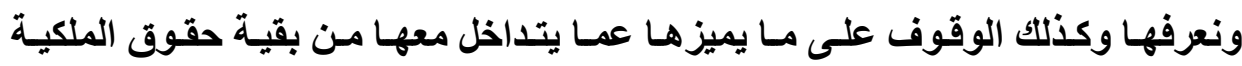
الصناعية والتجارية ثم بيان الثروط اللازم توافرها فيها حتى تتمتع بالحماية القانونية. وعليه سيقسم هذا المبحث إلى ثُلاثة مطالب كالتالي:

\section{المطاب الأول \\ تعريف المعلوهات التجارية السرية}

تتبنى التشريعات المقارنة تعريفات ومسميات مختلفة للأسرار التجاريـةكما أن الاجتهادات الفقهية تتباين ايضا في هذا المجال. ويعود ذلك إلى الصعوبة العملية في

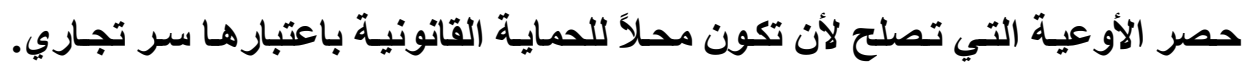

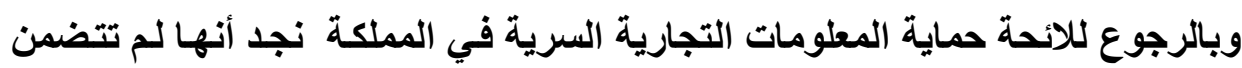
تعريفاً شاملاً ودقيقًا للمعلومة التجارية السرية إنما اكتفت بسرد ما تعتبره من الأسرار

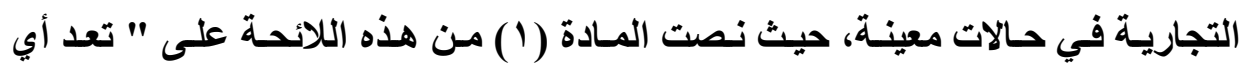
معلومة سراً تجارياً في أي من الحالات الآتي بيانها: 1- إذا كانت غير معروفة عـادة في صورتها النهائيسة، أو في أي من مكوناتها

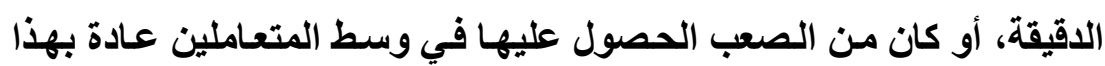

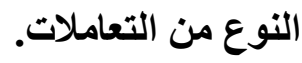


r- إذا كانت ذات قيمة تجارية نظراً لكونها سرية.

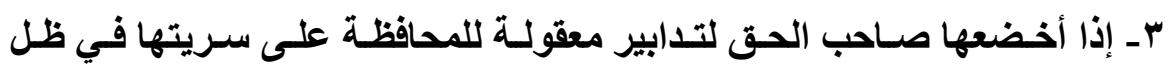

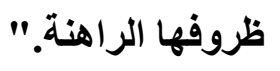

وبالرغم مما اكتفف هذه المادة من عيب وخطأ في الصياغة(') لاعتبارها أن توفر

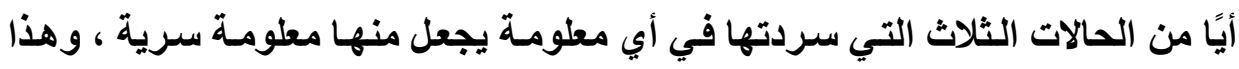

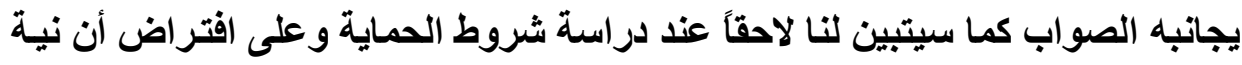
المنظم لم تتجه لذلك فإنا نلاحظ أن محاولة هذه المسادة لتعريف الأسرار التجارية جاء التهاء

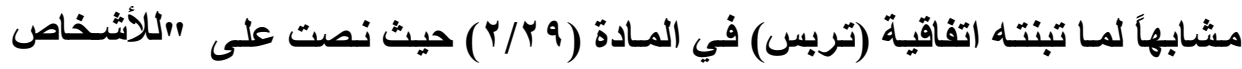

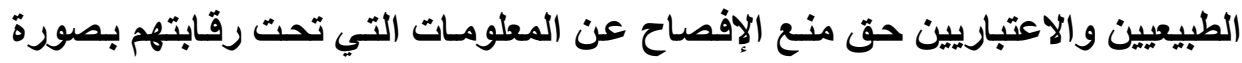

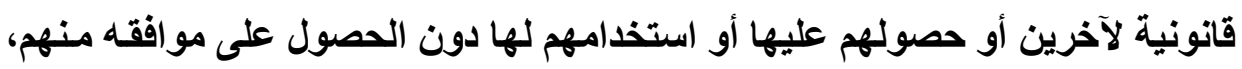
بأسلوب يخالف الممارسات التجارية النزيهة طالما كانت تلك المعلومات: () سرية من حيث أنها ليست، بمجموعها أو في الشكل والجميع اللقيقين لمكوناتها

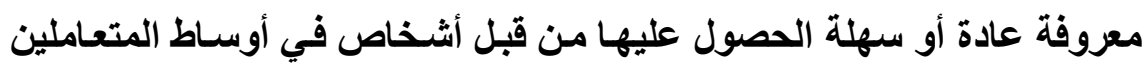
عادة في النوع المعني من المعلومات. ب) ذات قيمة تجارية نظرا لكونها سرية.

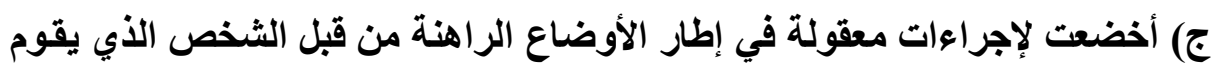

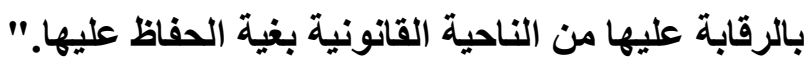

( ) د.زياد القرشي ،الحماية القانونية للأسرار التجارية ، دراسة تحليلية مقارنة بين النظام السعودي

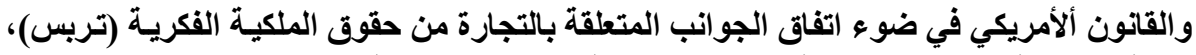

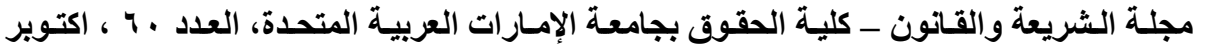


ويلاحظ أيضاً ان المنظم السعودي لم يقيد مفهوم السر التجاري بـأنواع معينة

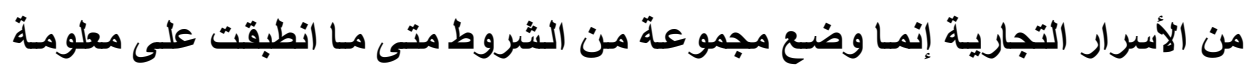

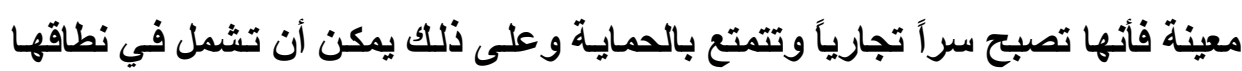

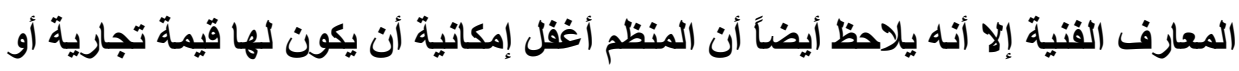

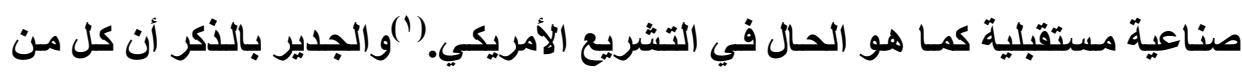

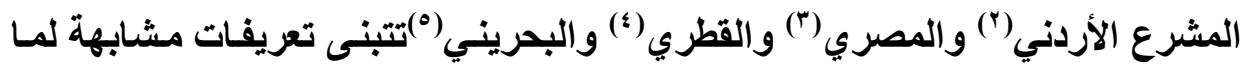
أورده المنظم السعودي واتفاقية (تربس) وفي نفس السياق تبنى قانون حماية الأسرار

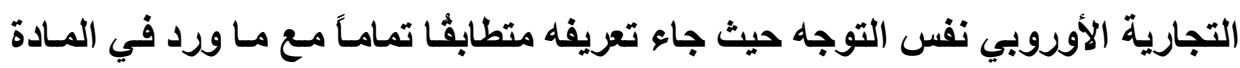

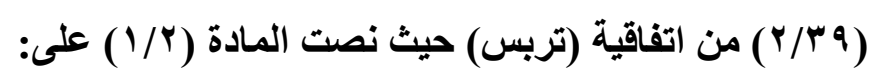

"'trade secret' means information which meets all of the following requirements:

(a) it is secret in the sense that it is not, as a body or in the precise configuration and assembly of its components, generally known among or readily accessible to persons within the circles that normally deal with the kind of information in question;

(b) it has commercial value because it is secret;

(1)Defend Trade SecretsAct of 2016,18 U.S.C. $§$ 1839(3/b).

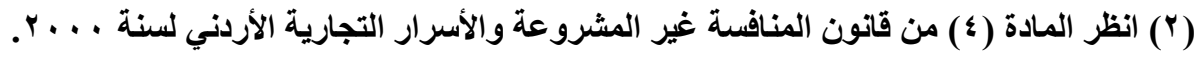

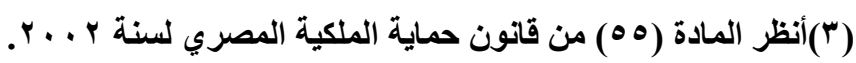

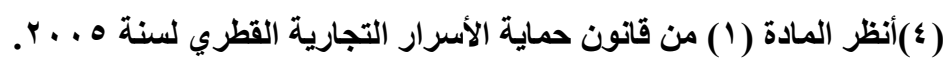

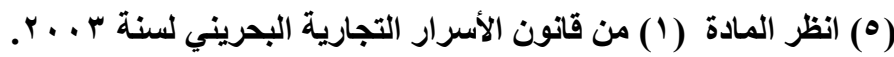


(c) it has been subject to reasonable steps under the circumstances, by the person lawfully in control of the information, to keep it secret;"

$$
\text { الا ان المادة (ז/؟ ) نصت على: }
$$

"infringing goods' means goods, the design, characteristics, functioning, production process or marketing ....".

ويستفاد من ذلك بأن السلع المخالفة قد تكون تصاميم أو خصائص أو وظائف

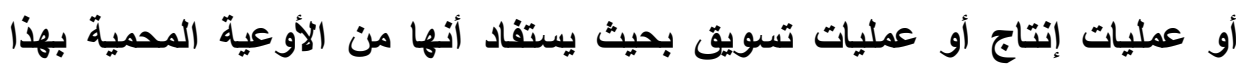
القانون.ويلاحظ أن التشريعات السابقة أغفلت تعداد ما يمكن اعتباره سراً تجارياً بثكل مباشر وهذا بخلاف قانون الأسرار التجارية الأمريكي الجديد حيث نص على:

"the term "trade secret" means all forms and types of financial, business, scientific, technical, economic, or engineering information, including patterns, plans, compilations, program devices, formulas, designs, prototypes, methods, techniques, processes, procedures, programs, or codes, whether tangible or intangible, and whether or how stored, compiled, or memorialized physically, electronically, graphically, photographically, or in writing..."(1)

(1) Defend Trade Secrets Act of2016, 18 U.S.C. § 1839(3). 
ويعني ذلك أن مصطلح السر التجاري هو" المعلومـات المالية ، التجاريـة ، العلميـة،

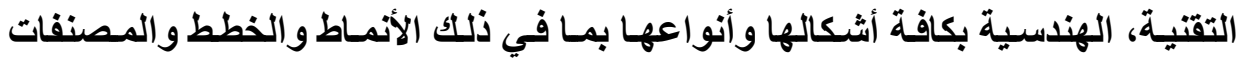
وأجهزة البرمجـة والتركيبـات والتصاميم و النمـاذج والنظريـات والأسـاليب التقتيـة و العمليات والإجراءات سواء كانت ملموسـة أو غير ملموسة بغض النظر عن طريقة

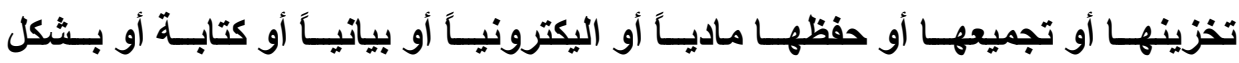

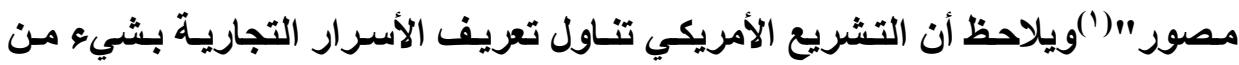

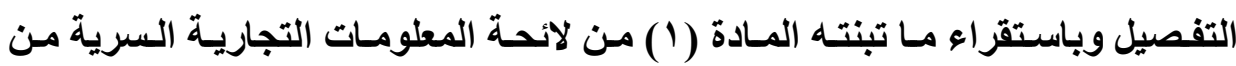

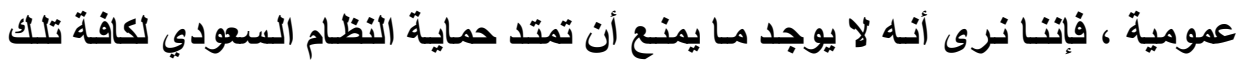
الأنواع التي وردت في التشريع الأمريكي، وعلى الرغم من إغفال المنظم السعودي

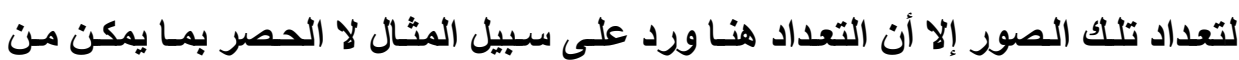
القياس على هذه النوعية من الأعمال متى ما تو افرت شروط القياس.

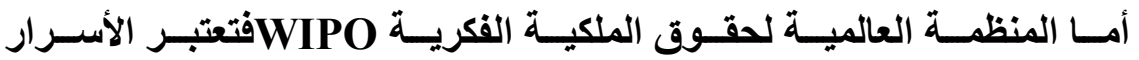

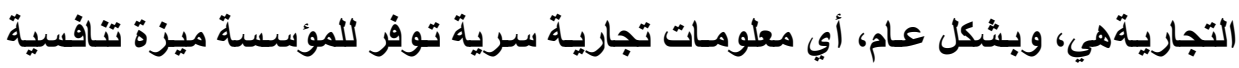

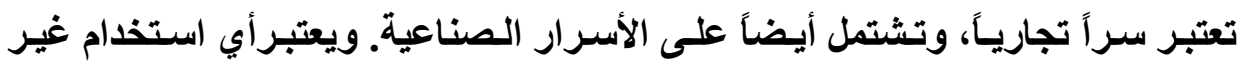

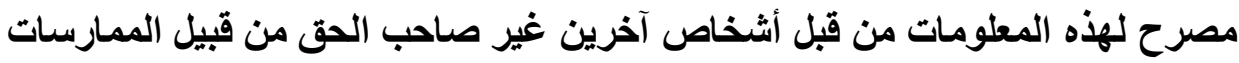

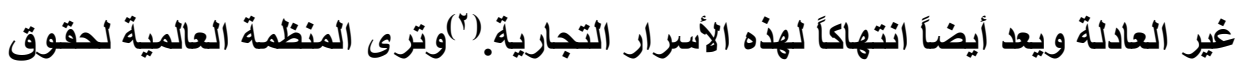

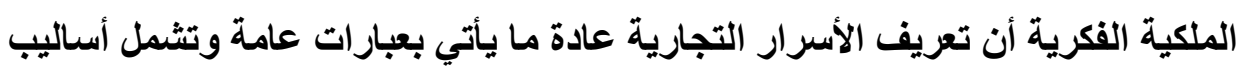

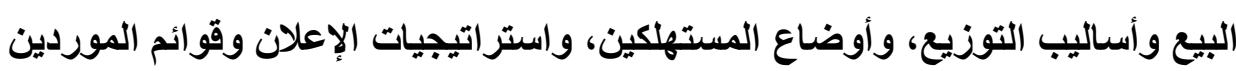

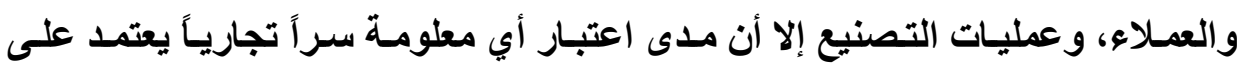

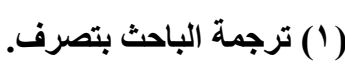

(2)http://www.wipo.int/sme/en/ip_business/trade_secrets/trade_secrets.htm 
ظروف كل حالة على حدة ـو واعتبرت منظمـة WIPO أن الممارسـات غير العادلة أو

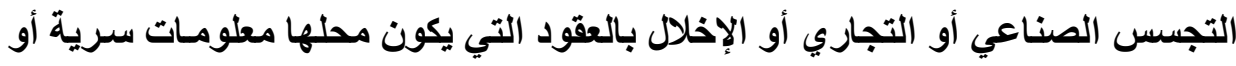

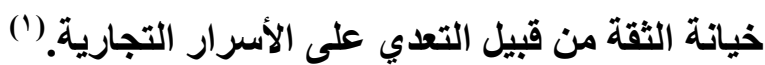
وقد تنـاول الفقه أيضًا تعريف الأسرار التجاريـة فذهب جانباً منه إلى تعريفها بأنها " المعلومات التي تكون نتاج جهود كبيرة توصل إليها صاحبها واحتفظ بسريتها،

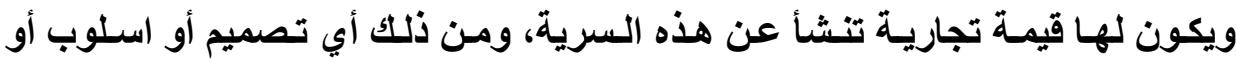

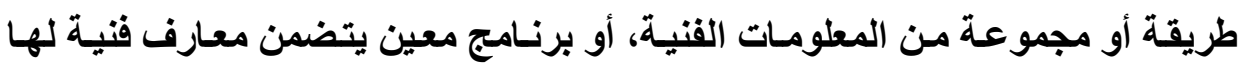
قيمة تجاريـة".(") وبعد استقراء التعريفات السابقة، نلاحظ أن الأسرار التجاريـة هي عبارة عن مطلومـات تجاريـة أو صناعية سرية بمـا فيها المهارات والخبرات الفنيـة

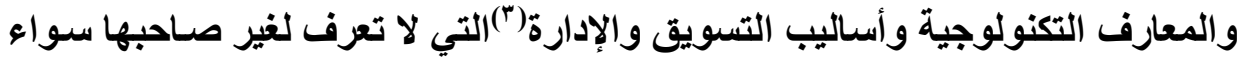

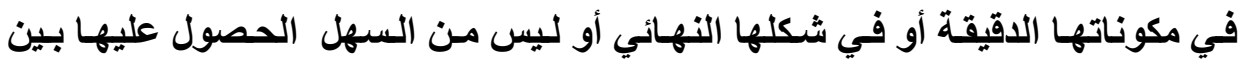

(1)http://www.wipo.int/sme/en/ip_business/trade_secrets/trade_secrets.htm

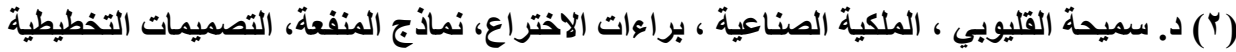

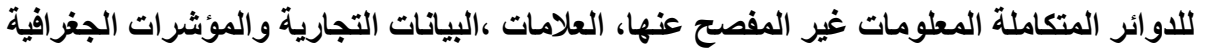

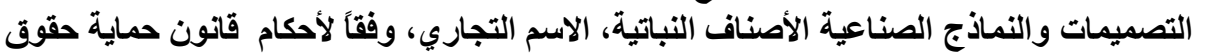

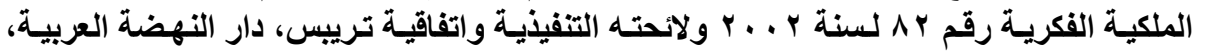

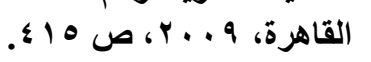

See Also, Brian T. Yeh, Protection of Trade Secret: Overview of Current Law and Legislation, Congressional Research Service, 7-5700, ( 2016), P.2.

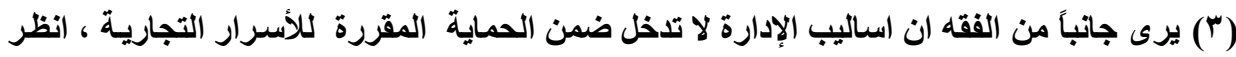

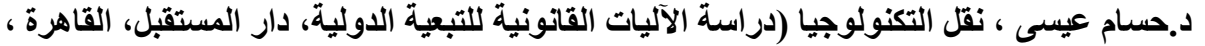

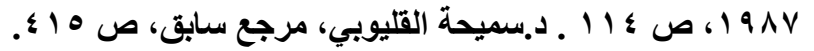


المتعاملين في محلها عادة ويشترط أن يكون لها قيمـة تجاريـة حالية أو مستقبلية وأن يأخذ صاحبها من التدابير الوقائية ما يضمن سريتها و الحفاظ عليها. (') ويذهب الراجح في الفقه إلى أن أبرز مـا تشمـه الأسرار التجارية في مفهومها

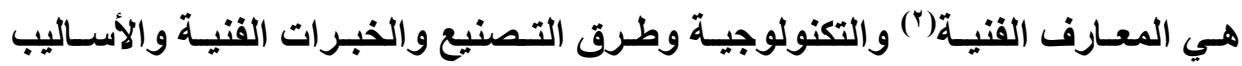
الإدارية و التنظيمية والتسويقية.(")

ونحن بدورنا نؤيد ما ذهب إليه الفقه من توجه في هذا المجال نظراً لأن هذه

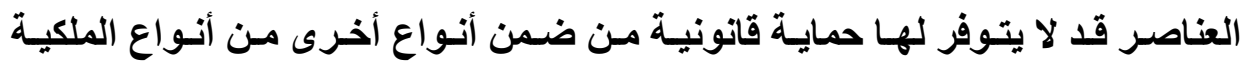

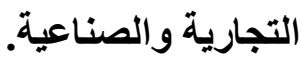

(1)Daniel Gervais, Intellectual Property and Trade and Development, (Oxford University Press; 2 ed., 2014), p.168.

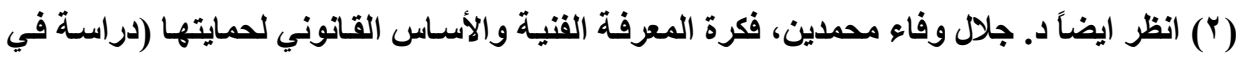

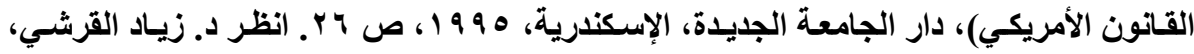

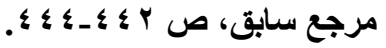

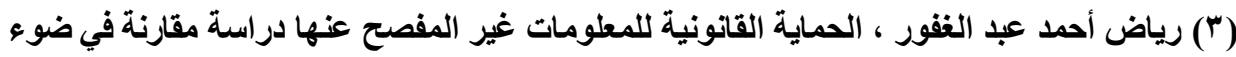

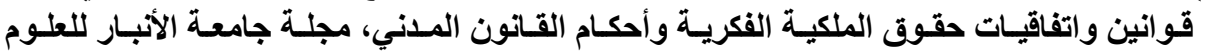

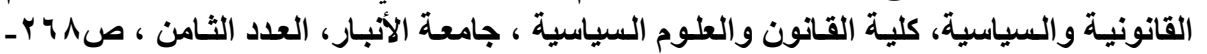

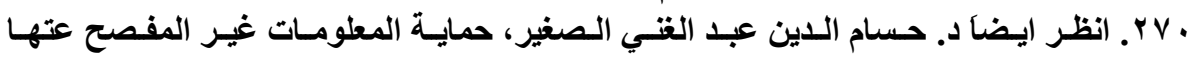

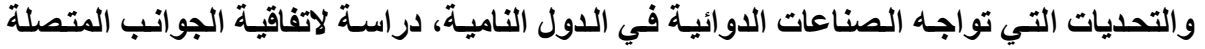

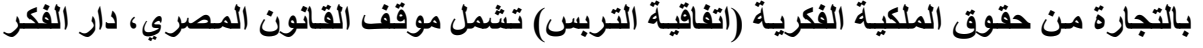

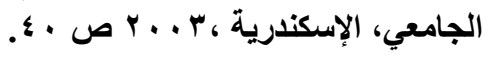




\section{الاطلب الثاني \\ تمييز المعلوهات التجارية السرية بها يتداخل همها}

تثترك الأسرار التجارية مع أنواع الملكية الصناعية والتجارية في أنها جميعاً

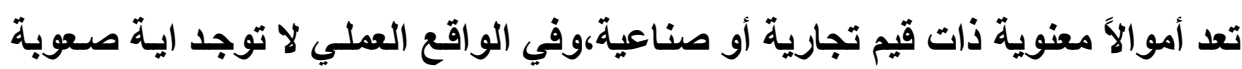

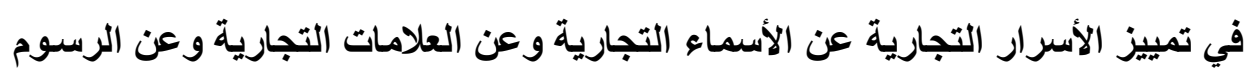

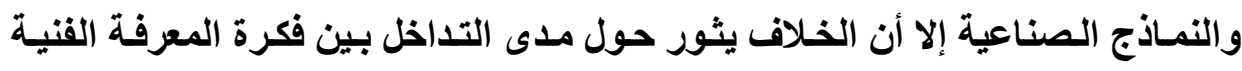
وبراءات الاختراع من جانب وبين الأسرار التجاريـة من جانب آخر.

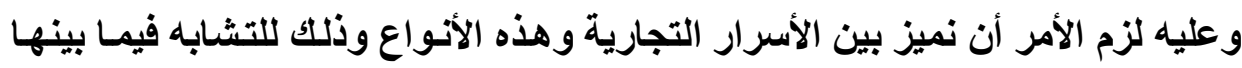

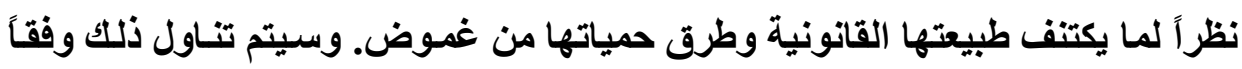

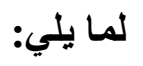
أولاً: المعلوهات التجارية السرية وفكرة المعرفة الفنية.

تثثير فكرة المعرفة الفنية كثير من الإثكاليات القانونية على المستويات الوطنية والدولية على حد سواء ويعتبر مصطلح المعرفة الفنية من المصطلحات الجديدة وتتفق الإنق

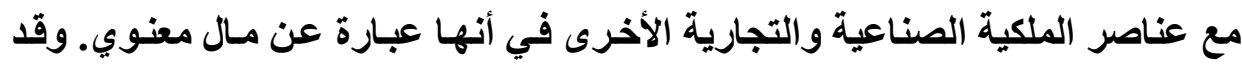

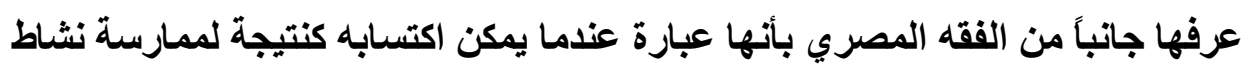
معين من مهارات وخبرات وتوظيفها في العملية الإنتاجية للمشروع بما يضمن ما يزيد

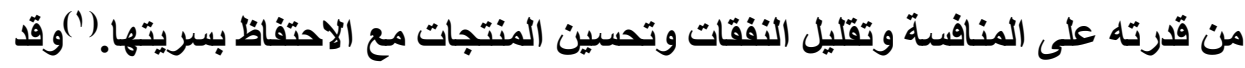

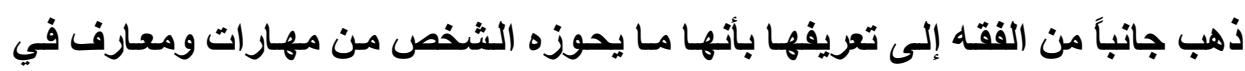

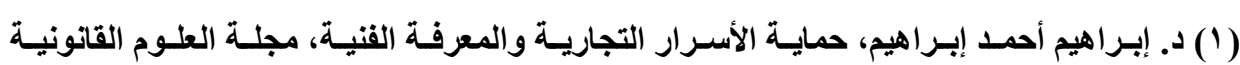

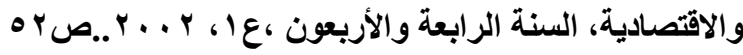


مجال معين بمـا يمكنه من الوصول إلى درجة الإتقان في العمل. (') وقد تعرض هذا الرأي إلى الانتقاد لمـا يثيره من خلط بين مهارات الشخص الفردية وبين المهارات

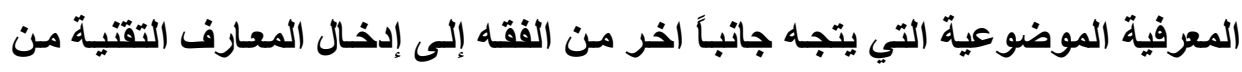

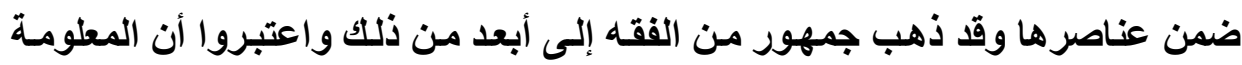

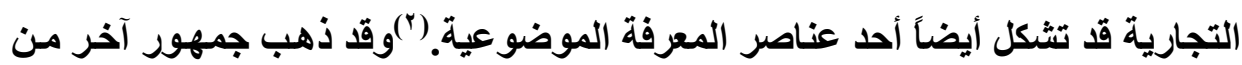

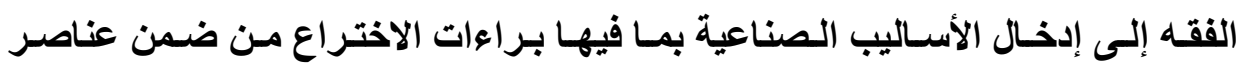

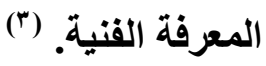

وفي هذا السياق أيضاً ذهب جانب من الفقه الأمريكي إلى أن المعرفة الفنية لها

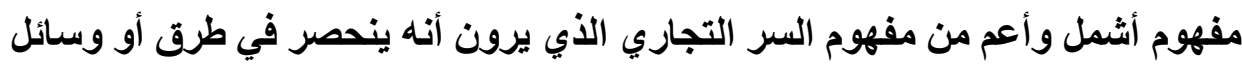
أو مركبات لها قيمة تجارية بينما تثثمل المعرفة الفنية مجموعة متكاملة من الابتكارات

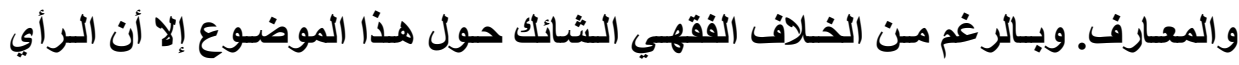

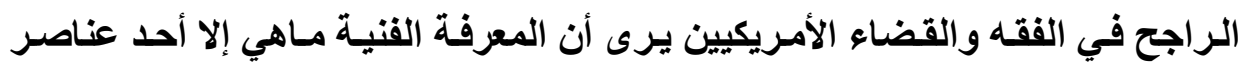
الأسرار التجارية. () وبدورنا نؤيد هذا الرأي لا سيما وأن الحماية القانونية للمعارف الفنية تستدعى أن تكون سرية وتتمتع بقيمة اقتصادية وفي حالة عدم نقلها للغير فإنها تتمتع بالحماية الكاية

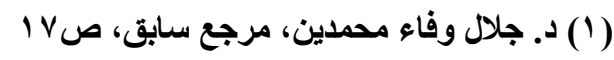

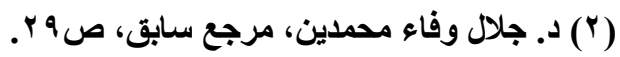

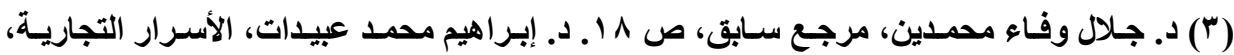
المفهوم والطييعة القانونية وألية الحماية (دراسة مقارنة)، دار الثقافة للنشر والتوزيع، عمان،

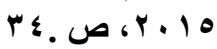

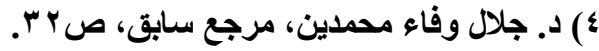




$$
\begin{aligned}
& \text { وفقاً لقواعد المسؤولية التقصيرية أمـا في حالة التعاقد مـع الغير لنقلها كأسلوب من } \\
& \text { الأساليب التقنية التكنولوجية فإن وسيلة حمايتها هي التعاقد الذي انصب عليها. } \\
& \text { ونلاحظظ أن المسنظم السعودي واتفاقيـة (تـربس) أغقلت إدراجهـا مسن ضـمن } \\
& \text { الأسرار التجاريـة،إلا أن قانون الاتحـاد الأوروبي حسم هذا النزاع الفقهي والتشريعي } \\
& \text { واعتبر أن المعرفة الفنية صورة من صور الأسرار التجارية. (1) }
\end{aligned}
$$

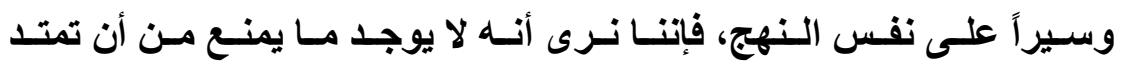

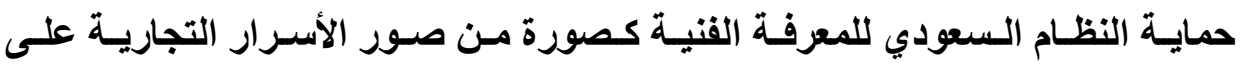

$$
\begin{aligned}
& \text { الرغم من إغفال المنظم لها، وسندنـا في ذلك أن تعداد تلكك الصور الوارد في المسادة } \\
& \text { الأولـى مسن اللائحسة إنمـا ورد على سـبيل المثـال لا الحـصر وبالتـالي يمكن القيـاس } \\
& \text { على ما ورد فيها وإضفاء الحمايـة للمعرفة الفتية باعتبارهـا من الصور المهمـة للسر } \\
& \text { التجاري. }
\end{aligned}
$$

(1) Recital (1) of the Trade Secret Directive states as follow:" ........another means of appropriating the results of innovation is to protect access to, and exploit, knowledge that is valuable to the entity and not widely known. Such valuable know-how and business information, that is undisclosed and intended to remain confidential, is referred to as a trade secret". Also recital (14) states as follow: "'..It is important to establish a homogenous definition of a trade secret without restricting the subject matter to be protected against misappropriation. Such definition should therefore be constructed so as to cover know-how, business information and technological information where there is both a legitimate interest in keeping them confidential and a legitimate expectation that such confidentiality will be preserved. Furthermore, such know-how or informationshould have a commercial value, whether actual or potential. Such know-how or information should be considered to have a commercial value....". 


\section{ثانيًا: المعلوهات التجارية السرية وبراءات الاختراع}

يقصد بالاختراع في النظام السعودي وفقاً للمادة (ץ) من نظام براءات الاختراع و التصميمات التخطيطة للارسات المتكاملة والأصناف النباتية والنماذج الصناعية لعام ه ب ا ا هـ بأنه " فكرة يتوصل إليها المخترع، وينتج عنها حل مشكلة معينة في مجال

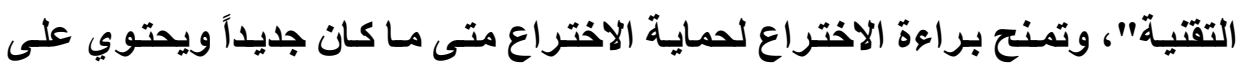
خطوة ابتكارية ويكون قابلاً للتطبيق الصناعي.

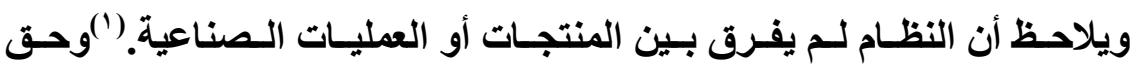
الاختر اع يخول لصاحبه سلطة استعمال اختراعه، وسلطة استغلاله سواء بنفسه أو بأي طريقة أخرى عن طريق الغير، وسلطة التصرف فيه بعوض أو دون عوض. (†)وتعمل التشريعات الوطنية والاتفاقيات الدولية على الموازنة بين مصالح المخترع والمصلحة العامة، فيمنح المخترع حق استثثاري في الإفادة من اختراعه عن طريق استغلاله لمدة الماته الأح r .

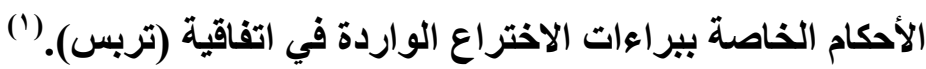

(1) أنظر المادة (ب \&) من نظام براءات الاختراع والتصميمات التخطيطية للارارت المتكاملة والأصناف

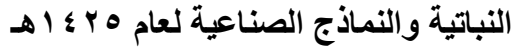

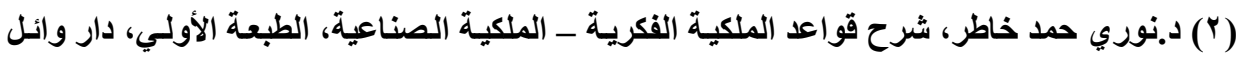

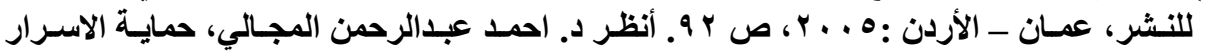

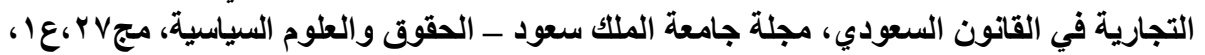

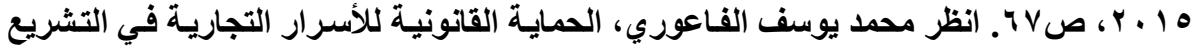

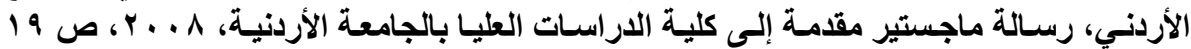

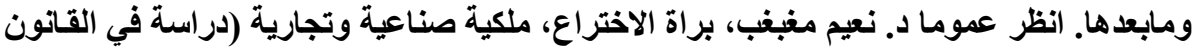

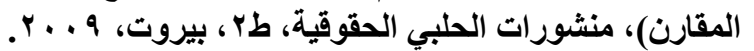

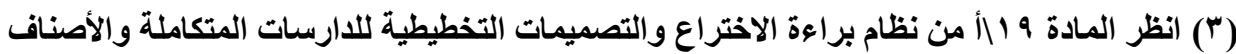

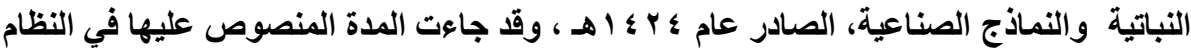

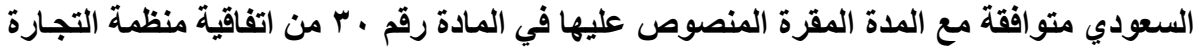
$=$ 
مما سبق يتضح أن حماية براءات لاختراع تستلزم الحصول على وثيقة البراعة البتاء

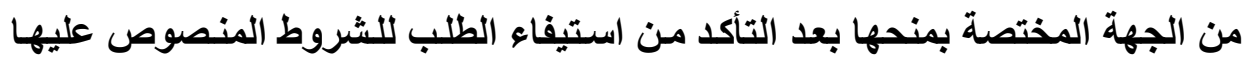

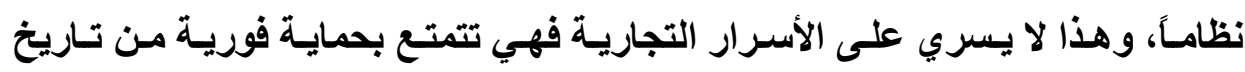

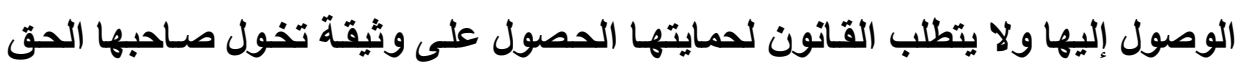
فيها.

وتمنح براءة الاختراع صاحبها حقاً استثنارياً على اختراعه بحيث يستطيع منع

الغير من استعماله أو استغلاله أو التصرف فيه حتى لو توصل الاغتراعل الغير لنفس الاختراع

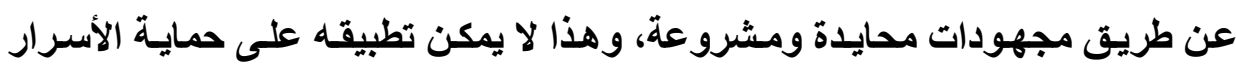
التجارية فهي لا تخول لمالكها حقاً استئثارياً ولا تحمى المعلومة من استعمال الغير لها لهابل

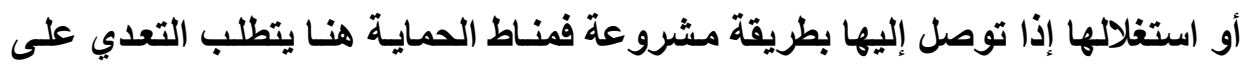
السر التجاري بشكل غير مشروع.

كما ويستلزم المنظم شرط الجدة والابتكار والقابلية التصنيعية لمنح الحمايـة للاختراع، ولا يتطلب تـوفر هذه الـشروط لإسبـاغ الحمايـة القانونيـة على الأسـرار

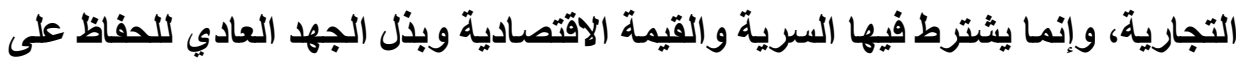

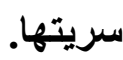

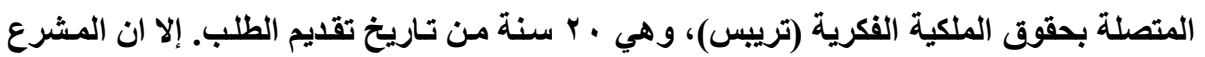

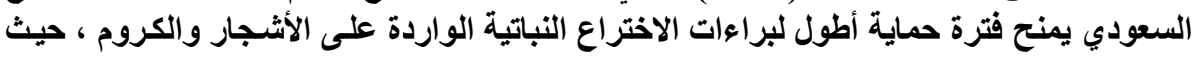

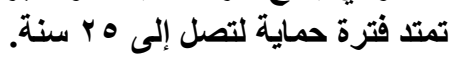

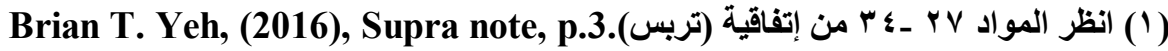




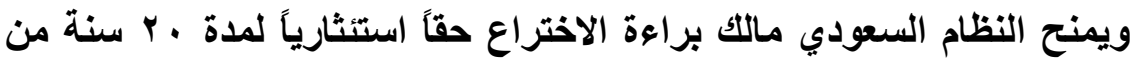
تاريخ تسجيله للبراءة، وتحديد المدة هنا لا يسري على الأسرار التجارية التي قد تكون

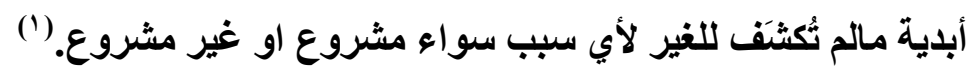

إضافة إلى ذلك يلزم المنظم كغيره من التثريعات المقارنة المخترع بالإفصاح عن مكونات وطرق تركيب اختر اعه وكيفية الوصول إليه وخطوات تصنيعه وهذا أيضاً

$$
\text { لايسري على الأسرار التجارية.ت (؟) }
$$

\section{المطاب الثالث}

\section{شروط الحماية المقررة للمعلوهات التجارية السرية}

يشترط المنظم السعودي لإسباغ الحماية القانونية على المطومات التجارية

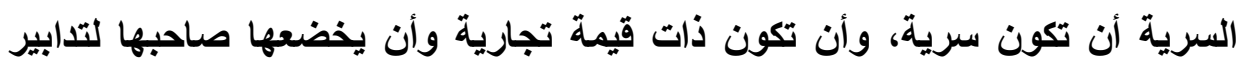
معقولة تضمن الحفاظ على سريتها وألا تكون متعارضة مع أحكام النظام العام والآداب. ونلاحظ أن هذه الشروط تتو ائم مع ما تضمنته اتفاقية (تربس) بهذا الخصوص الخصاص وكنلك الحال مع قانون الاتحاد الأوروبي الجليد لحماية الأسرار التجارية، ويلاحظ أيضاً

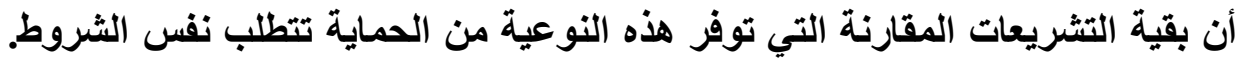

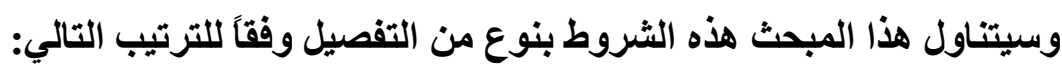

(1) وانظر المسادة (9 //أ) مـن نظـام براءات الاختراع والتصميمات التخطيطية للارسـات المتكاملـة

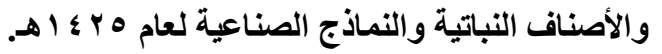

(2)Dogra, Rahul; Dhiman, Vijay; Gupta, Nipun, Intellectual property rights (ipr) and mechanisms for intellectual property protection (ipp): a review,International Journal of Pharmaceutical Sciences and Research 3.11, (2012), p.4055. 


\section{الفرع الأول:سرية المعلوهة}

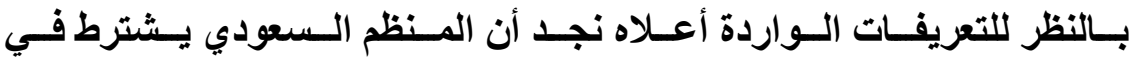
المادة (1/1) من لانحة حماية المعلومـات التجاريـة السرية، أن تكون تلك المعلومـات

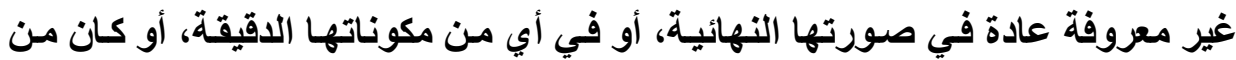
الصعب الحصول عليها في وسط المتعاملين عادة بهذا النوع من التعاملات. () ويلاحظ

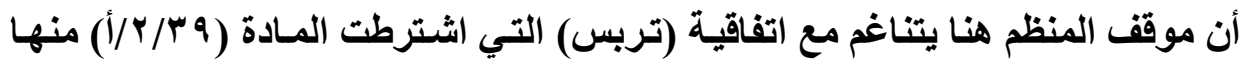
أن تكون المعلومـة سرية في مجموعها أو في شكلها وتجميعها الدقيقين لمكوناتها ويلزم أن تكون غير معروفة أو يسهل الوصول إليها عن طريق من يتعاملون عادة في النشاط المعني بها. (") وفي نفس السياق نجد أن القانون الأوروبي لحماية الأسرار

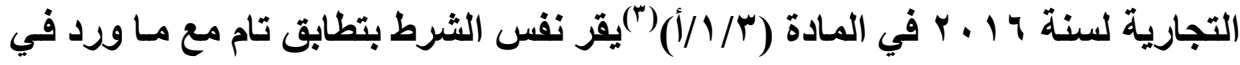
اتفاقيـة (تربس)ويستنتج مـن ذلكت مـدى تـأثر النظـام السعودي والأوروبي باتفاقيـة

ويستخلص مما ورد أعلاه أن القانون يتطلب لحماية المعلومـة أن تكون سرية

وغير معروفة لاى الغير ويستدعى ذلك أن تكون هذه المعلومة غير مفصح عنها وغير متداولة بين الأثخاص المتعاملين فيها سواء في المجال التجاري أو الاقتصادي أو فئون

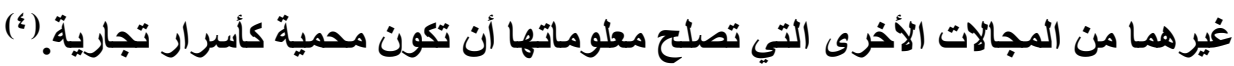

$$
\begin{aligned}
& \text { (1) (1) أظر المادة (1/1) من لانحة حماية المعلومات التجارية البرية. }
\end{aligned}
$$

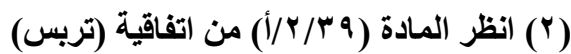

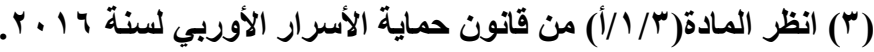

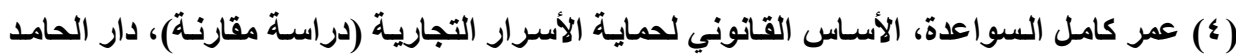

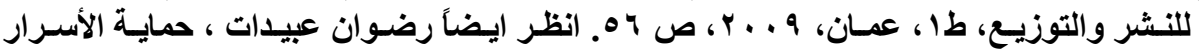

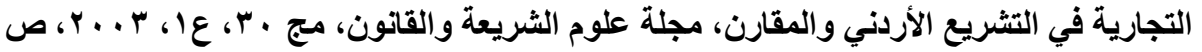

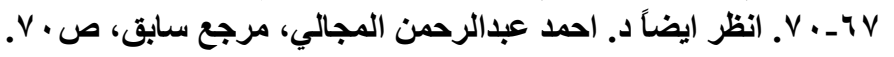


وسرية المعلومة بهذا الثكل توفر الهذف من إسباغها بالحماية القانونية، وهو تمكين

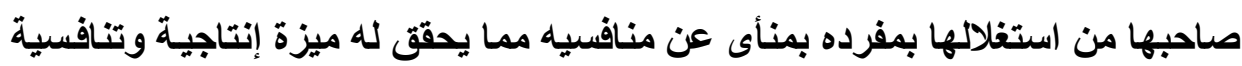
لا يعرف سر تحققها غيره، وهذا دفع جانباً من الفقه إلى اعتبار فكرة السرية هنـا

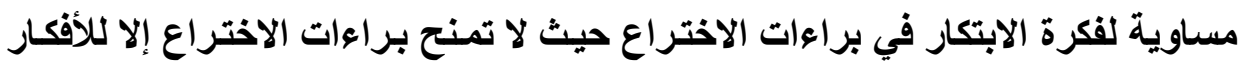
الابتكارية."(1) ولا يفهم من النصوص أعلاه أن القانون يتطلب توفر السرية المطلقة في

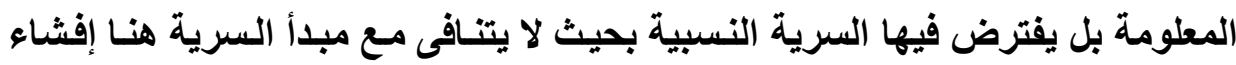

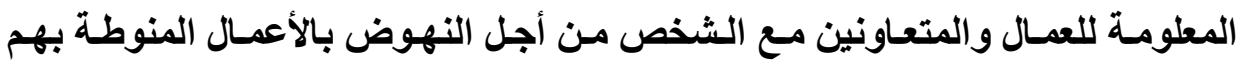
وتحقيق أهداف المنشأة. (†)ومن هنا ينشأ الالتزام على صـاحبها والعاملين معاه بعدام

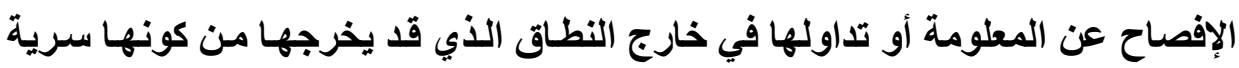

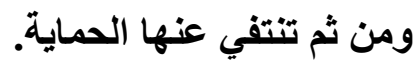
وتقتضي الأحوال أن يكون الوصول للمعلومة ليس بالأمر السهل بين المتعاملين

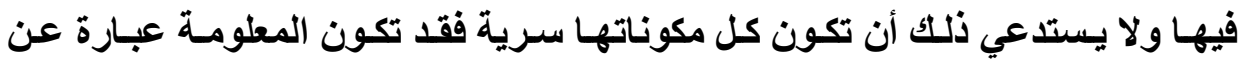
تركيبة من معلومات مشاعة مما خلق لها ميزة اقتصادية وأصبحت في مجملها سراً

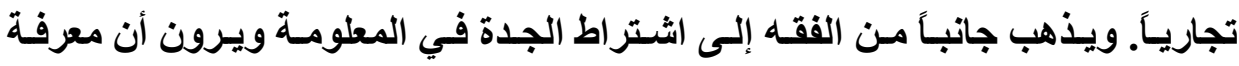

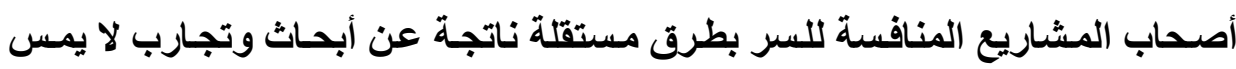

(1)Dr. François Dessemontet, "Protection of Trade Secrets and Confidential Information", Intellectual Property and International Trade : The TRIPs Agreement, (Kluwer Law International, La Haye, 1998), p. 247

(2) See, Nuno Sousa Silvia, What exactly is trade secret under the proposed directive?, journal of Intellectual Property Law \& Practice, Vol 9, No. 11, (2014), p. 928. 
بسرية المعلومة. (')وتجدر الإشارة إلى أن المعلومـات تبقى سراً تجارياً حتى لو كاتت معروفة لأثخاص غير منافسين لصاحب الحق في السر التجاري.

\section{الفرع الثاني: القيسمة التجارية للمعلوهة}

يشترط المنظم السعودي في المادة ( (Y/l) من لانحة المعلومات التجارية السرية

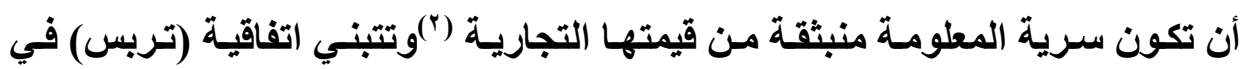

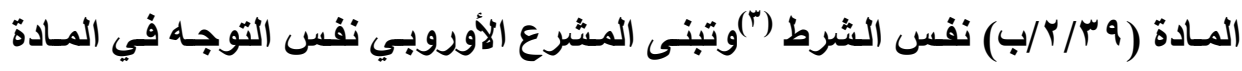

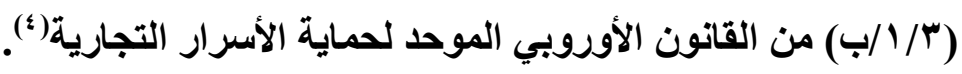
ويقتضي هذا الشرط أن يكون من شـأن المعلومـة أن تجلب لصاحبها عوائد

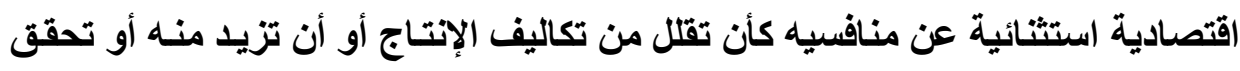

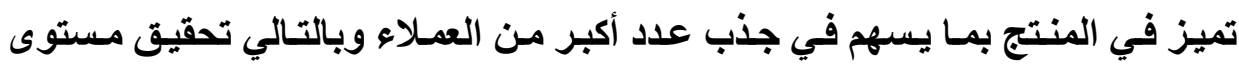
ربحية أعلى أو أي منفعة تسهم في تحقيق مركز تجاري تنافسي. ويكفي في هذا المجال

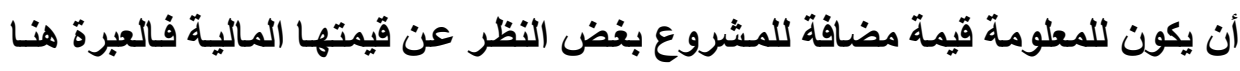

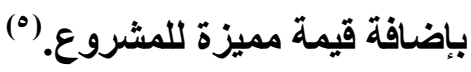

ويلاحظ أن إيراد هذا الشرط في النصوص أعلاه يتفق مـع المنطق في أن

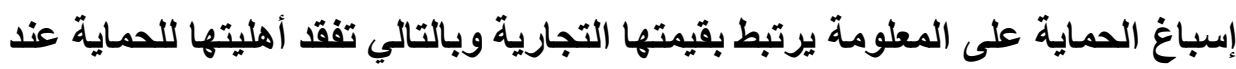
تخلف شرطو جود قيمة تجارية لها. وغني عن الذكر أن اشتراط ذلك يحقق الأهداف

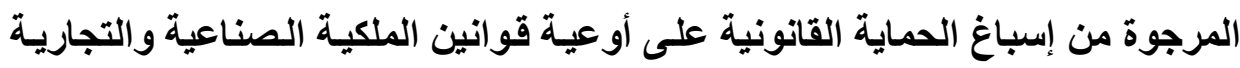

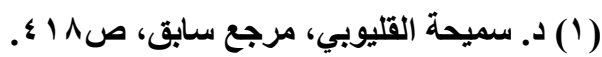

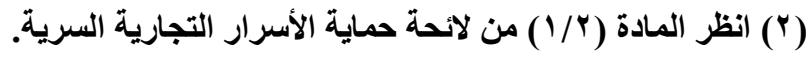

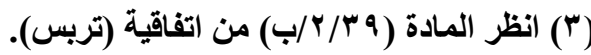

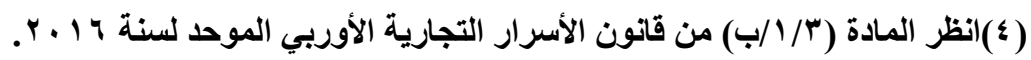

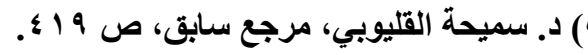


في تنظيم المنافسة داخل البيئة الاقتصادية وتثجيع الابتكار والتقدم الصناعي وتحقيق

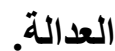

ويلاحظ أيضاً ان النصوص السابقة لم تنص على ما إذا كاتت القيمة التجاريـة حالية أو مستقبلية وكان من الأجدر الإشـارة إلى ذلك عند صياغة هذه النصوص لأن

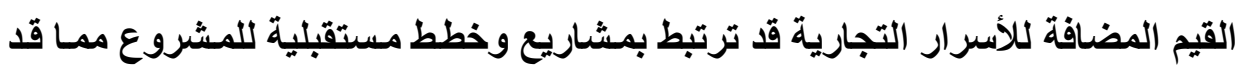

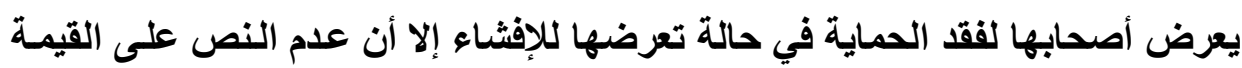

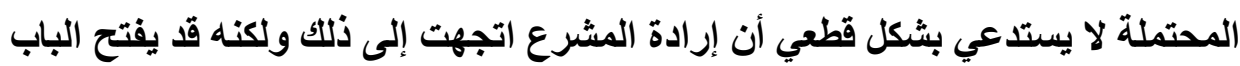

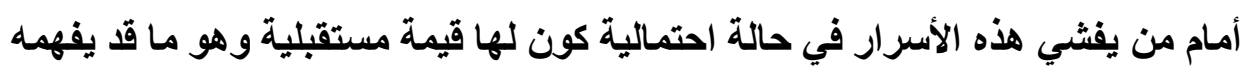
البعض من استقراء تلك النصوص.

ونرى أن يضاف إلى تلكك المـادة مـا يفيد بأن الحمايـة تمتد للقيمة الحالية أو

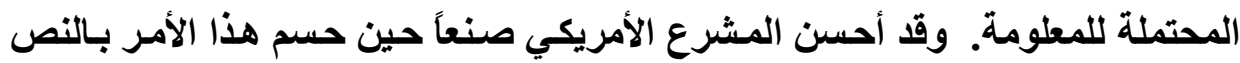

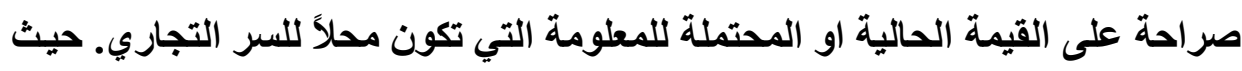
نصت المادة رقم (ॅ) منDefend Trade Secrets Act of2016 على : "......the information derives independent economic value, actual or potential, ......."

ونظرا لاختلاف القيمة السوقية للسر التجاري المعتدى عليه فرضت المادة

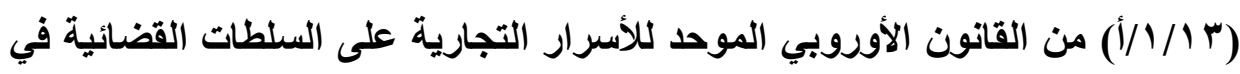

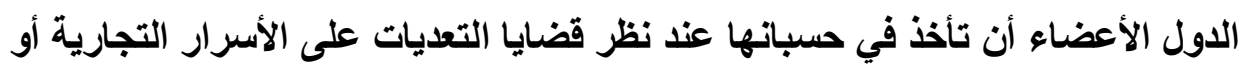

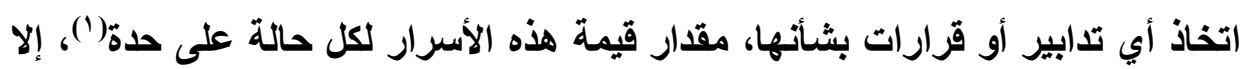

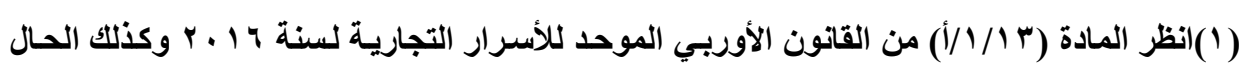

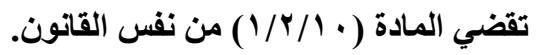


أن القيمة التجارية للمعلومة تخضع في تقدير ها لضوابط اقتصادية موضوعية(') وليس

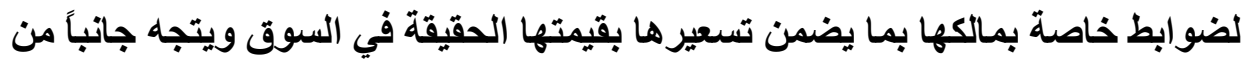

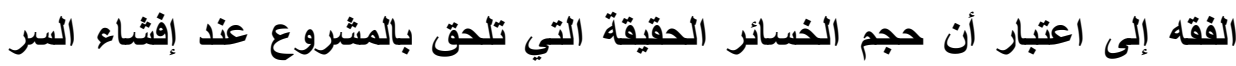

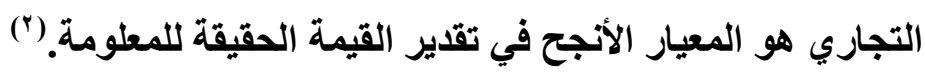

\section{الفرع الثالث: إخضاعها لتدابير هعقولة للحفاظ على سريتها}

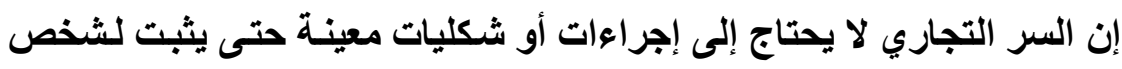

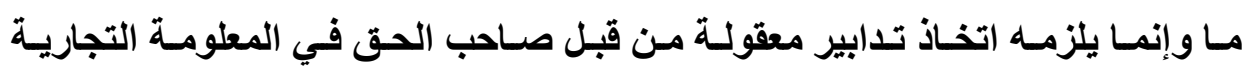

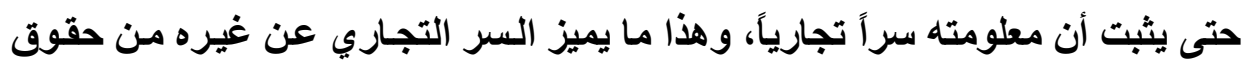

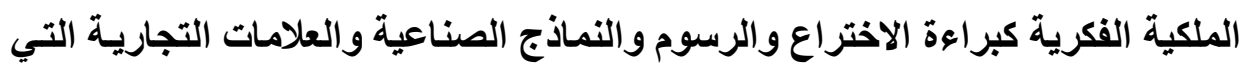

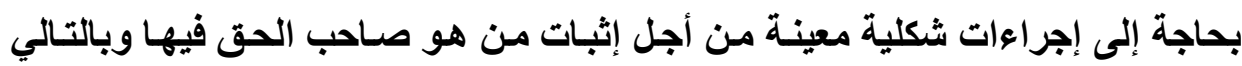
حمايتها.

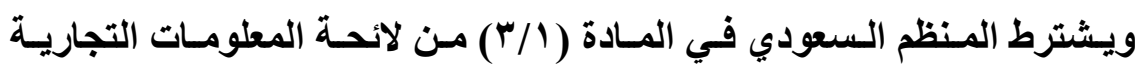

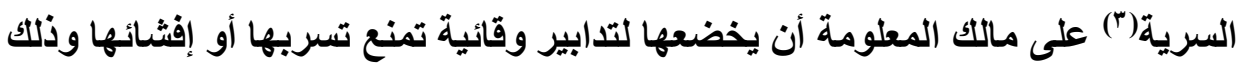

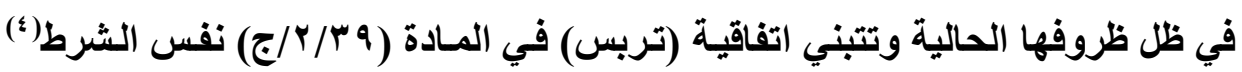

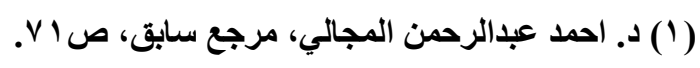

(2) See, Halling, R Mark, Weyand, Richard F., The Economic Valuation of trade secret, Journal of internet Law, Feb. 2006, P.19-20. See also, Wes Anson, Donna Suchy, Fundamentals of Intellectual Property Valuation: A Primer for Identifying and Determining Value, (American Bar Association (October 31, 2005), P.86 Also, See, Michael L. Rustad, The Negligent Enablement of the Trade Secret Misappropriation, Technology Law Journal, 22, 3, Mar 2006. P.469.

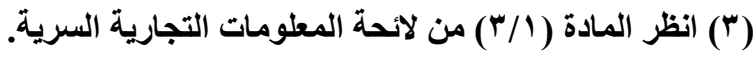

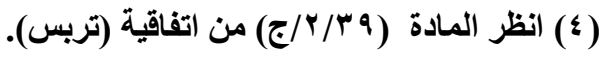


وتبنـي المشرع الأوروبي نفس التوجهه في الهـادة (ب// /ج) مسن القـانون الأوروبي الموحد لحمايـة الأسرار التجاريـة(') ، ويلاحظ أيضاً أن هنـاكت تطابق تـام بين اتفاقيـة

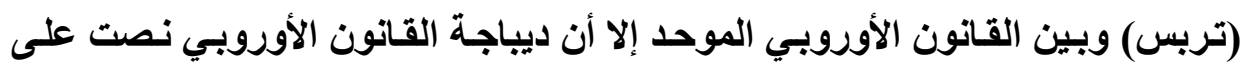

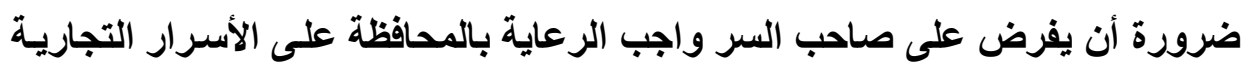

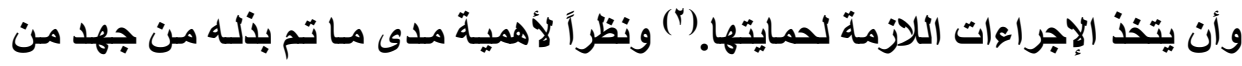

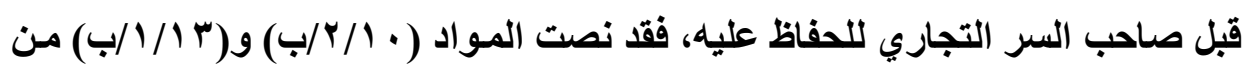
القانون الأوروبي الموحد للأسرار التجارية على السلطات القضائية في الدول الأعضاء

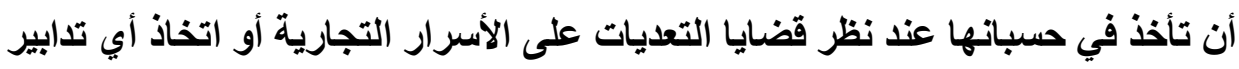

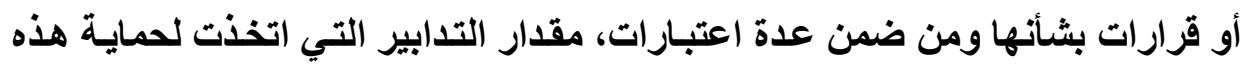
الأسرار قبل التعدي عليه("). ويلاحظ أيضاً أن المنظم السعودي اكتفي بالنص على ضرورة إخضاعها لتدابير

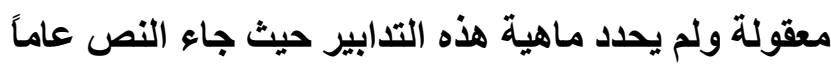
ونرى نظرا لأهمية الموضوع أن يتطرق المنظم إلى بعض الإجراءاءت الوهاء الوقائية و الأمنية العامة التي يمكن أن تتذذ لحماية كافة الأسرار الصناعية والتجارية. ويعتبر هذا الثرط امتداداً للشروط السابقة له بحيث تقتضي الحماية أن يبذل

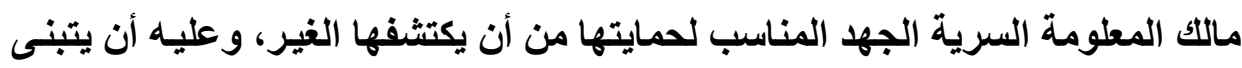

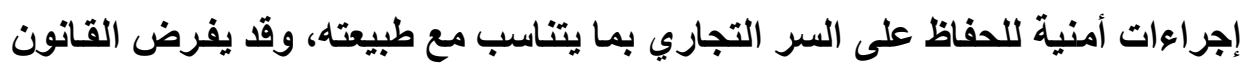

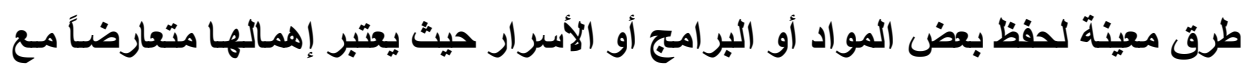


بذل الجهـ للحفاظ عليها. (1) ففي الأحوال العاديـة وبحسب طريقة حفظها سواء في وثثائق ورقية أو صور أو نماذج فإن الإجراء المعقول للحفاظ على سريتها هو حفظها

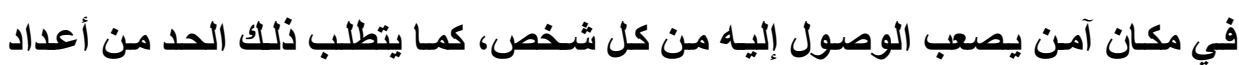
الأثخاص المسموح لهم بالاطلاع عليها(") ، وإذا كانت هذه المعلومسات محفوظة بشكل إليكتروني فيتطلب أن تتم حمايتها من الاختراقات الإليكترونية بالطرق التقنية المتبعة

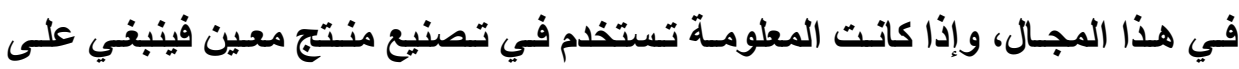

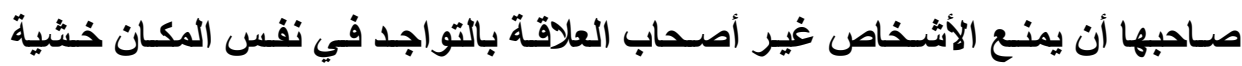
الاطلاع على السر وربما إفثائه.

ويستطيع صـاحب الحق أيضاً أن يلخل في علاقات تعاقية من شـأنها الحفـاظ

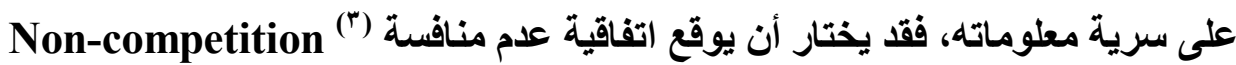

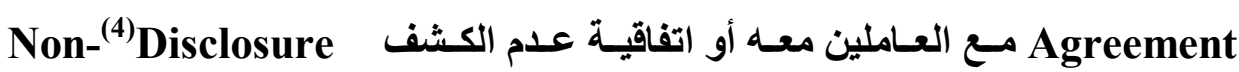

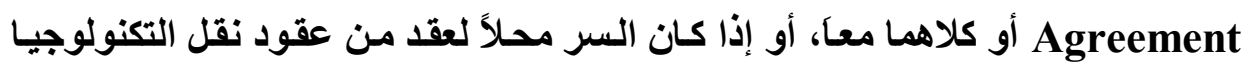

(1)Michael L. Rustad, (2006), Supra note, P.469.

(2)Dr. François Dessemontet, ( 1998), Supra note, p. 250.

(r) عادة ما يدرج هذه الشرط في قانون العمل ويجد اساسسه في التشريعات التي تحكم عقود العمل

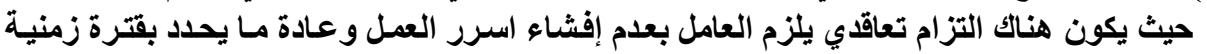

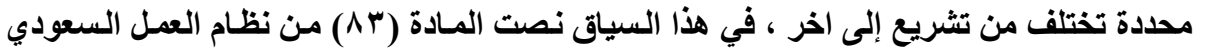

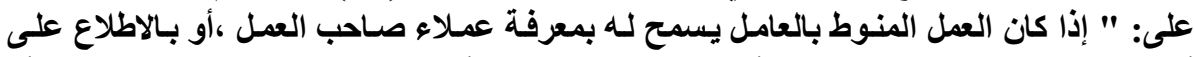

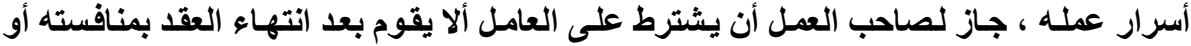

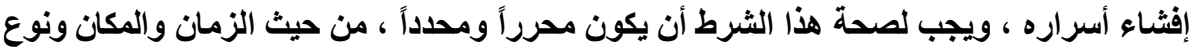

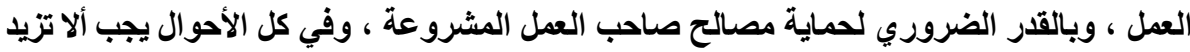

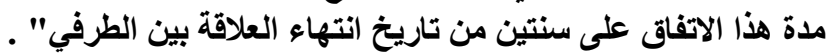

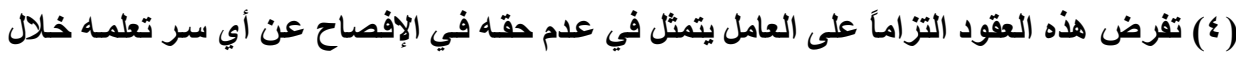

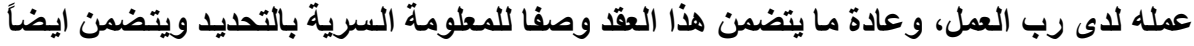
بعض المعلومات التي لا تعد سرية ولا بد أيضا ان يكون محداً بمدة محددة. 
فإن صاحب الحق يستطيع أن يضمن هذا العقد البنود اللازمة لحماية سرية المعلومـة

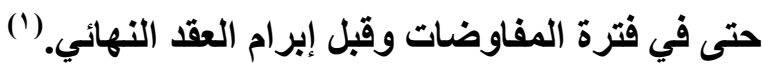
ويلاحظ أن تمتع صـاحب المطلومـة بالحمايـة مرتبط بمدى مـا يبذله من تدابير وإجراءات من أجل الحفاظ على سريتها وبالتالي إذا تقاعس عن القيام بما يكفل حمايتها

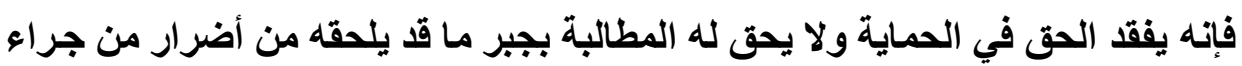

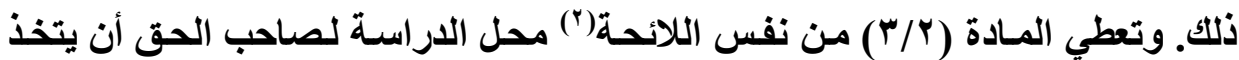

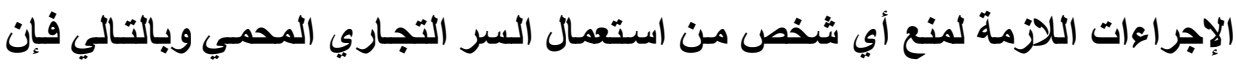

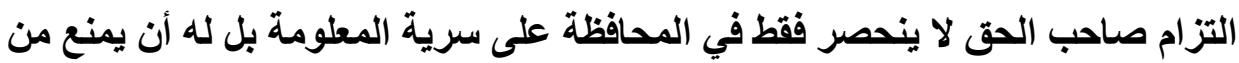
تعلى عليها بشكل غير مشروع. وفي المقابل لا يعد تعد غير مشروع إذا توصل شخص آخر إلى السر بطريقة مستقلة أو عن طريق الهندة العكسية.(") ويلاحظ في هذه الحالة أن الحماية المقررة للأسرار التجاريـة تختلف عن نظيرتها المقررة لبراءات الاختراع حيث تمتـ الحمايـة وتنفذ في مواجهة الغير حتى لو توصل إلى نفس الاختراع بطريقة مثروعة. ومع أن صاحب الحق قد يتخذ من التدابير والإجراءات(؛) مـا يكفل حماية سره التجاري من الإفثاء والوقوع في يد الغير، إلا أن المنظم السعودي أورد بعض الإنياء الحالات

(1) للاطلاع بتوسع حول السرية في هذه العقود ، نحيل إلى أبو العلا علي النمر، الالتزام بالمحافظة

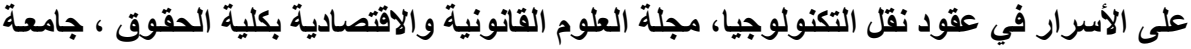

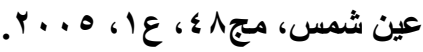

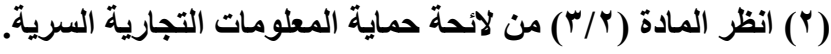

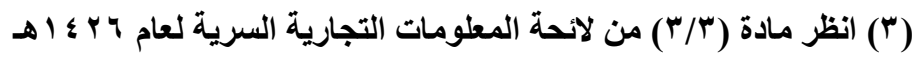

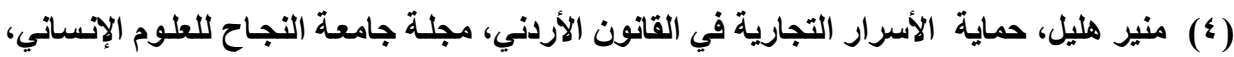

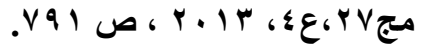


التي يجوز فيها كثف السر التجاري حيث فرضت المسادة الرابعة من نفس اللائحسة التزاماً على الجهات المختصة بحفظ الأسرار التجارية، بعدم الإفشاء إلا إذا كانت هنـاك

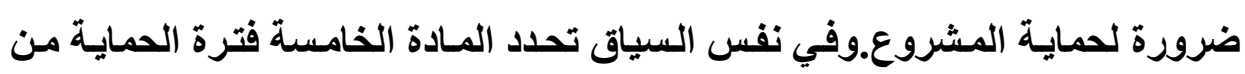

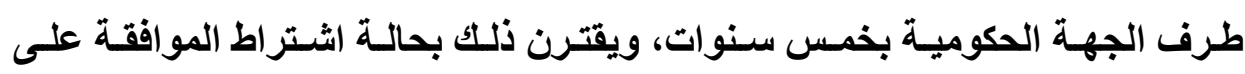

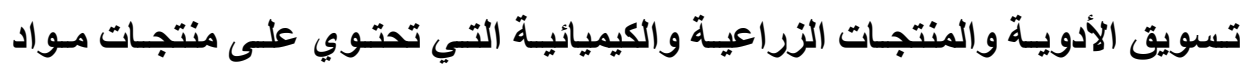
كيميائية جديدة. (1)

وفي نفس السياق أيضاً تقضي المادة السادسة من نفس اللانحة(')بأحقية الجهة

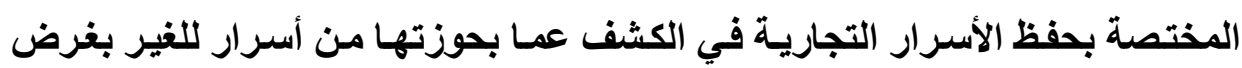

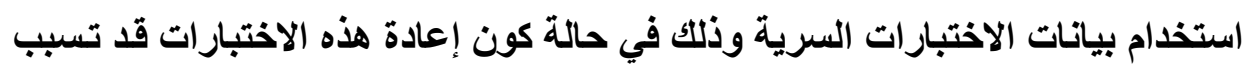

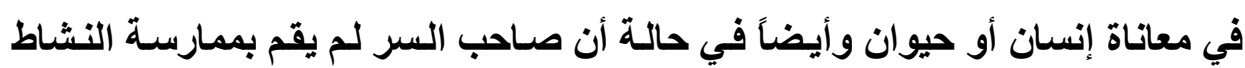

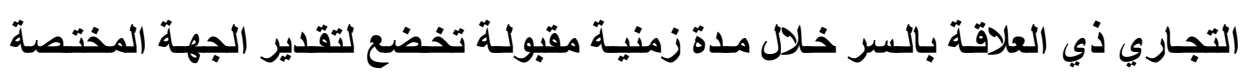
وأخيراً في حالة وجود ضرورة ملحة تقدر ها الجهة المختصة ايضاً. يلاحظظ مـن المـواد الـسابقة أن إفـشاء الأسـرار فـي الحسالات الـواردة فيهـا

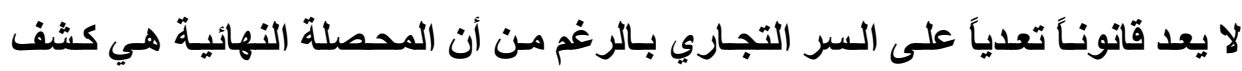

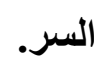

ويلاحظ أن المادة الخامسة وضعت شروطاً لطلب الكثف عن الأسرار التجاريـة

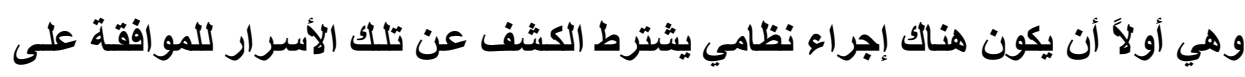

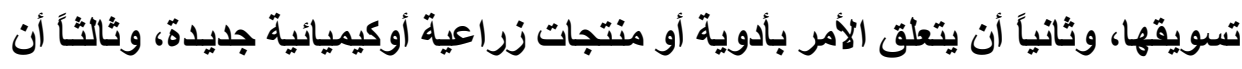


تحتوي هذه المنتجات على مواد كيميائية جليدة، وبالتالي فِان المشرع لم يترك الأمر هنا لتقدير الجهة إنما وضع لها ضواب ابط معينة.

إلا أنه يلاحظ في المادة الخامسة أن أمر تقدير الظروف بفترة عدم الآتجار أو تقدير الضرورة الملحة تركت للجهة المختصة ولم تنص اللانحة على ضوابط معينة

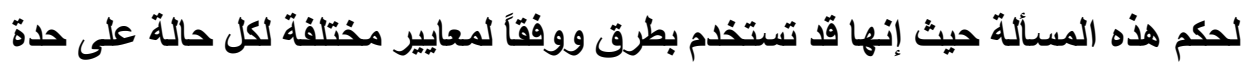
بما قد يتسبب في إلحاق الضرر بأصحاب الثأن. وبدورنا نرى ضرورة وضع ضوابط ومعايير مشددة لهذه الإجراءات حتى لا يساء تفسير هذه المواد أو يُتَعَف في استعمالها.

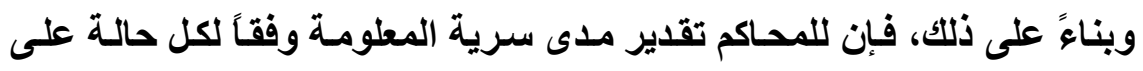

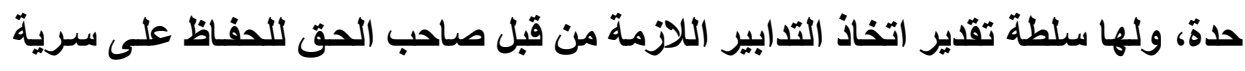

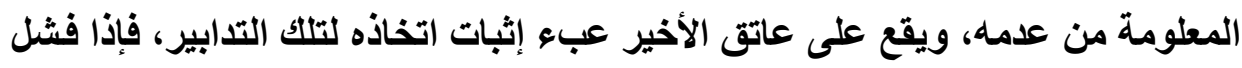

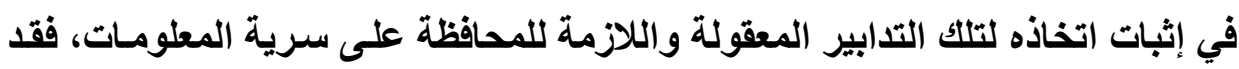
الحق في اعتبار معلومته سرية.

\section{الفرع الرابع: عدم هخالفة النظام العام والآداب}

تقضي السابعة من لائحة المعلومـات التجاريـة السرية(')بأن الحمايـة القانونية

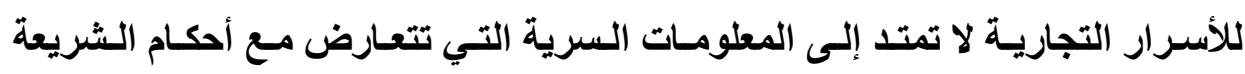

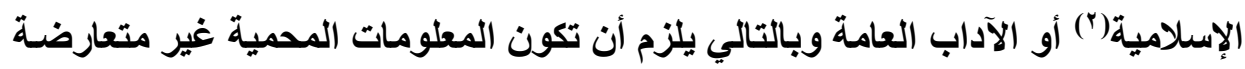
مع أحكام النظام العام والآداب.

(1) (1) انظر المادة (V) من لانحة حماية المطلومات التجارية السرية.

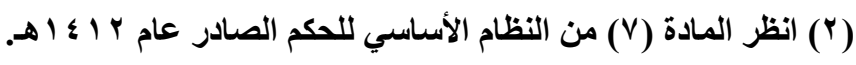


ويستفاد من هذه المادة أن الحماية تنحسر وتزول عن أي مطومة مخالفة مهمـا كانت قيمتها الاقتصادية أو الجهد الذي بذل للوصول إليها سواء كـان كشفها بشكل

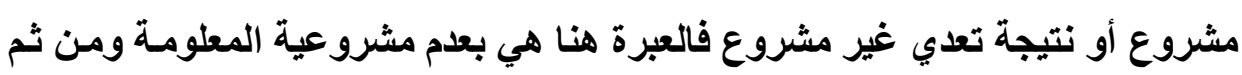

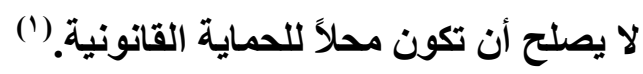
أما اتفاقية (تربس) فلم تتناول هذا الثرط، ولكنها لم تمنع الدول الأعضاء من ويلاحظ أن قانون حمايـة الأسرار التجاريـة الموحد لدول الاتحساد الأوربي قد

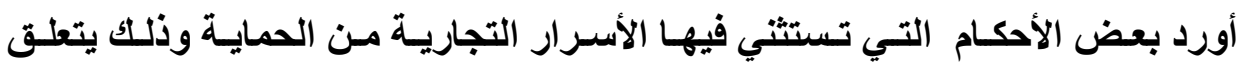

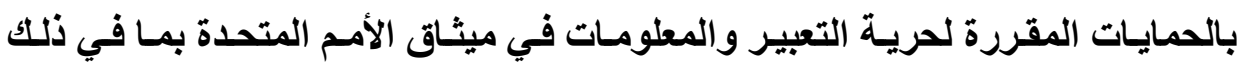
ضمان احترام الحرية والتعدادية في وسائل الإعلام ، وكذلكك يستثني من الحماية الأسرار

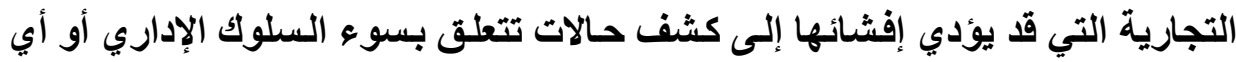

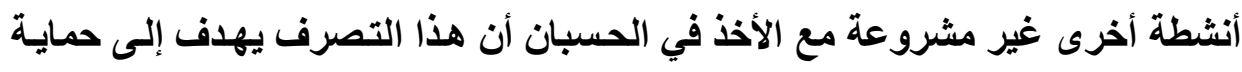

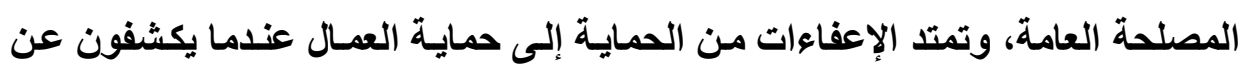
هذه الأسرار إلى ممثليهم بطريقة مشروعة إذا كان وظائف الممثلين تسمح لهم بكشف لإنف

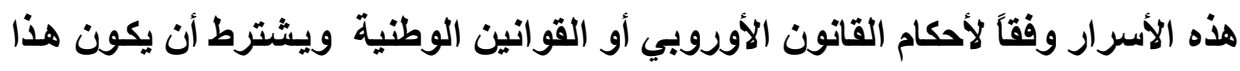
الكثف لأغراض مشروعة وضرورية، وأيضاً يستثني هذا القانون الأسرار التجارية التهانية

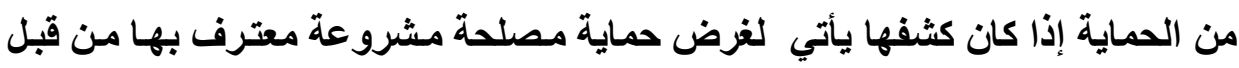

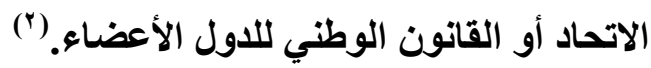

(1) بد.عبدالهادي محمد الغامدي، الملكية الصناعية ، وفقاً لأنظمة الملكية الصناعية السعودية واتفايتيني

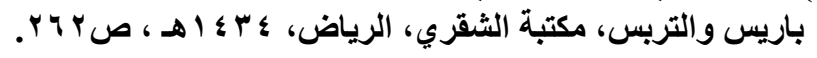

(2)Article 5 of the Trade Secret Directive states as follow: "Exceptions Member States shall ensure that an application for the measures, $=$ 


$$
\begin{aligned}
& \text { والجدير بالذكر أن مـا أورده القـانون الأوروبـي يعد مـن المقومـات التي تقوم } \\
& \text { عليها المجتمعـات الأوروبيـة، فهي تتعلق بالنظـام العـام والآداب، وبالتـالي يستفاد أن } \\
& \text { النظام السعودي يتفق مع نظيره الأوربي في اشتراط هذا الشرط. }
\end{aligned}
$$

procedures and remedies provided for in this Directive is dismissed where the alleged acquisition, use or disclosure of the trade secret was carried out in any of the following cases:

(a) for exercising the right to freedom of expression and information as set out in the Charter, including respect for the freedom and pluralism of the media;

(b) for revealing misconduct, wrongdoing or illegal activity, provided that the respondent acted for the purpose of protecting the general public interest;

(c) disclosure by workers to their representatives as part of the legitimate exercise by those representatives of their functions in accordance with Union or national law, provided that such disclosure was necessary for that exercise;

(d) for the purpose of protecting a legitimate interest recognised by Union or national law". 


\section{المبحث الثاني \\ صور الاستخدام المشروع للمعلومات التجارية السرية المئي}

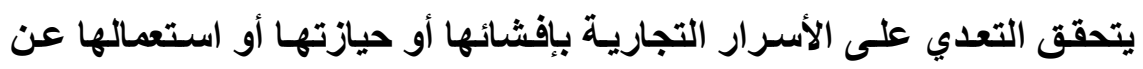

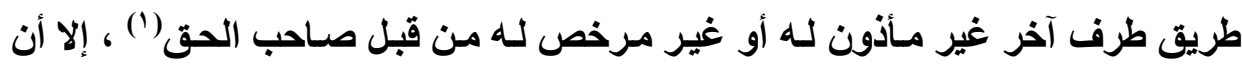

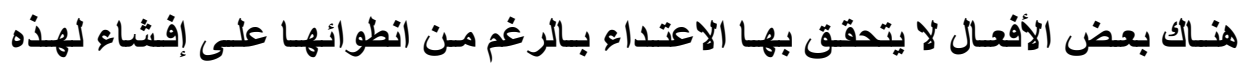
الأسرار أو استعمالها أو حيازتها، ويتحقق ذلك بأحد الصور التالية:

\section{المطلب الأول: التوصل إلى السر التجاري بصورة هستقلة أو عن طريق الهندسة العكسية العية العية}

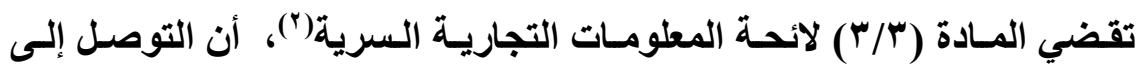

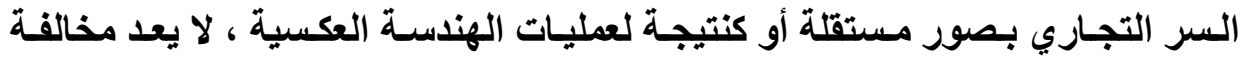

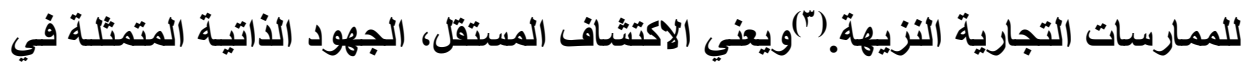

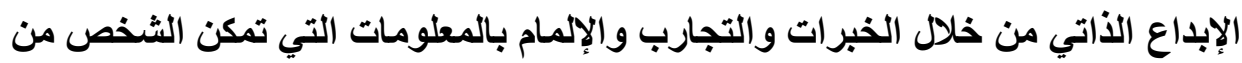

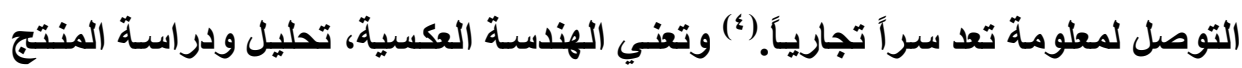
لغرض معرفة تفاصيل تصميمة وتركيبه وطرق عمله بهدف التوصل لمنتج مشابهة

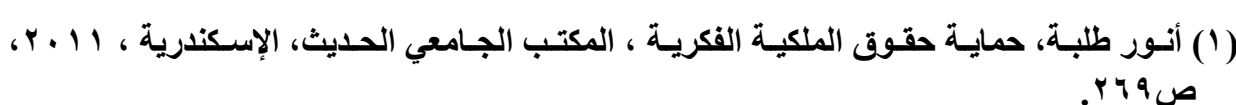

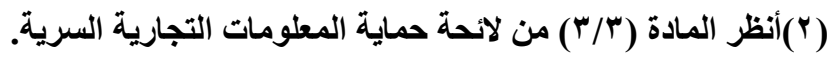

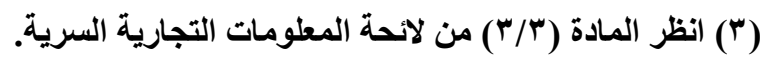

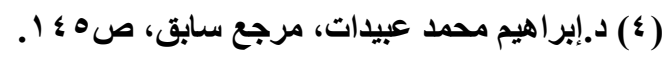


له. (1) ويتسنى ذلك بتفكيكه بطريقة عكسية من أجل التوصل لكثف سر طريقة صناعته

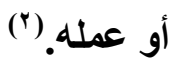

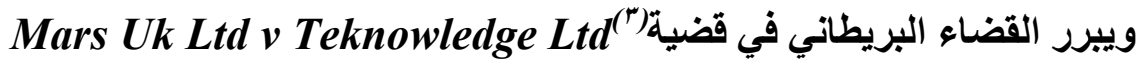

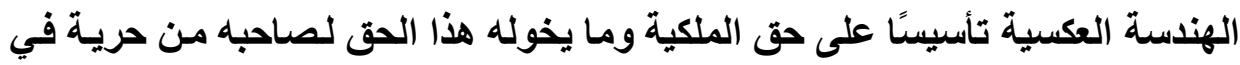
التصرف على الشيء الملـوك لـه امسا القضاء الأمريكي في حكم للمحكمـة العليـا الأمريكية في قضية Bonito Boats, Inc. v. Thunder Craft Boats, Inc فيبرر مشروعية الهندسة العكسية تأسيسًا على مبدأ اقتصادي هدفه تشجيع الابتكار والاختراع و عدم الرغبة في وضع قيود قانونية على ذلك.

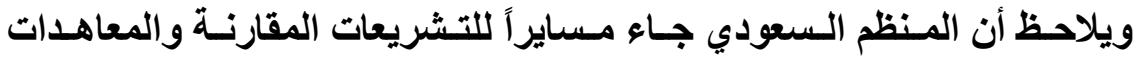
الدوليـة ذات العلاقـة بعدم إسباغه حمايـة قانونيـة استئثاريه مطلقة على الأسـرار

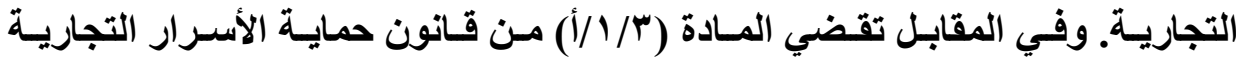

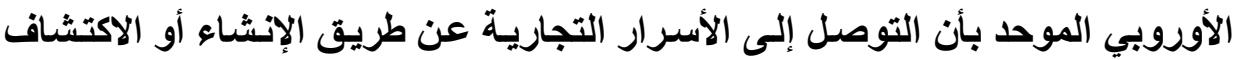

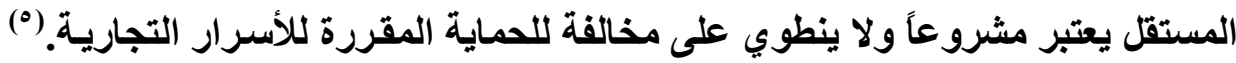

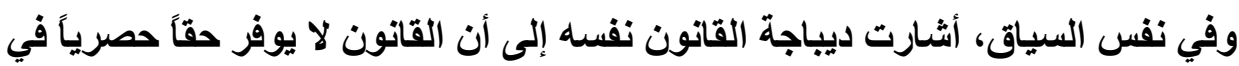

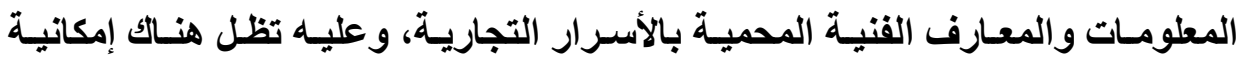

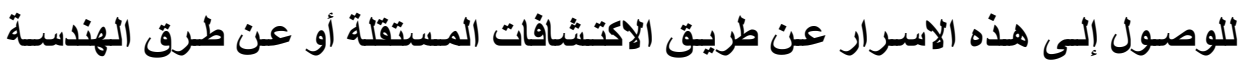

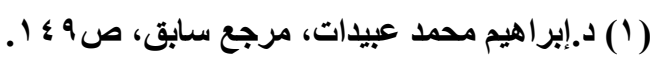

(2)Aplin, Tanya, Reverse Engineering and Commercial SecretsCurrent Legal Problems 66.1 (2013), p.342.

(3)Mars Uk Ltd v Teknowledge Ltd (No 2); ChD 8 Jul 1999.

(4)Bonito Boats, Inc. v. Thunder Craft Boats, Inc., 489 U.S. 141 (1989)

(5) Article (3/1/a) states as follow: 1. The acquisition of a trade secret shall be considered lawful when the trade secret is obtained by any of the following means: .(a) independent discovery or creation;...." 
العكسية بما لا يعد مخالفة للقانون ما دام هذا التوصل لا يخالف التعاقدات المتفق عليها بين الأطراف. (") ويلاحظ أن المشرع الأوروبي أيضاً لا يقر الحماية الإستثنارية للأسرار

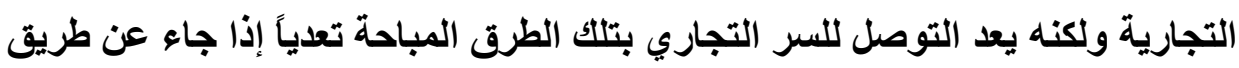

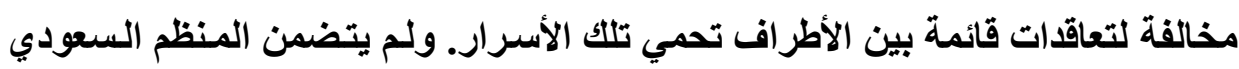

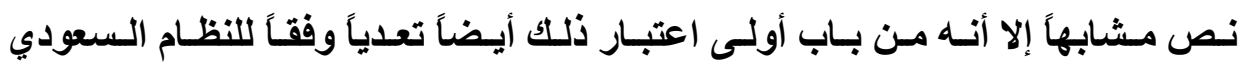

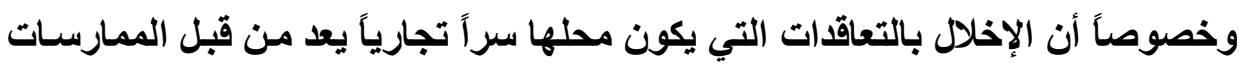

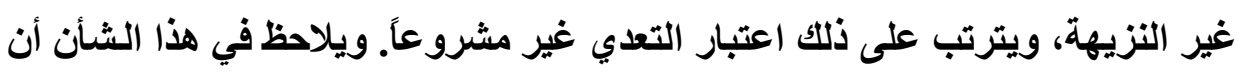
اتفاقية (تربس) لم تتضمن أي نصوص تحكم هذه المسألة.

\section{المطاب الثاني \\ التوصل إلى السر التجاري عن طريق البحث العلمي والملاحظة}

قـ يـتم التوصـل للسر التجـاري عن طريـق الأبحـاث أو الارارسـات العلميـة أو

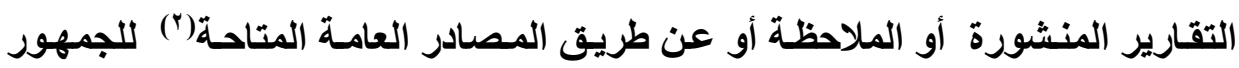

Recital 16 of the Trade Secret Directive States as follows: ".In the (1) interest of innovation and to foster competition, the provisions of this Directive should not create any exclusive right to know-how or information protected as trade secrets. Thus, the independent discovery of the same know-how or information should remain possible. Reverse engineering of a lawfully acquired product should be considered as a lawful means of acquiring information, except when otherwise contractually agree....".

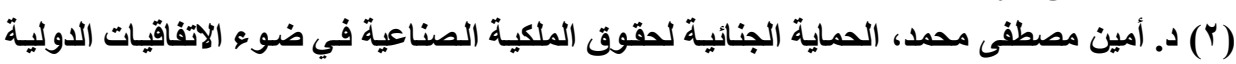

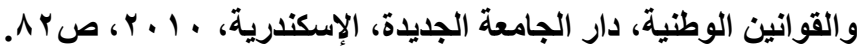


كالمكتبات والسجلات الحكومية (1)، وفي تلك الحالات لا يعد التوصل للمعلومة بأي من تلك الطرق متعارضاً مع الممارسات النزيهة.

وقد قضى قانون حماية الأسرار التجارية الأوروبي الموحد بمشروعية ما يندرج تحت تلك الحالات حيث نصت المادة (ب/// ب) على أن:

".....(b)observation, study, disassembly or testing of a product or object that has been made available to the public or that is lawfully in the possession of the acquirer of the information who is free from any legally valid duty to limit the acquisition of the trade secret;....."

ويعنـي ذلكـ أن التوصـل للسر التجـاري عن طريـق الملاحظة أو الدراسـة أو

التفكيك أو اختبارات تجربة المنتج تعتبر من قبيل الصور المشروعة، ويسرى ذلك أيضاً على المعلومات التي تمت إتاحتها للعامة وتمتـ أيضاً المشروعية إلى المعلومـات التي

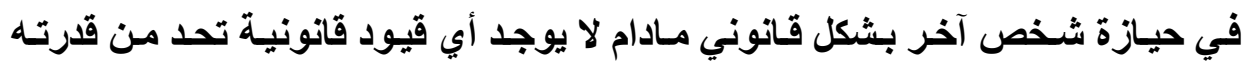

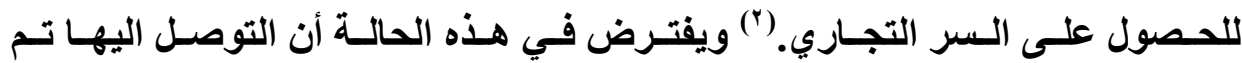

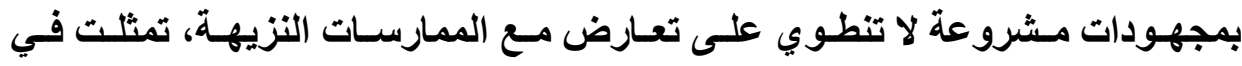
التوصل للمعلومة عن طريق الفحوصات والاختبارات للمنتجات المتاحة في الأسواق. ويلاحظ في هذا الثأن أن المنظم السعودي قد أغفل بيان هذه الصور المشروعة و اكتفي بييان صورة الاكتثاف المستقل والهندسة العكسية. 
ومـن جانبنـا نـرى أنسه لا مـاتع مـن أن تتـدرج الأفعـال التـي أوردهـا القـانون

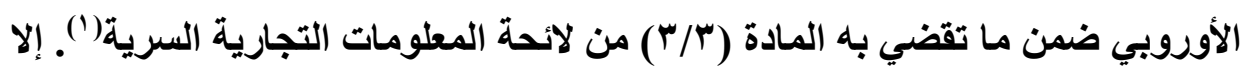

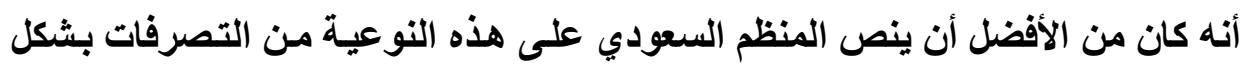

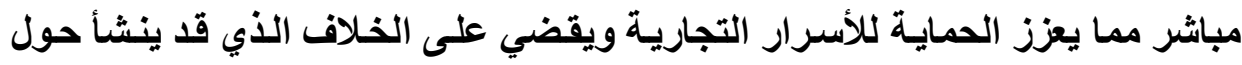

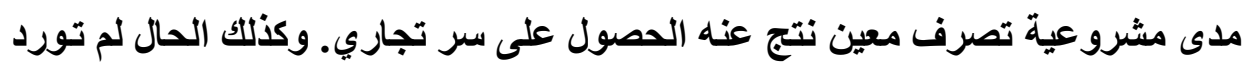
اتفاقية (تربس) أي نصوص مثابهة لحكم هذه التصرفات.

\section{الاملب الثالث \\ الحصول على المعلومات نتيجة اشتراطات حكوهية}

تختلف الأسرار التجارية عن براءات عن الاختراع في أن الحماية المقررة لها لا تستدعي تسجيلها لاى الجهة الحكومية المختصة ويالتالي لا يمكن تصور أن يمنح حائز

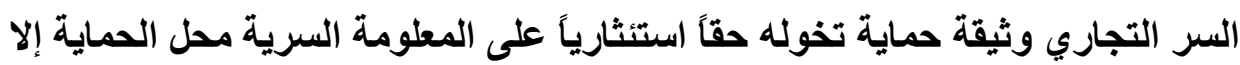

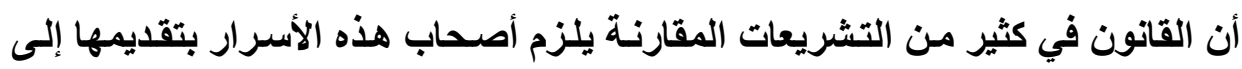

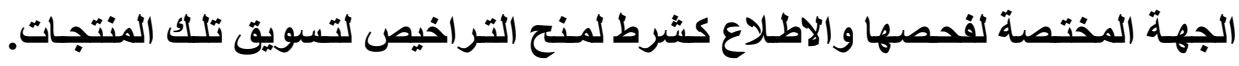

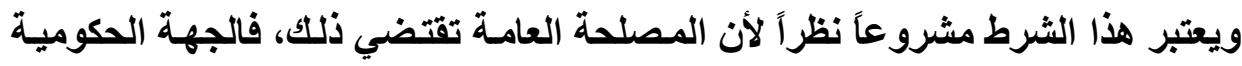

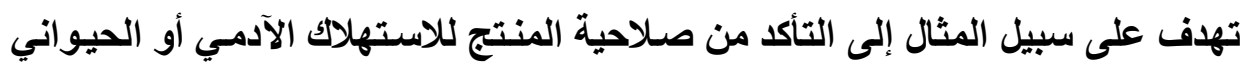

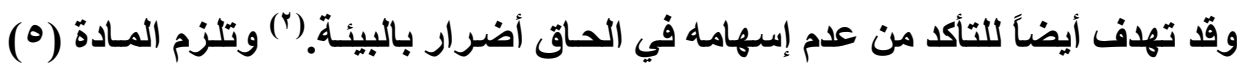

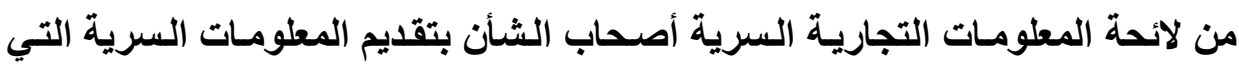

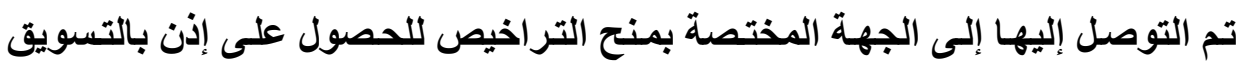

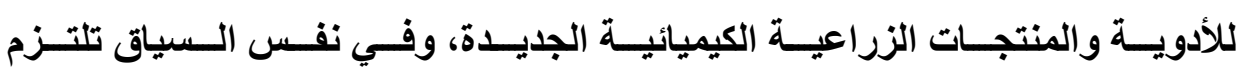

$$
\text { (1) (انظر المادة (//\%) من لانحة حماية المعلومات التجارية السرية. }
$$

(2)Dr. François Dessemontet, (1998), pp. 254. 
الجهة الحكوميـة بحمايـة هذه الأسرار لمدة خمس سنوات من تـاريخ الحصول على

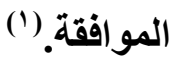

ونلاحظ أن المنظم السعودي لا يثترط لحماية الأسرار التجارية أن يتم تسجليها

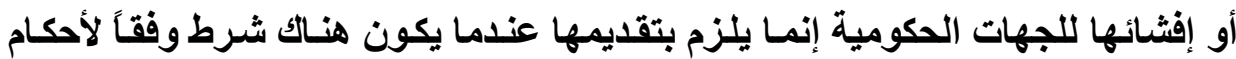
القـانون للحصول علـى إذن لتسويق منتجـات معيــة كالأدويـة والمنتجـات الزراعيـة الكيميائية. ونستنتج من ذلك أن المنظم وضع شروط لهذا الكثف وهي كالتالي: ا'. وجود شرط صريح من جهة حكومية معينـة يتطلب الكشف عن المعلومـة

$$
\text { السرية. }
$$

r r أن يكون التوصل للمعلومة تم عن طريق اختبارات وجهود معتبرة سرية. ". أن تكون المنتجـات المـراد تـسويقها عبـارة عن أدويـة أو منتجـات زراعيـة

\section{كيميائية.}

؛. أن تكون المواد الكيميائية المستخدمة في التصنيع جديدة. (")

ويستلزم تحقق الثروط أعلاه حتى يجبر صاحب السر قانونأ على إفثائه إلى الجهات الحكومية، وتلتزم الجهة الحكومية الحختصة بالتسجيل بالحفاظ على السر

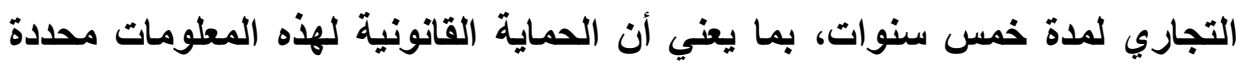
بخمس سنوات وبعد انقضائها تصبح من المعلومات العامة المباحة للجميع ولا يستطيع صاحب الحق منع التعدي عليها أو مطالبة من يقوم بذلك. ونحن بدورنا نرى أن هذه العدة قصيرة ونقترح أن يعيد المنظم النظر في ذلك

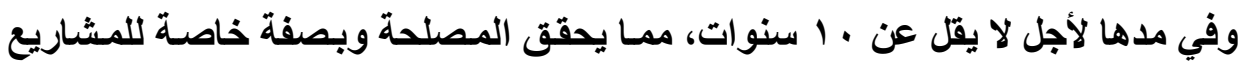

$$
\text { (1) أنظر المادة (0) (0) من لانحة حماية المعلومات التجارية السرية. }
$$




$$
\begin{aligned}
& \text { المنشأة حديثًا وللايها أسرار تجاريـة وترغب في الحصول على الإذن. وفي سياق } \\
& \text { مختلف فيمـا يتطق بالمدد، نجد أن القانون الأوروبي لحماية الأسرار التجارية يحداد }
\end{aligned}
$$

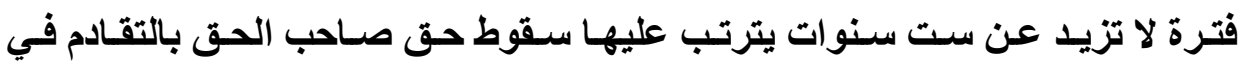

$$
\begin{aligned}
& \text { الاعاوى الناشئة عن التعدي على أسراره التجارية'() ، ولا شكك أن لذلك التحديد فائدة }
\end{aligned}
$$

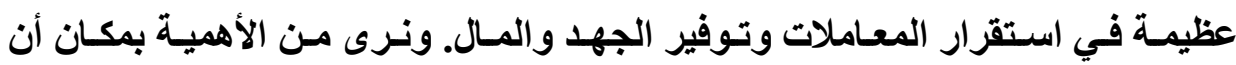

$$
\begin{aligned}
& \text { يتضمن النظام السعودي نصا صريحاً يحدد فيه مدة التقادم للاعوى التي يكون محلها } \\
& \text { التعدي على معلومة تجارية سرية. }
\end{aligned}
$$

وتجيز المادة السادسة من نفس اللائحة للجهة المختصة بالتسجيل الكثف عن

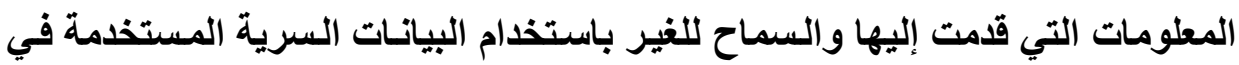

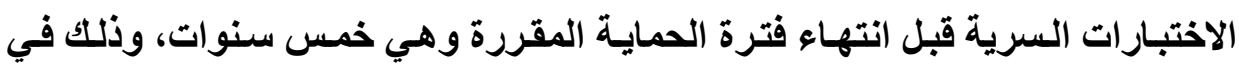

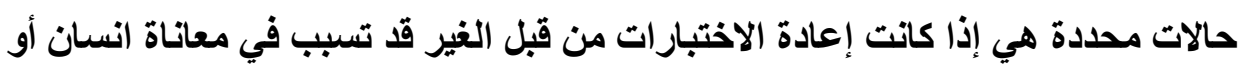

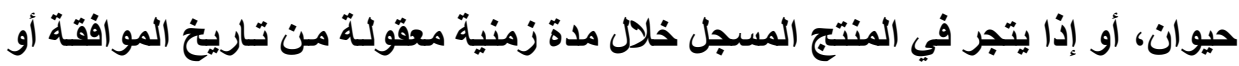

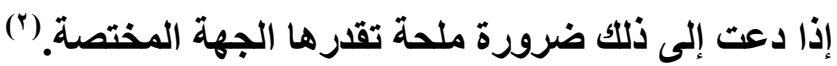

(1) Article 8 of the Trade Secret Directive states as follow: " 1. Member States shall, in accordance with this Article, lay down rules on the limitation periods applicable to substantive claims and actions for the application of the measures, procedures and remedies provided for in this Directive. The rules referred to in the first subparagraph shall determine when the limitation period begins to run, the duration of the limitation period and the circumstances under which the limitation period is interrupted or suspended.

2. The duration of the limitation period shall not exceed 6 years".

$$
\text { (ץ) انظر المادة (؟) من لاثحة حماية المعلومات التجارية السرية. }
$$


ويلاحظ على المادة أعلاه أنها سمحت بالكثف عن الأسرار المسجلة لأغراض الماض البحث والتحليل والاختبارات المتعلقة بهما مما يمكن اعتباره ميزة للدعم البحث العلمي

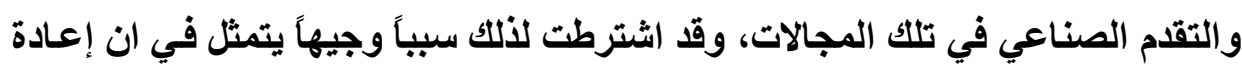

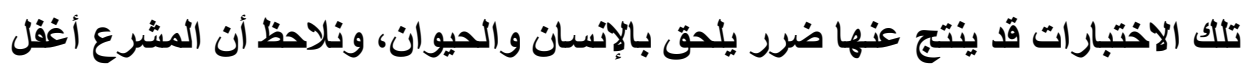
الأضرار التي قد تلدق بالبيئة من جراء ذلك فكان من الأحرى النص على ذلكت. ويقتضي

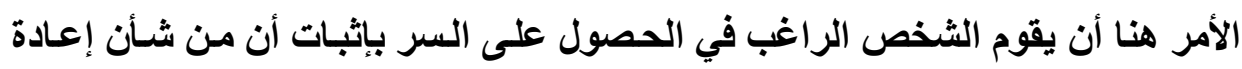

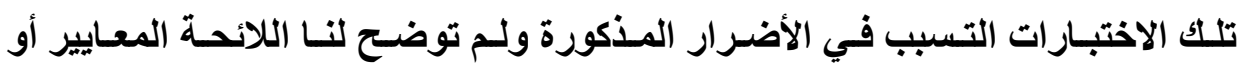

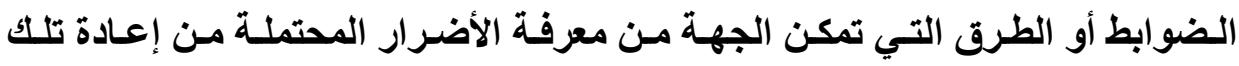

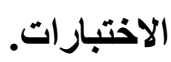

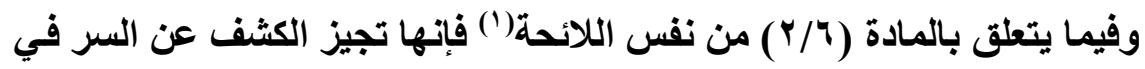

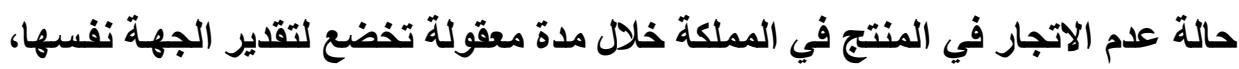
ونجد أن هذه الفقرة وإن كان لها مـا يبررها من الجوانب الاقتصادية والتقنية إلا أنها

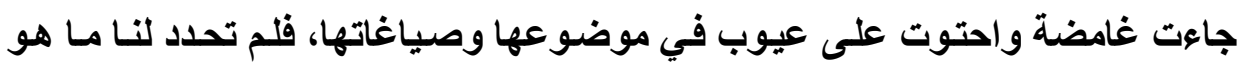

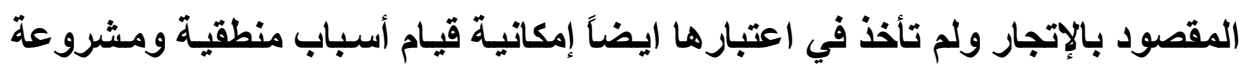

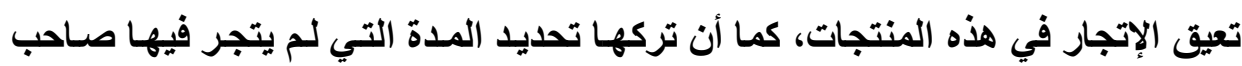

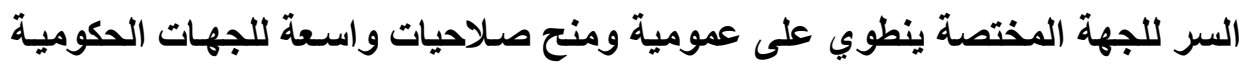

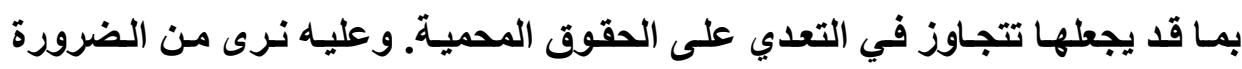
بمكان تعديل هذه الفقرة والنص صراحة على شروط وضوابط تحكم عملية عدم الإتجار.

(1) (1) أنظر المادة (؟/؟) من لانحة حماية المعلومات التجارية السرية. 
ويلاحظ على المادة (؟/\%) من نفس اللانحة"(1) أنها جاءت ايضاً عامة وغامضة حيث أن منطوق الضرورة الملحة التي تدعي للكثف عن الأسرار التجارية المسجلة قد

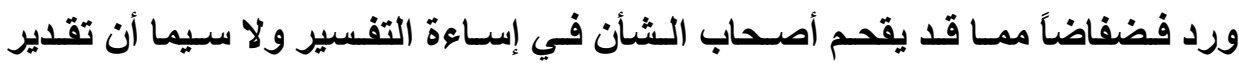

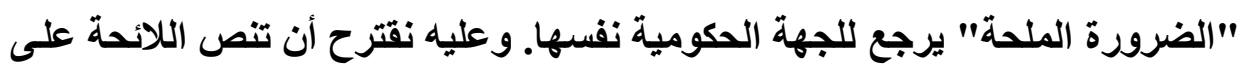

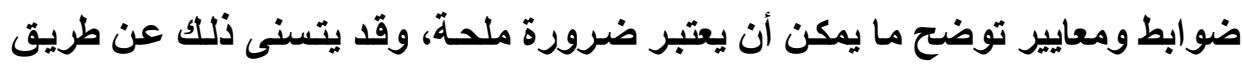

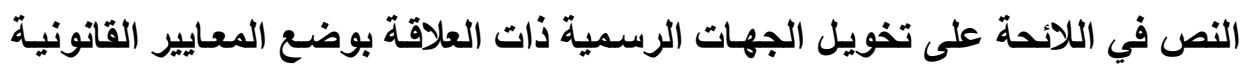
والفنية التي تحكم هذه الضرورات.

وفي غير الحسالات الواردة أعلاه تلزم المـادة (ع) من نفس اللانحة (ب) الجهة

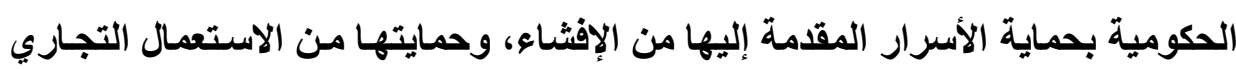

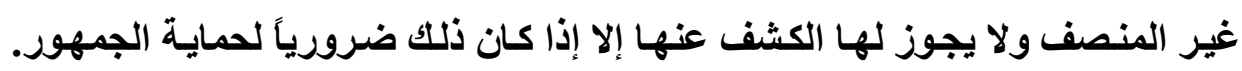
ويلاحظ أن المنظم قد أورد أسباب منطقية تستوجب كثف الاسرار التجاريـة ولا يجيز

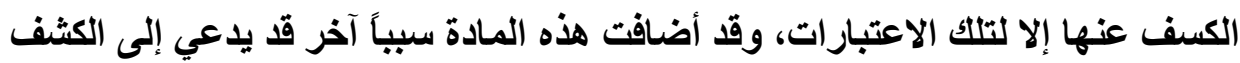
عن الأسرار المحمية وهي الضرورات الداعية لحماية الجمهور.

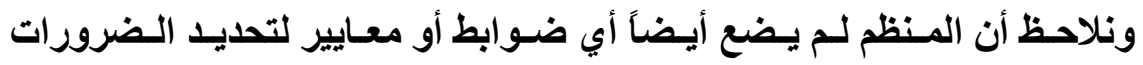

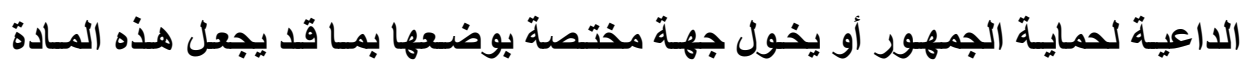

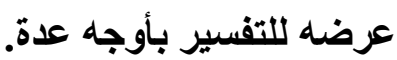

وعليه نقترح نفس الاقتراح السابق بضرورة تقييد عمومية هذه المسادة بمـا يضمن حماية الأسرار التجارية ويشجع على الاستثمار والصناعة في ظل بيئة تنافسية عادلة.

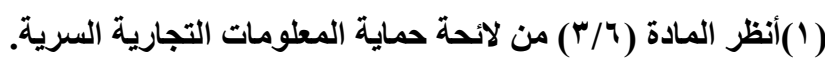

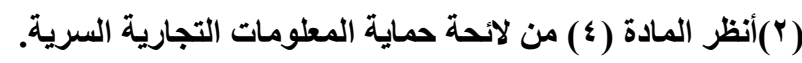


ونلاحظ أن موقف المنظم السعودي يتناغم مع المعايير الدولية في هذا الجاتب،

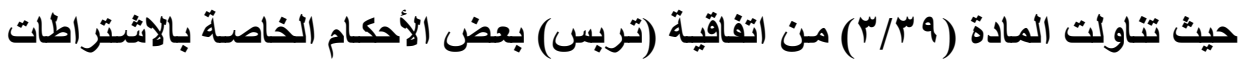
الحكومية حيث أجازت للاول الأعضاء أن تثترط الكثف عن الأسرار التجارية المتعلقة بالأدوية والمنتجات الزراعية الكيميائية التي تحتوي على مواد كيميائية جديدة إذا كان

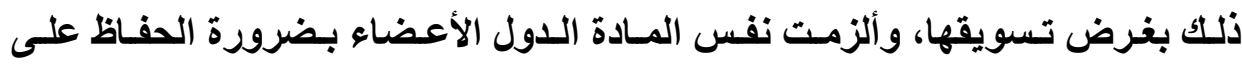

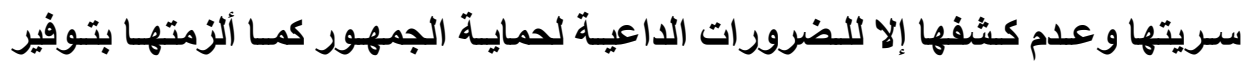
الحماية من الاستخدام التجاري غير المنصف(') ويلاحظ أن نصوص الاتفاقية أيضًا

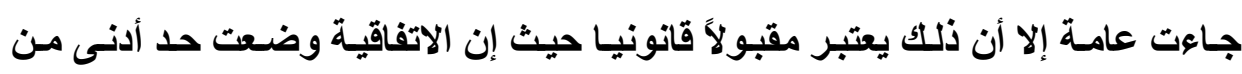

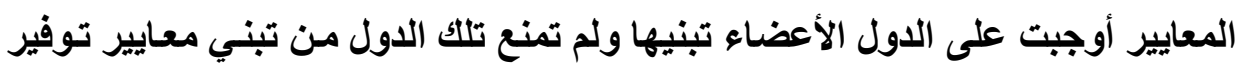
حماية أقوى مما ورد في الاتفاقية. () ويسرى ذلك أيضاً على القانون الأوروبي الموحد لحماية الأسرار التجارية، حيث نصت فئ الاتفئه المادة (ب/ץ) من التوجيه الأوربي الموحد لحماية الأسرار التجارية على: "...2. The acquisition, use or disclosure of a trade secret shall be considered lawful to the extent that such acquisition, use or disclosure is required or allowed by Union or national law...".

ويعني ذلك أن حيازة أو استعمال أو إفشـاء السر التجاري يعتبر مشروعاً إذا

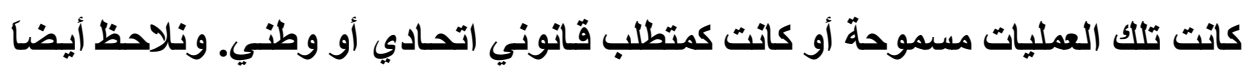
أن القانون الأوروبي لم يضع أي معايير تتعلق بما يمكن اعتباره متطلب لكشف السر

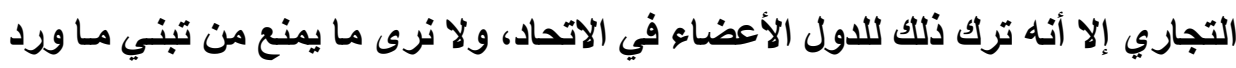

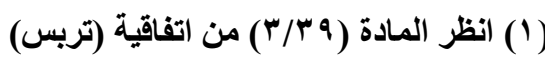

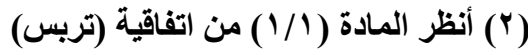


في اتفاقية (تربس) فيما يتعلق باشتراط الحكومة الكشف عن الأسرار التجاريـة التي

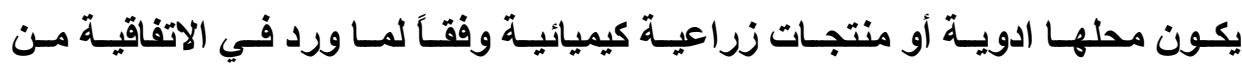

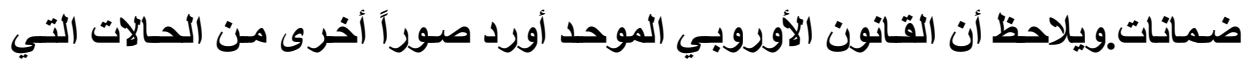
يعتبر كثف السر التجاري فيها مشروعاً ومنها الممارسة التي تعتبر من حقوق العان العمال

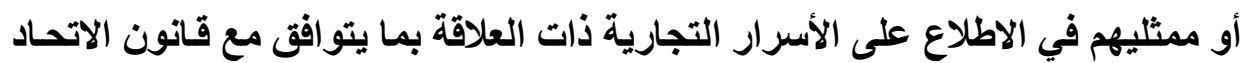

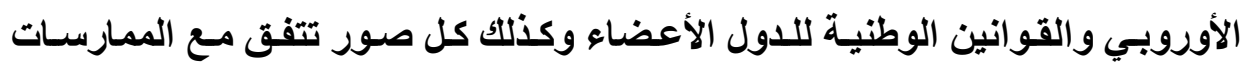
التجارية الثريفة.(1) - (1)

Article (3/1/ c \& d) states as follows:(1)

"1. The acquisition of a trade secret shall be considered lawful when the trade secret is obtained by any of the following means:

.... (c) exercise of the right of workers or workers' representatives to information and consultation in accordance with Union law and national laws and practices;.......

(d) any other practice which, under the circumstances, is in conformity with honest commercial practices......" 


\section{المبحث الثالث}

\section{التعدي على المعلوهات التجارية السرية}

مـا إن تتحقق الشروط أعلاه حتى تصبح الأسرار التجاريـة متمتعة بالحمايـة

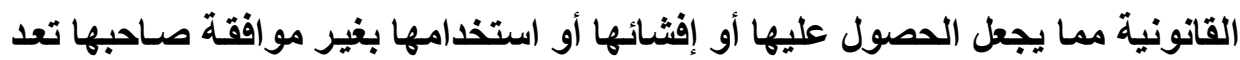

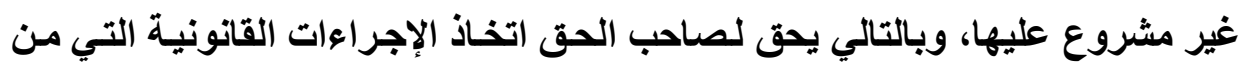
شأنها حماية حقه بما فيها الدعوى القضائية. وعليه سنتولى في هذا المبحث صور التعدي على الأسرار التجارية في النظام السعودي والتوجيه الأوربي الموحد لحماية الأسرار التجارية.

تنص المادة (T/1/) من لاتحة المطومات التجارية السرية في المملكة على أن "

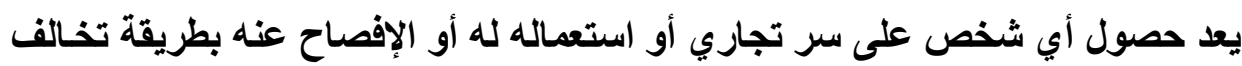

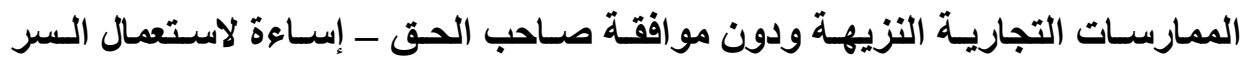

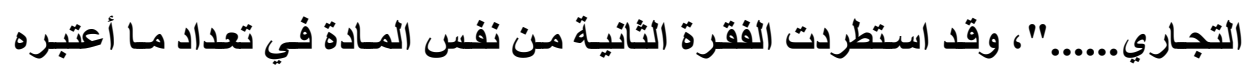

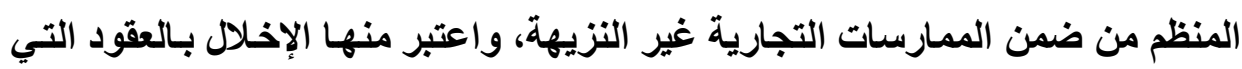

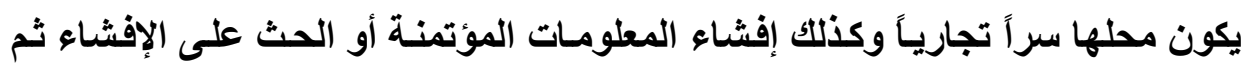

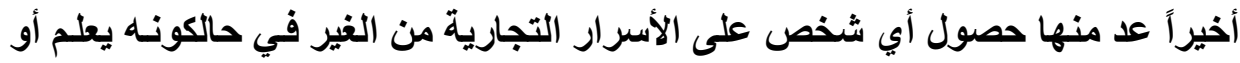
كان بمقدورهالعلم بأنها وصلت إليه نتيجة ممارسـة تجاريـة غير نزيهة.

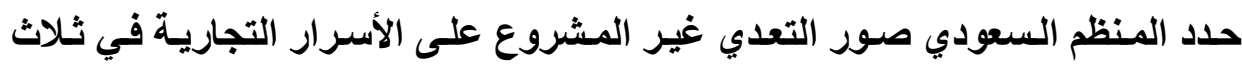
صور ويلاحظ أن المسادة محل العرض تضمنت نفس حالات الممارسـات غير الثريفة الواردة في الهامش رقم (• (1) من اتفاقية (تربس) على اعتبار انها تفسير للمقصود (1) أنظر المادة (ז/厂) من لانحة حماية المعلومات التجارية السرية. 
بتلك الممارسـات. (1) ونلاحظ من استقراء مـا أورده المنظم السعودي من صور لتلك

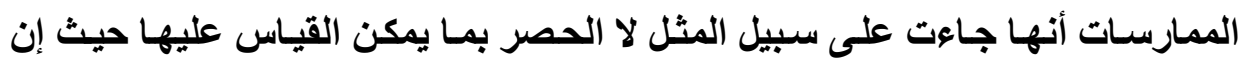
هناك عدد غير محدود من الممارسات غير النزيهة. وبـالرجوع للمـادة رقم (\&/ץ/أ وب) مسن القـانون الأوروبـي الموحــ للأسـرار

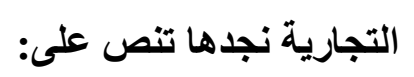

2. "The acquisition of a trade secret without the consent of the trade secret holder shall be considered unlawful, whenever carried out by:

(a) unauthorised access to, appropriation of, or copying of any documents, objects, materials, substances or electronic files, lawfully under the control of the trade secret holder, containing the trade secret or from which the trade secret can be deduced;

(b) any other conduct which, under the circumstances, is considered contrary to honest commercial practices".

ويغني ذلك "تعد حيازة السر التجاري دون موافقة صاحب الحق فيه غير قانونية، متى ما تمت بأحد الطرق التالية:

(1) ينص الهامش رقم (· ( ) من اتفاقية (تربس) على ان اي أسلوب يخرالف الممارسات التجارية

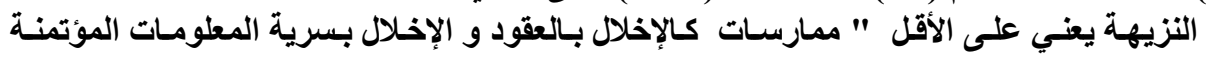

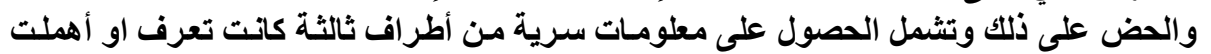

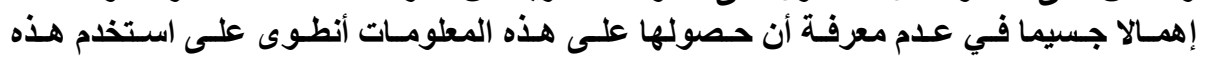

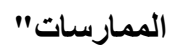




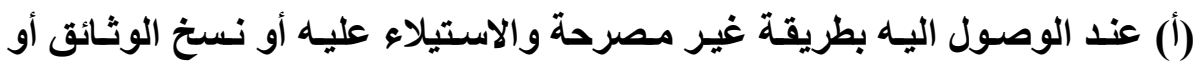

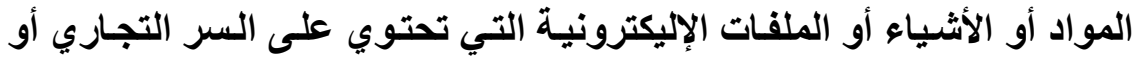

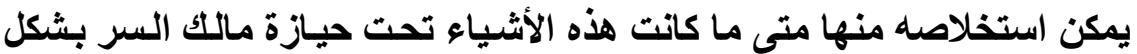

$$
\text { مشروع. }
$$

(ب) أي سلوك آخر، في ظل الظروف المحيطة به يعتبر مخالفة للممارسات التجارية

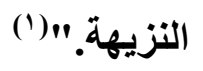

ويلاحظ أن المششرع الأوروبـي عدد بعض الأعمـال الماديـة التـي مـن شـأنها المساهمة في الحصول على السر التجاري ويفهم سياق المـادة أعلاه أن هذه الأعمال

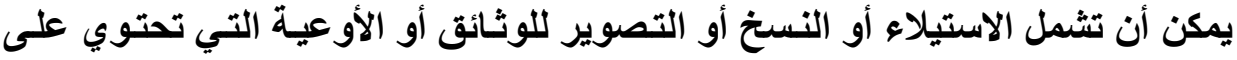

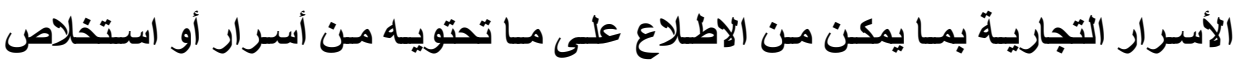
الأسرار من محتوياتها. ويلاحظ أن القانون الأوروبي جـاء مسايراً للوسـائل التقنيـة

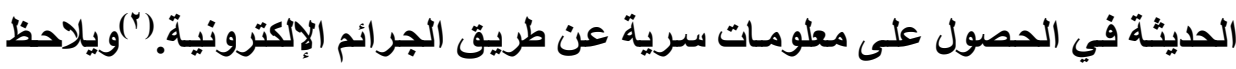
أيضاً أن القانون الأوروبي في المادة أعلاه اعتبر هذه النوعية من الأعمال تؤدي إلى الكي

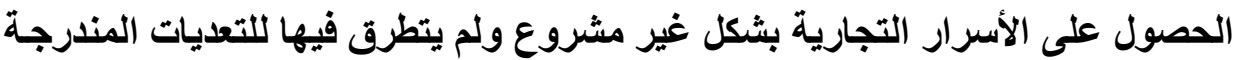

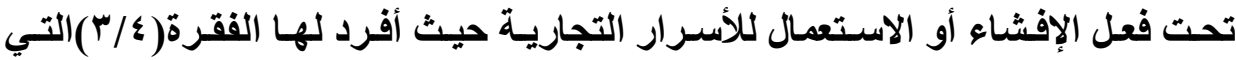

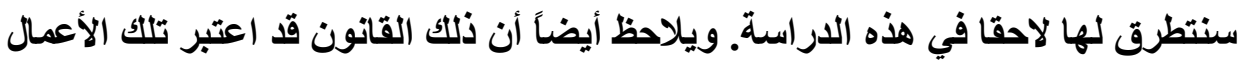

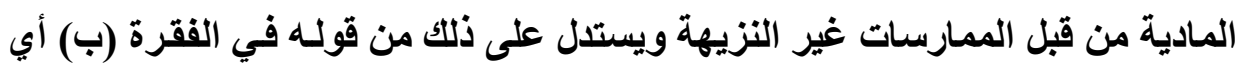
سلوك آخر يعد من قبيل الممارسات غير النزيهة.

(1) (1) - ترجمة الباحث بتصرف.

(2) Marco Alexandre Saias ,Unlawful acquisition of trade secrets bycybertheft: between the Proposed Directiveon Trade Secrets and the Directiveon Cyber Attacks, JournalofIntellectual Property Law \& Practice, 2014,Vol.9, No 9, P.723. 
ويمكنتا القول أيضاً أن هذا التعداد ورد هنـا على سبيل المثال لا الحصر وقابل للقياس عليه لا سيما إذا لاحظنا أن هذه المادة تعتبر مادة استرشاديه،وأيضاً يحق للادول الأعضاء تبني حماية أقوى وأكثر تفصيلاً مما ورد في هذا القانون.

وبذلك يخالف القانون الأوروبي اتفاقية (تربس) و النظام السعودي فيمـا أورده

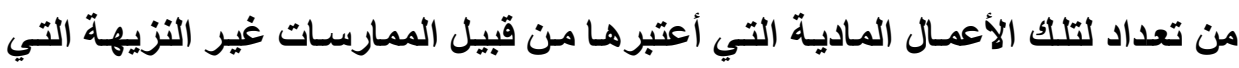

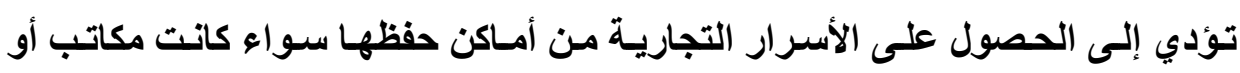

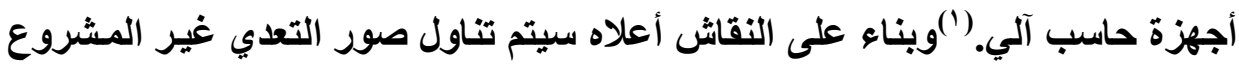

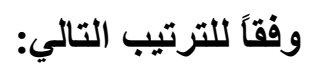

\section{المطاب الأول}

\section{التعديات الناتجة عن إفشاء المعلوهات المؤتمنة أو الحث على إفشائها}

تناولت المادة (ז/ץ/ب) من لاتحة المعلومات التجارية السرية (")، حالة إفشاء

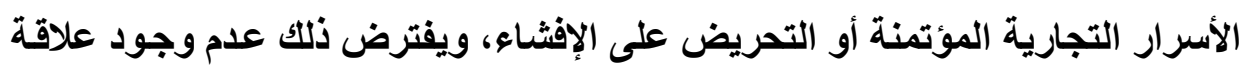

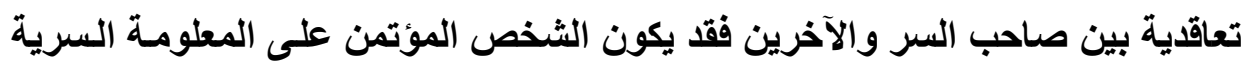

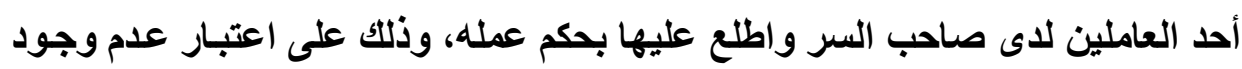

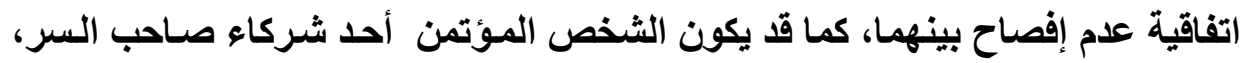

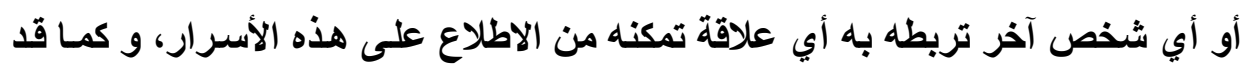

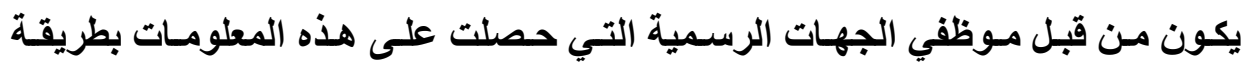

(1) Marco Alexandre Saias ,supra note, P.725.

(Y) انظر المادة (ז/ץ/ب) من لاتحة حماية المعلومات التجارية السرية. 
مشروعة من أجل منح مو افقات أو تراخيص لتسويق منتجـات معينة ،كالحالة التي يطلب فيها القانون الكشف عن الأسرار التجاريـة التي تلدخل في الأدويـة أو المنتجـات الزراعية الكيميائية وذلك لأجل الحصول على تراخيص تسويقية لها. (') كما تفرض بعض التثريعات التزامات بعدم إفثاء الأسرار على نوعيات محددة

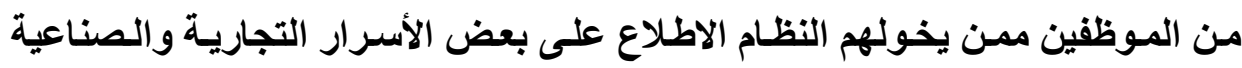

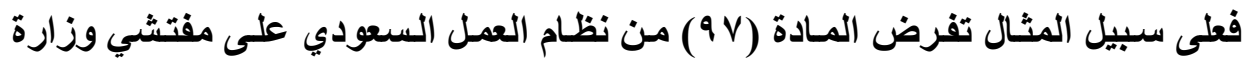

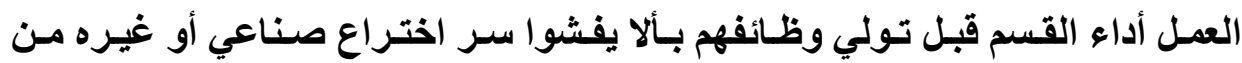
الأسرار التي يطلعون عليها بحكم عملهم ويسري عليهم الحظر حتى بعد نهاية علاقاتهم

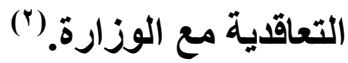
وفي نفس السياق حتى لو لم يتم توقيع اتفاقيـة عدم إفصاح مـع العمال فإن

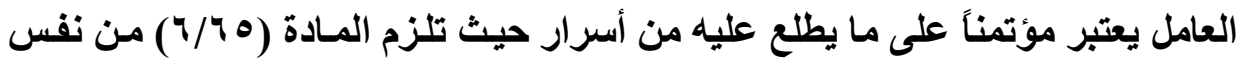
النظام بحفظ الأسرار الفنية والتجارية والصناعية للمواد التي ينتجه أو التهائ التي أسهم في إنتاجها بصورة مباشرة أو غير مباشرة، وجميع الأسرار المهنية المتعلقة بالعمل أو الو

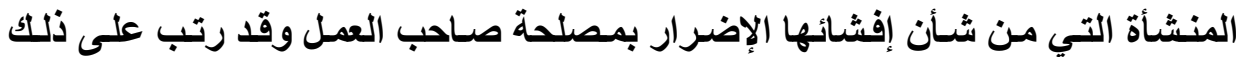
مجموعة من العقوبات التي يمكن توقيعها في حق العامل من قبل رب العمل. (") والتي قد تصل إلى فصل الموظف الذي أفشى المطومسات التي تمثل أسراراً تجارية من دون إثعار أو تعويض مع حرمانه من مكافأة نهاية الخدمة. كما أجاز النظام

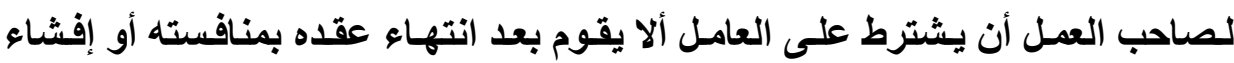
الأسرار التي حصل عليها أثناء عمله.

(1) انظر المادة (؛ و () من لانحة حماية المعلومات التجارية السرية.

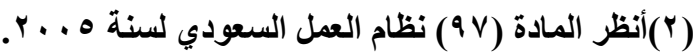
(Y) 
ولقيام المسؤولية عن هذا النوع من الممارسـات غير النزيهة بشرط أن تنت عملية الإفثاء بدون إذن من صاحب الحق في السر. ويستوي أن يكون فعل الإفشاء تم

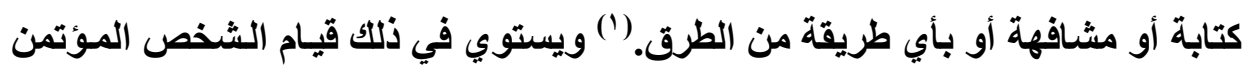

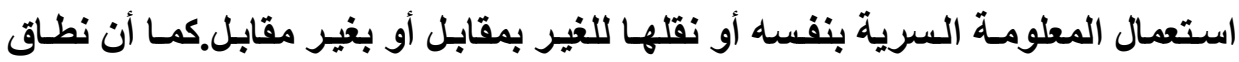

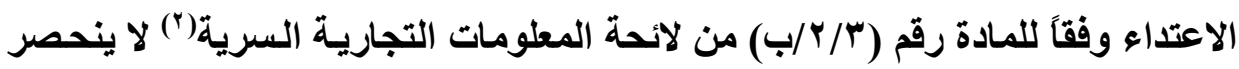

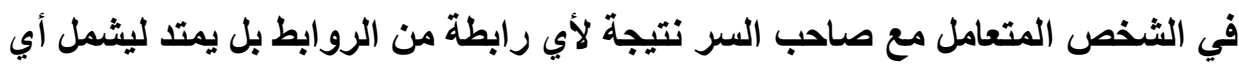

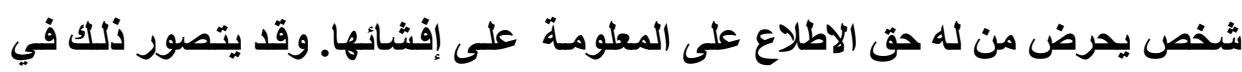

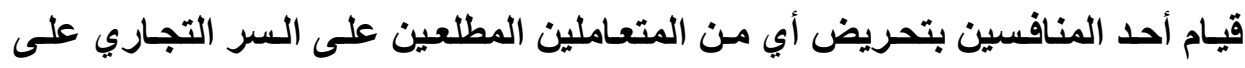

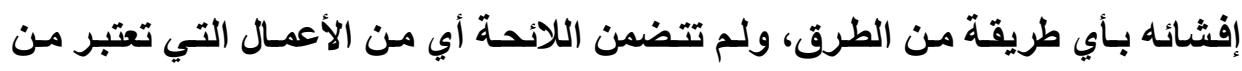

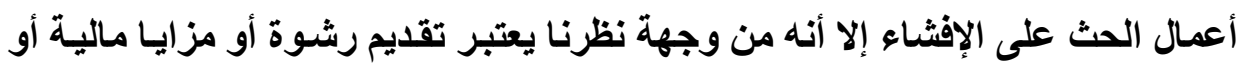

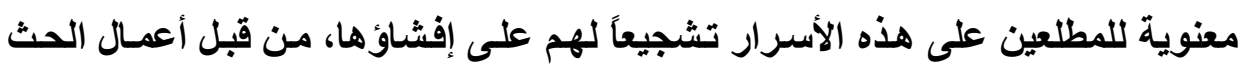

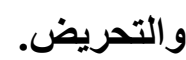

ويلاحظ أن المنظم السعودي لم يحدد منهم الأشخاص الذين قد يكونون عرضة

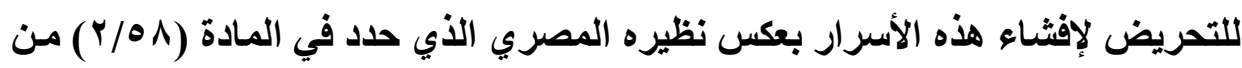

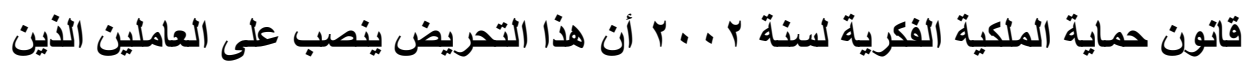

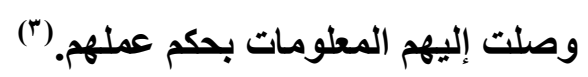

ويلاحظ ان المنظم السعودي هنـا يتفق مع مـا ورد في الهامش رقم (· • (1) من

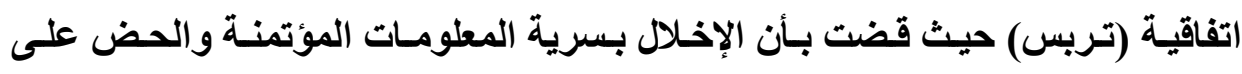

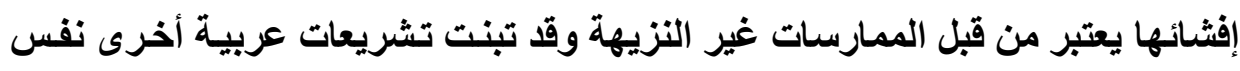

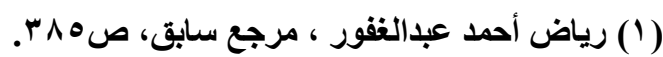

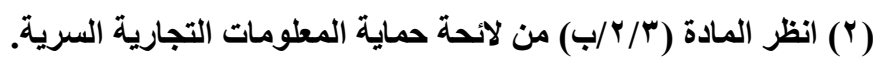

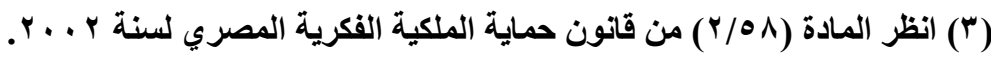


التوجه كالتشريع الأردني على سبيل المثال. (') ويلاحظ أن القانون الأوروبي الموحد لم

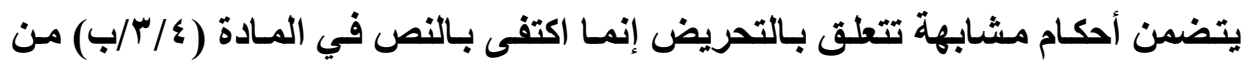
لائحة حماية المعلومات التجارية السرية(")، على اعتبار أن عمل الإفثاء أو الاستعمال

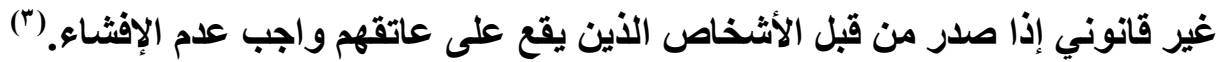
وفي تطور غير مسبوق يقر القـانون الأوروبي الموحد للأسرار التجاريـة في

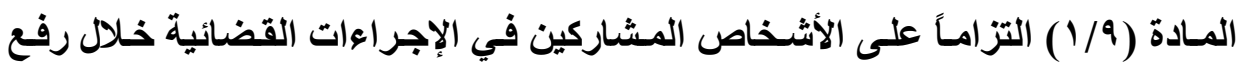

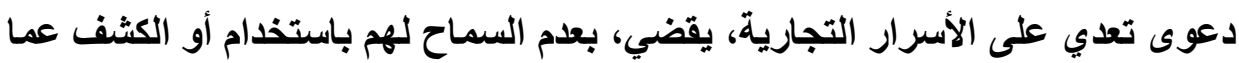

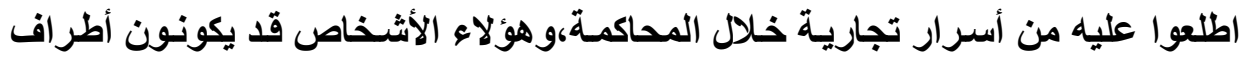

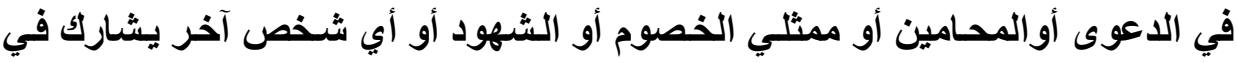

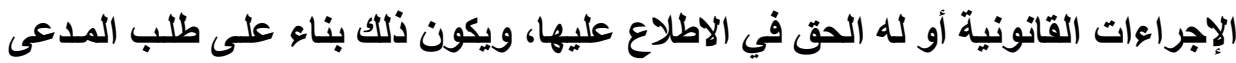

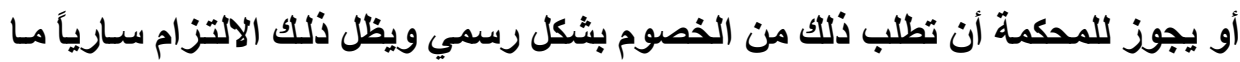

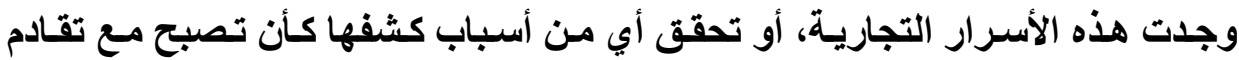
الوقت معروفة للمتعاملين في مجالها.(4) ولم يكتف القانون الأوروبي للأسرار التجارية التهائ

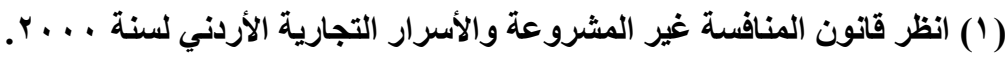

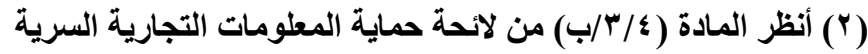

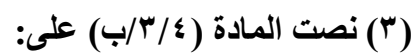

" being in breach of a confidentiality agreement or any other duty not to disclose the trade secret"

(4) Article (9/1) of the Trade Secret Directive states as follow: "...1. Member States shall ensure that the parties, their lawyers or other representatives, court officials, witnesses, experts and any other person participating in legal proceedings relating to the unlawful acquisition, use or disclosure of a trade secret, or who has access to documents which form part of those legal proceedings, are not permitted to use or disclose any trade secret or alleged trade secret ........ The obligation referred to $=$ 


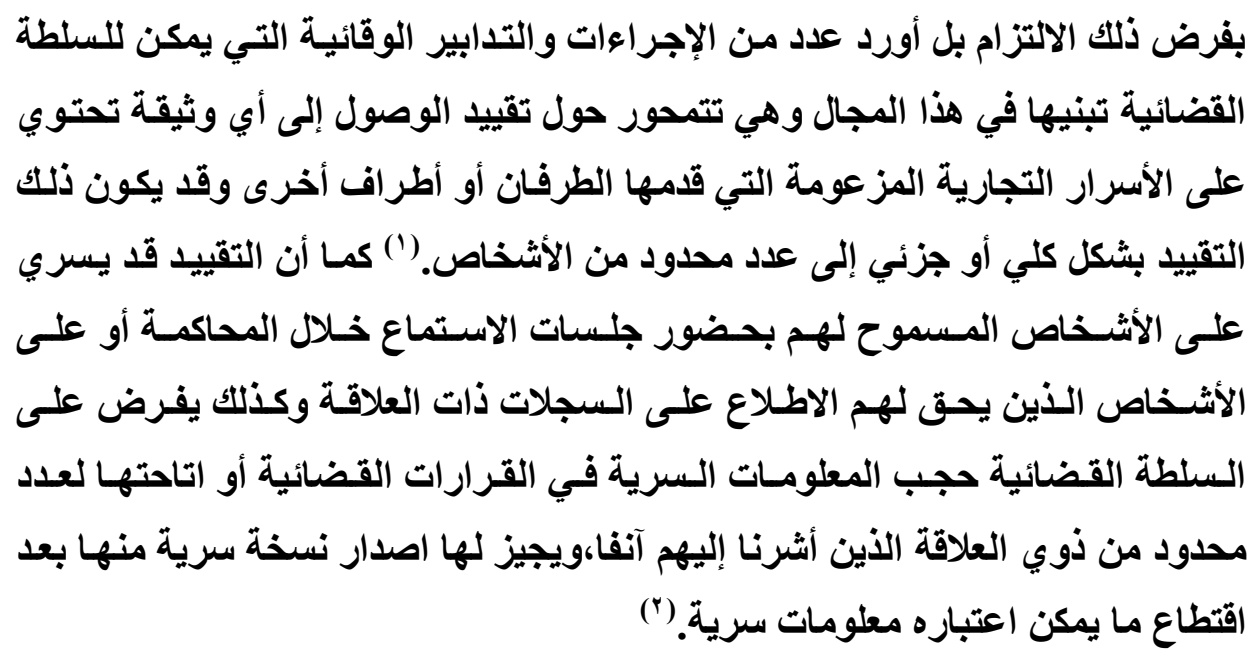

in the first subparagraph shall remain in force after the legal proceedings have ended. However, such obligation shall cease to exist in any of the following circumstances: (a)where the alleged trade secret is found, by a final decision, not to meet the requirements set out in point (1) of Article 2; or (b)where over time, the information in question becomes generally known among or readily accessible to persons within the circles that normally deal with that kind of information.....".

(1) Article (9/2/a) of the Trade secret Directive States as follow: ".....The measures referred to in the first subparagraph shall at least include the possibility: (a)of restricting access to any document containing trade secrets or alleged trade secrets submitted by the parties or third parties, in whole or in part, to a limited number of persons.."

(2) Article (9/2/b\&c) of the Trade Secret directive states as follow:".... (b) of restricting access to hearings, when trade secrets or alleged trade secrets may be disclosed, and the corresponding record or transcript of those hearings to a limited number of persons; (c)of making available to any person other than those comprised in the limited number of persons referred to in points (a) and (b) a non-confidential version of any judicial $=$ 
ولا شكت أن المشرع الأوروبي أحسن صنعاً في ذلكت على اعتبار أن هؤلاء

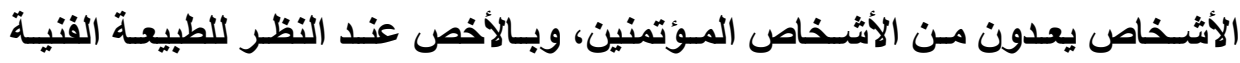
والقانونية للأسرار التجارية إذ يترتب على كثفها أو الإفصاح عنها خروجها من دائرة

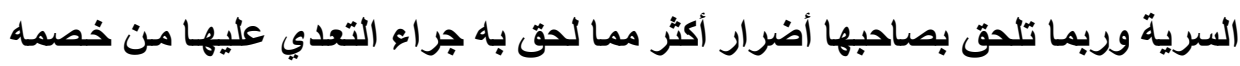

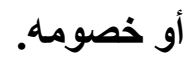

وباستقراء النظام السعودي لم نجد أي نص يشابه ذلك ونرى أنه من الضرورة بمكان أن يتم تبني نصوص مشابهة لفرض الحماية خلال مباشرة الإجراءات القضائية المختلفة مع تبني المعايير اللازمة التي تكفل سريتها.

\section{المطالب الثاني}

\section{التعديات الناتجة عن الاخلال بالعقود المتعلقة بالأسرار التجارية}

تقضي المادة (ب/1/) من لائحة المعلومـات التجاريـة السرية (1)، بأن أي أعمال

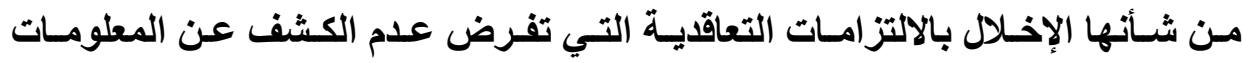

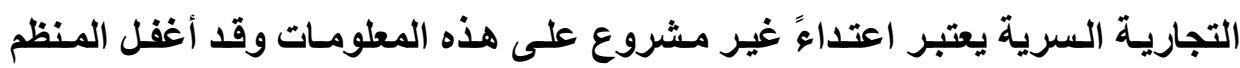
السعودي تعداد العقود التي قد يكون محلها سراً تجارياً واكتفى بالنص على على أي إخلال

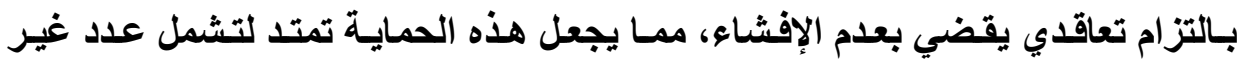

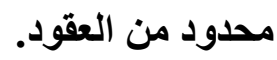

decision, in which the passages containing trade secrets have been removed or redacted.".

$$
\text { (1) (1) الظر المادة (T//) من لاتحة حماية المعلومات التجارية السرية }
$$




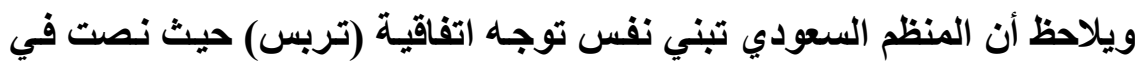
الهامش رقم (• (1) غند تحديد المقصود بالممارسات التجارية غير النزيهة على اعتبار

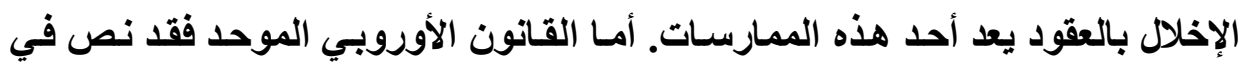

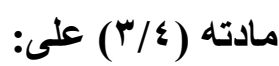

" The use or disclosure of a trade secret shall be considered unlawful whenever carried out, without the consent of the trade secret holder, by a person who is found to meet any of the following conditions:

(a) having acquired the trade secret unlawfully;

(b) being in breach of a confidentiality agreement or any other duty not to disclose the trade secret;

(c) being in breach of a contractual or any other duty to limit the use of the trade secret."

بمـا يعـي "يعد استعمال أو الكشف عن الأسرار التجاريـة غير قانوني طالمـا

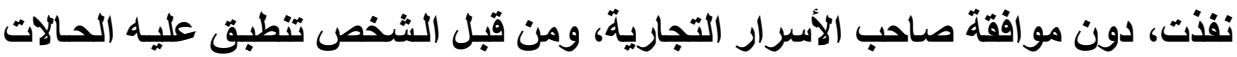

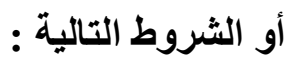

$$
\text { (أ) إذا حصل على الأسرار التجارية بصورة غير قانونية. }
$$

(ب) إذا كان في حالة خرق لاتفاق السرية أو أي واجب اخر يقضي بعدم الكثف عن

$$
\text { الأسرار التجارية. }
$$

(ج) إذا كان في حالة خرق تعاقدي أو أي واجب آخر للحد من استخدام الأسرار

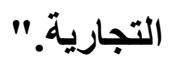


ويلاحظ أن القـانون الأوروبـي نص صـراحة على اتفاقيـات عدم الإفصاح أو أوات

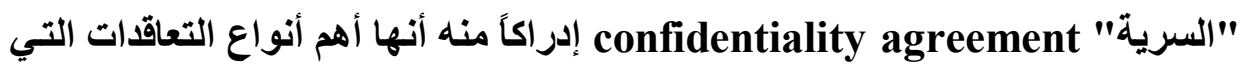
ترد على حقوق الأسرار التجارية وفي نفس الوقت لم يتطرق للعقود و التراخيص أسوة بالمنظم السعودي.

ومن جانبنا نرى أنه من الأهمية بمكان النص على هذه النوعية من الاتفاقيات

$$
\text { في اللانحة السعودية. }
$$

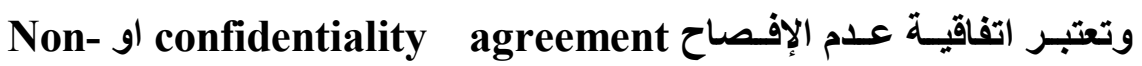

disclosure Agreement

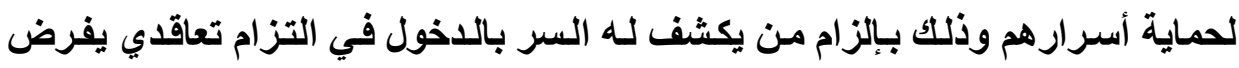

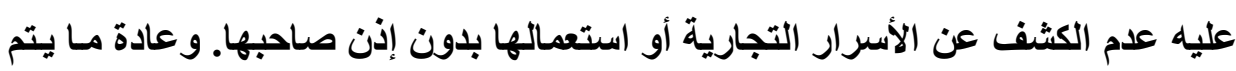
تضمين عقود التوظيف اتفاقيات تفرض عدم الإفصاح عن الأسرار التجارية أو قد التهات تكون ملحقة بها في بعض الحالات.

وتتكون هذه الاتفاقيات من عدد من البنود أهمها تحديد المعلومات السرية والتي

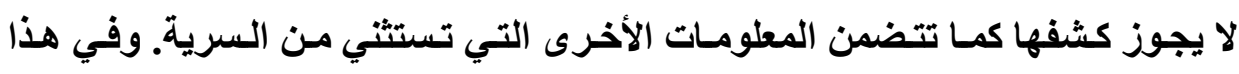

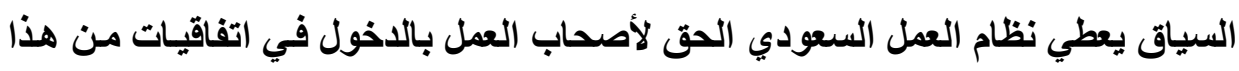

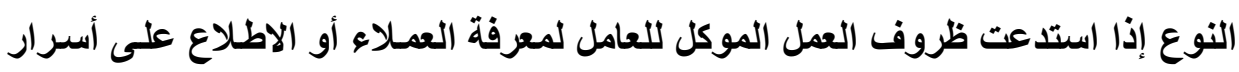

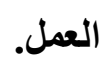

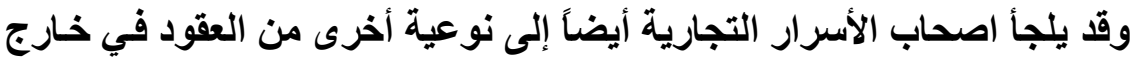

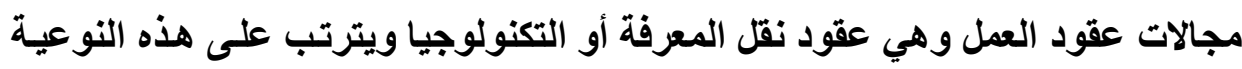

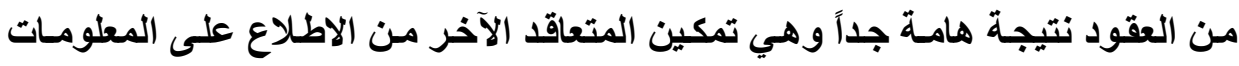

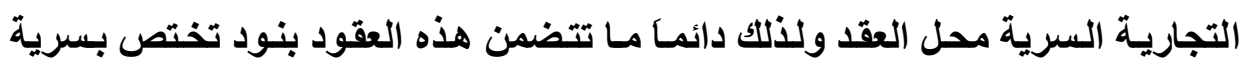

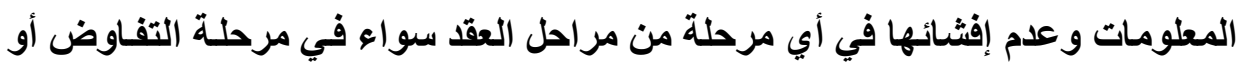

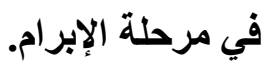


ويلاحظ أن الحماية هنا تجد أسساسها في العقد بمـا يعني أنها لا تسري إلا في

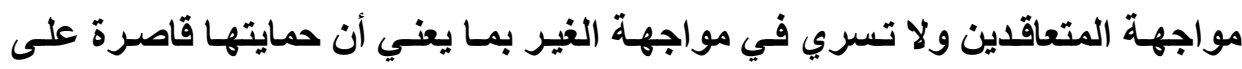
المتعاقدين ولا تنفذ أمام الغير.

وبالرغم من عدم النص على هذه النوعية من الاتفاقيـات صراحة في النظام السعودي، فإننا نرى انه لا يوجد ما يمنع من أن تسري عليها الحماية المقررة في هذا

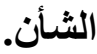

\section{المطلب الثالث: صورة التعدي على المعلوهات التجارية

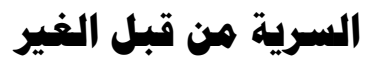

تتناول المادة (ب/ץ/ج) من لائحة المعلومـات التجاريـة السرية(')، الحالـة التي يحصل فيها الغير على سر تجاري من طرف آخر مع علمه أو قدرته على العلم بأن ذلك الك التهات

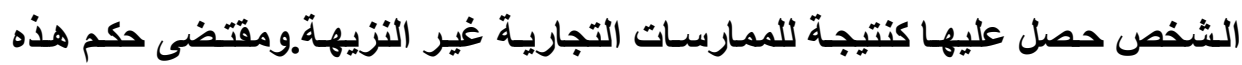

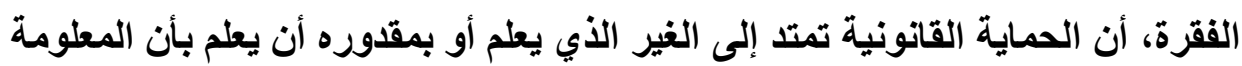

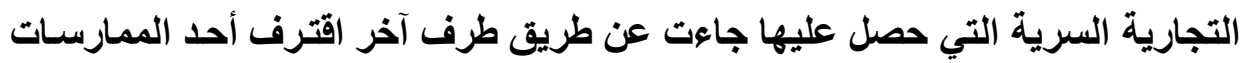

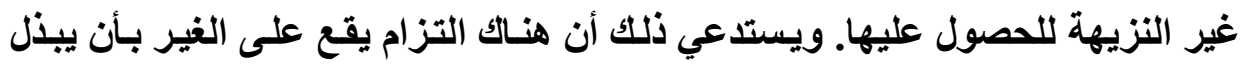

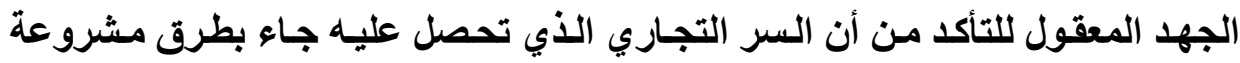
ولاتثترط اللانحة علمه فقط بل تفترض قدرته على العلم بحسب الظروف المحيطة بكل

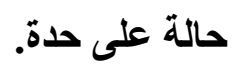

ويلاحظ أن نص هذه الفقرة جاء معيباً حيث تناولت فقط صورة واحدة من صور الاعتداء على الأسرار التجاريـة وهي الحصول عليها أو حيازتها وأغقلت استعمالها 
وعليهه نقترح أن تعدل هذه الفقرة وفقاً للتـالي: " حصول أو استعمال أو كشف أي شخص للأسرار التجاريـة من طرف آخر إذا كـان يطلم أو كـان بمقدوره أن يطلم بـان حصول ذلك الطرف عليها كان نتيجة مخالفة للممارسات التجارية النزيهة". ويلاحظ أن موقف المنظم السعودي في هذا السياق جاء متتاغمـاً مـع اتفاقيـة

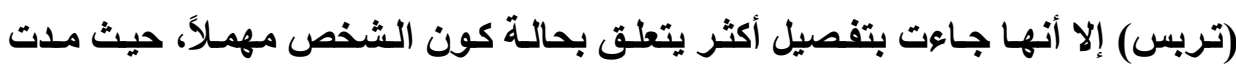
حماية الأسرار التجارية عند الحصول عليها من قبل الغير الذي بعلم بعدم مشروعيتها

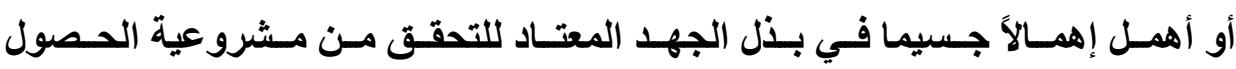
عليها. (') أما القانون الأوروبي الموحد للأسرار التجارية فقد تناول التعدي من قبل الغير

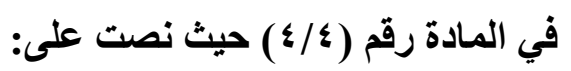

"The acquisition, use or disclosure of a trade secret shall also be considered unlawful whenever a person, at the time of the acquisition, use or disclosure, knew or ought, under the circumstances, to have known that the trade secret had been obtained directly or indirectly from another person who was using or disclosing the trade secret unlawfully within the meaning of paragraph 3."

ويعنـي ذلكك أنسه "تعتبر حيـازة أو استعمال أو كشف الأسـرار التجاريـة غير

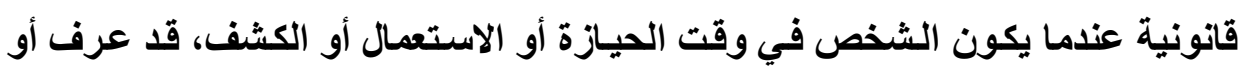

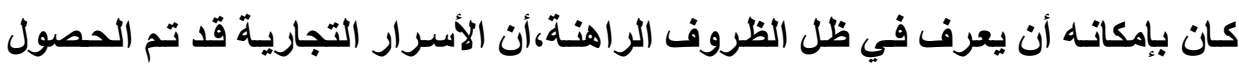
عليها بثكل مباشرة أو غير مباثر من شخص آخر قد استعمل أو كشف عن الأسرار 
التجارية بطريقة غير مشروعة بـالمعنى المقصود في الفقرة."(') ويلاحظ على هذا

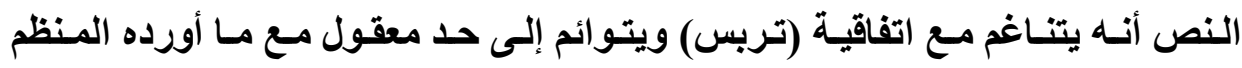
السعودي ألا أن النص أعلاه لم يقتصر على حصول الغير على المعلومة السرية بل مد العدان الحماية إلى حالات الكثف والاستعمال ونرى أنه من الضرورة بمكان أن يتبنى النظام

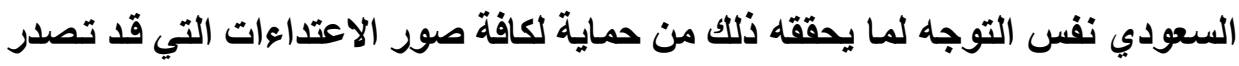

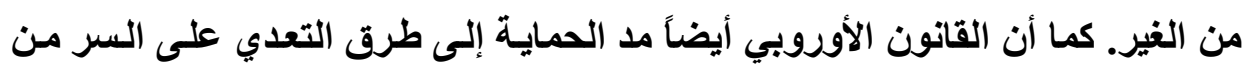

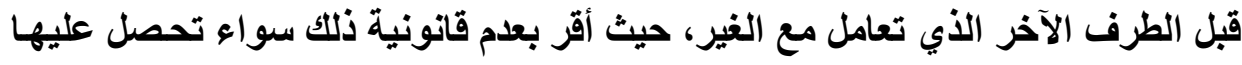
الثخص بطريق مباشر أو غير مباشر.ويشترط أن يكون التعدي هنا عمدي بمعنى أن

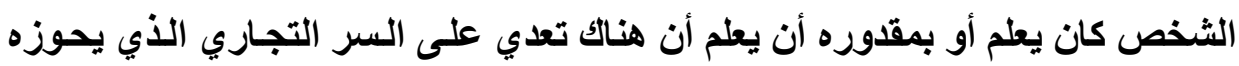

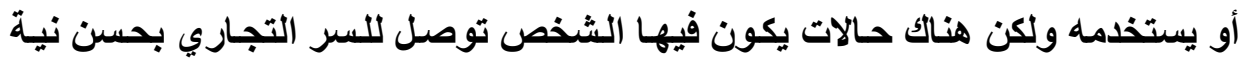
فمثلاً قد يحصل الثخص على سر تجاري بحسن نية كأن يكون توصل إليه عن طريقة

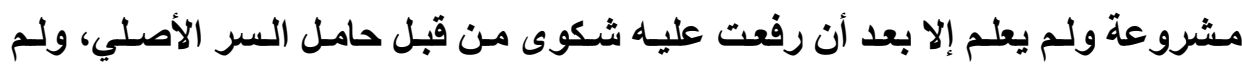

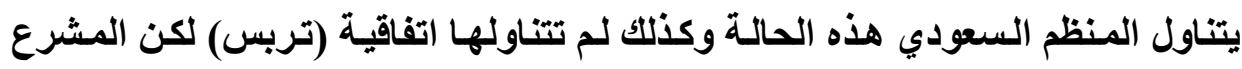

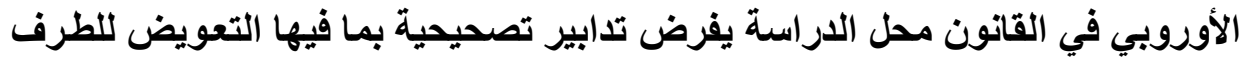

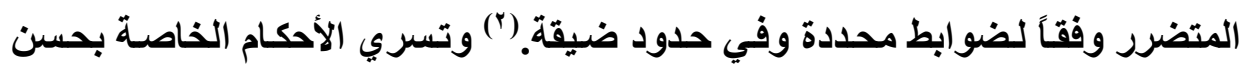

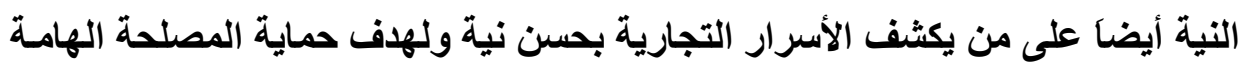

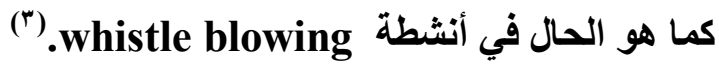




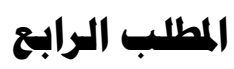 \\ التصرفات الواردة على السلع المخالفة}

الهاف الأساسي من التعدي غير المشروع على الأسرار التجارية هو الحصول

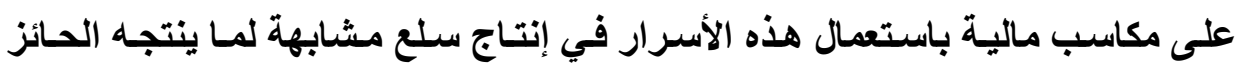

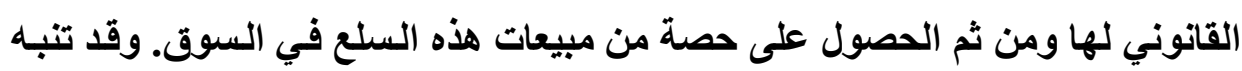

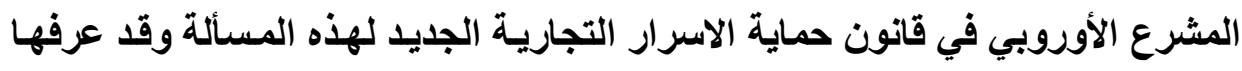

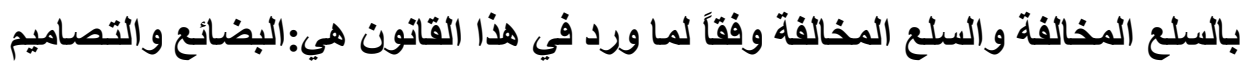
والخصائص والوظائف وعمليات الإنتاج أو التسويق التي تستفيد بشكل ملحوظ من فئ

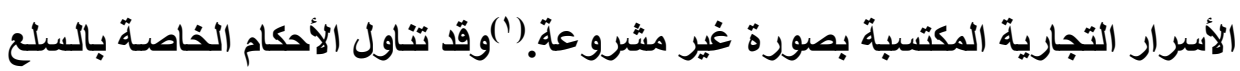

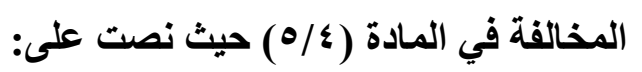

"The production, offering or placing on the market of infringing goods, or the importation, export or storage of infringing goods for those purposes, shall also be considered an unlawful use of a trade secret where the person carrying out such activities knew, or ought, under the circumstances, to have known that the trade secret was used unlawfully within the meaning of paragraph 3 ".

(1) Article (2/4) of the EC Trade secret Directive states as follow, "infringing goods' means goods, the design, characteristics, functioning, production process or marketing of which significantly benefits from trade secrets unlawfully acquired, used or disclosed". 
ويعني ذلك أنه "يعتبر إنتاج أو عرض أو طرح السلع المخالفة في الأسواق، أو

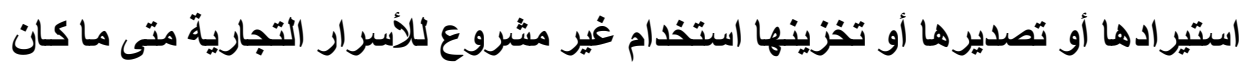

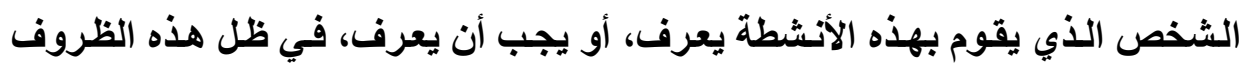

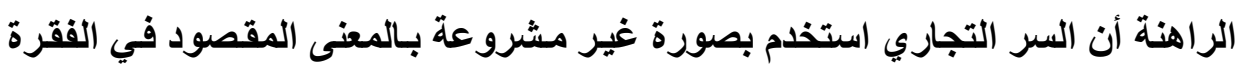

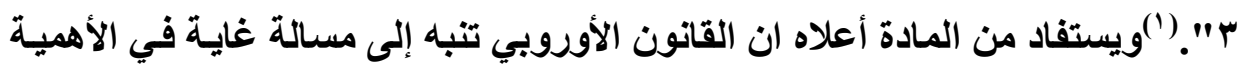

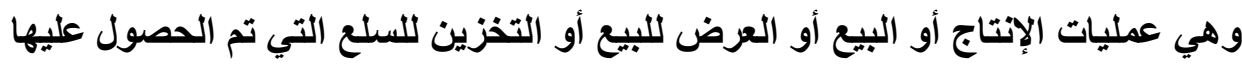

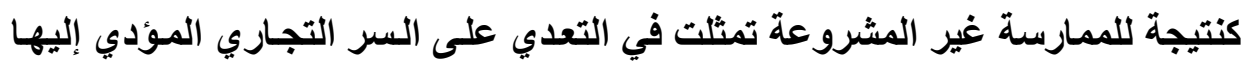

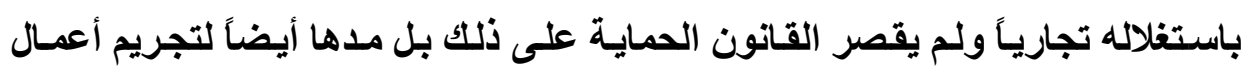

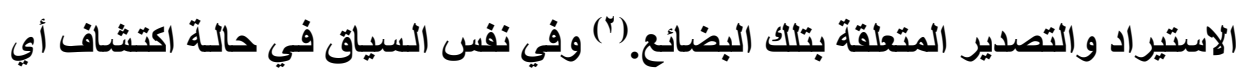

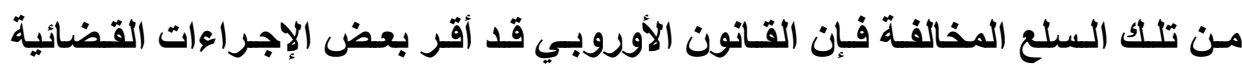

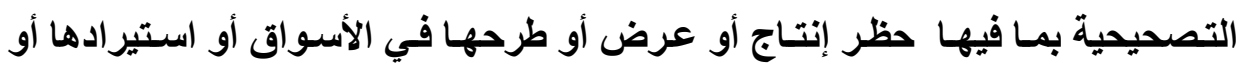

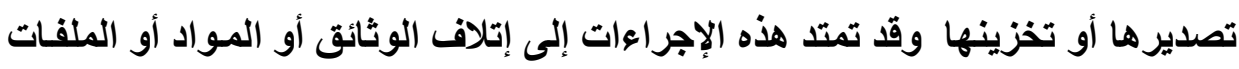

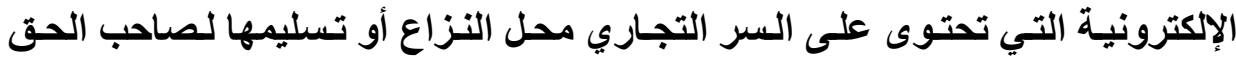

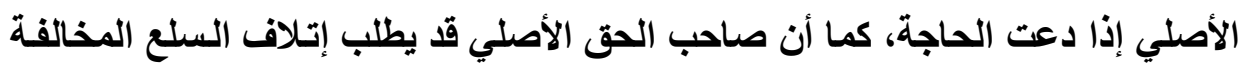

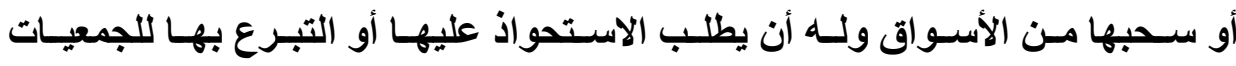

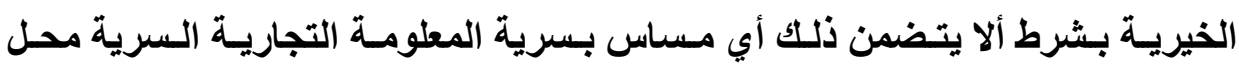
النزاع.(")

(1) (1) - ترجمة الباحث بتصرف.

(2) Roland Knaak, Annette Kur, Reto M. Hilty, Comments of the Max Planck Institute for Innovation and Competition of 3 June 2014 on the Proposal of the European Commission for Directive on the protection of undisclosed know-how and business information (trade secrets) against their unlawful acquisition, use and disclosure of 28 November 2013, COM(2013) 813 final. P.9.

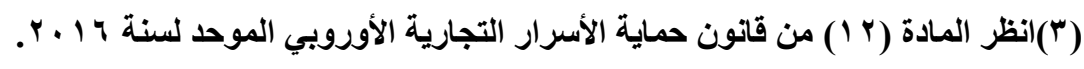


وفي هذا السياق نلاحظ أن لاتحة المعلومات التجارية السرية لم تتضمن أي

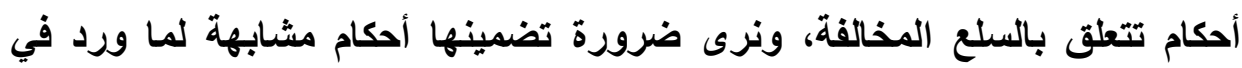

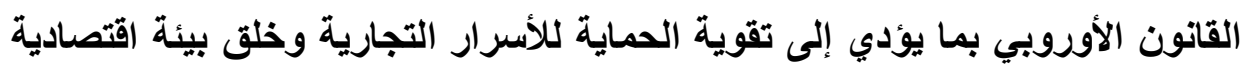

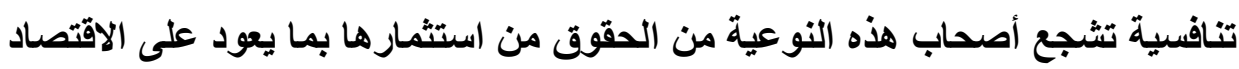
الوطني بالنفع والازدهار.

وبالرجوع لاتفاقية (تربس) وجد أنها أوردت من ضمن الأحكام العامـة الخاصة

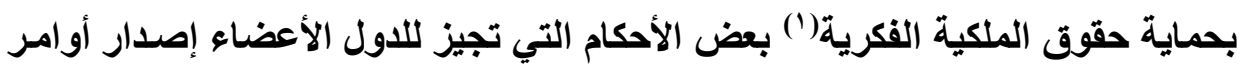

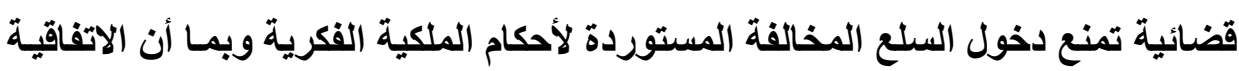
اعتبرت الأسرار التجارية من ضمن هذه الحقوق فبان هذا الحكم يسري على السلع

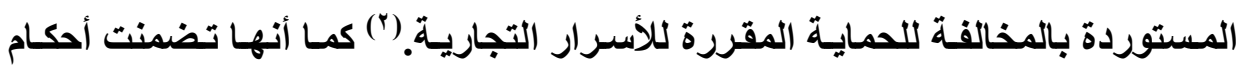

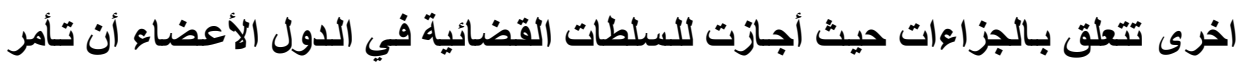

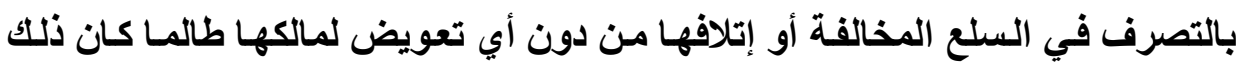

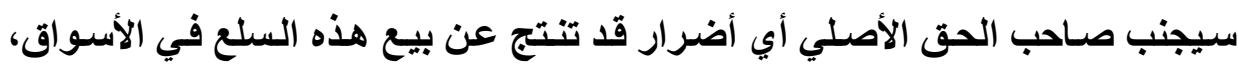

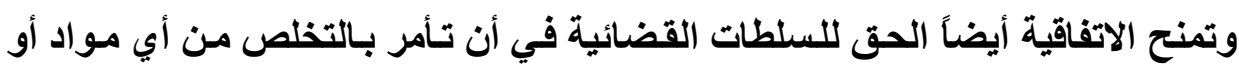
آلات أو معدت تستخدم في تصنيع السلع المخالفة.(")

(1) See in general, Carlos Correa , Trade Related Aspects of Intellectual Property Rights: A Commentary on the TRIPS Agreement (Oxford Commentaries on GATT/WTO Agreements, (OUP Oxford , 2007), p.119.

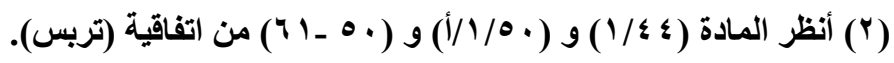

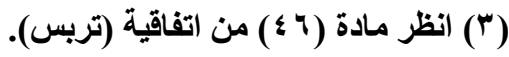




\section{الخاتمة}

عالجت هذه الاراسـة موضسوع مـا يعد تعدياً ومـا لايعد كذلك على الأسـرار التجاريـة، وانصبت هذه الدراسـة على لائحة حمايـة المعلومسات التجاريـة السرية في

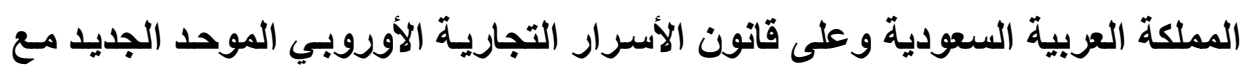

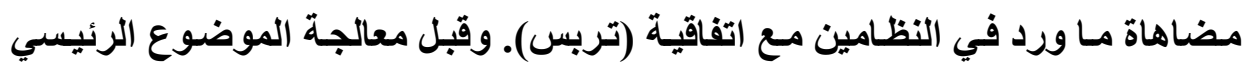

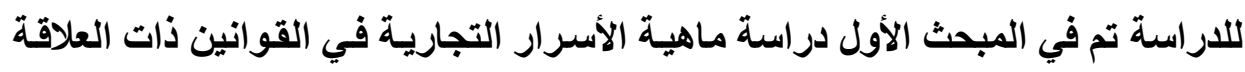

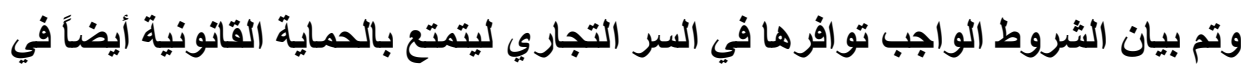

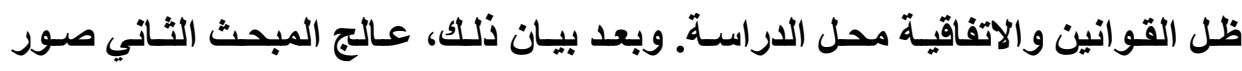

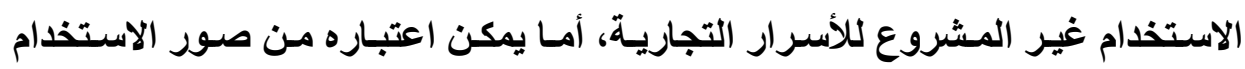

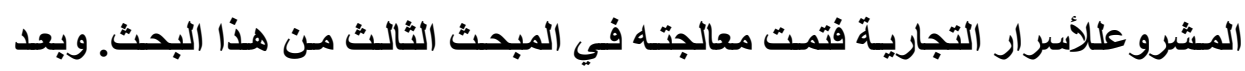

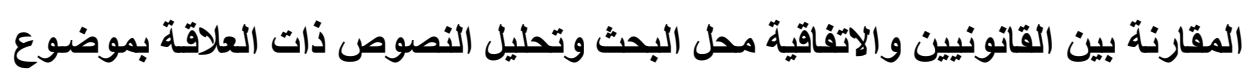

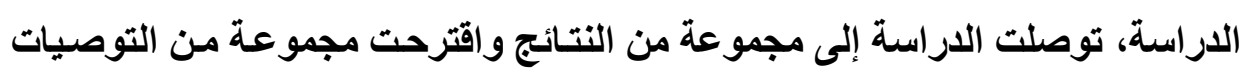

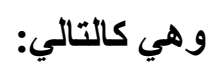

أولاً: النتائج كئح

جاعت لانحة حماية المطومات التجارية السرية إجمالا متتاغمة مـع المتطلبات الدولية المتمثلة في اتفاقية (تربس) وقد توصلت الدراسة إلى مجموعة من النتائج

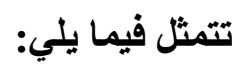

وجـات الاراسـة أن تعريـــ الأسـرار التجاريـة الـوارد فـي لاتحسة المعلومسات

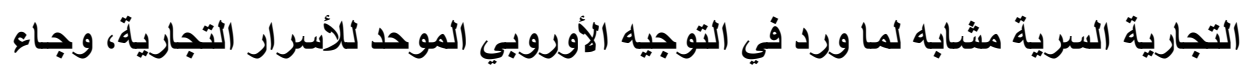
التعريف في كلاهما متتاغماً مع ما أوردته اتفاقية (تربس) من تعريف للأسرار التجارية 
إلا أن الدراسـة كثفت عن عيب فني وخطأ في صياغة المـادة ( ) من لايحة حمايـة الأسرار التجارية فيما يتعلق بمحاولتها لتعريف ماهية الأسرار التجارية وكشفت الاراسـة أيضاً أن التعريفـات التي وردت في القوانين محل الدراسـة جاوت عامة بحيث يمكن تطبيقها على مجال واسع من الأسرار التجارية دون الحاجة

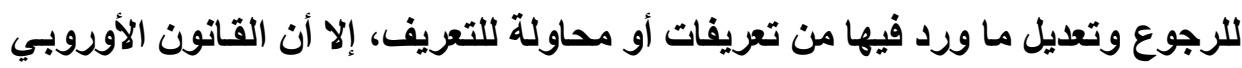
الموحد تميز باعتبـاره المعارف الفنيـة Know-How مسن ضسمن عناصر الأسـرار

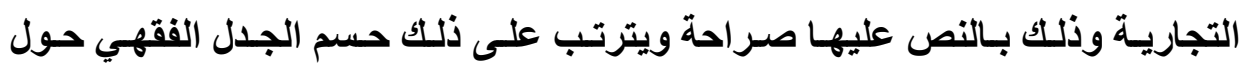
طبيعتها. أمسا فيمـا يتعلق بشروط حماية الأسرار التجارية،فكشفت الدراسـة أن هنـاك تطابق بين شروط الحماية في النظام السعودي والأوروبي، ممـا يجعلنـا نستنج المدى الندي الكبير لتأثير اتفاقية (تربس) على هذين النظامين. وجدت الدراسة أن صور التعدي غير المشروع على الأسرار التجارية في النظام

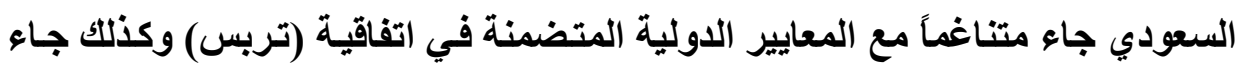

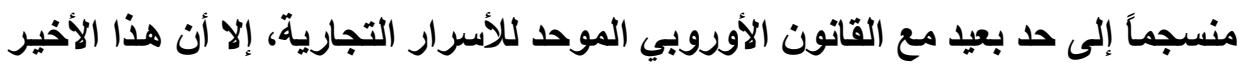

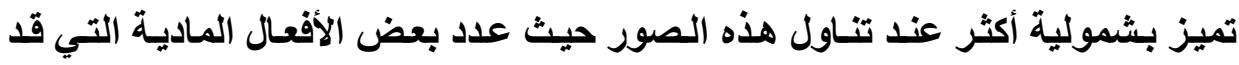

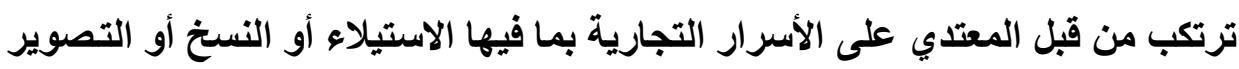

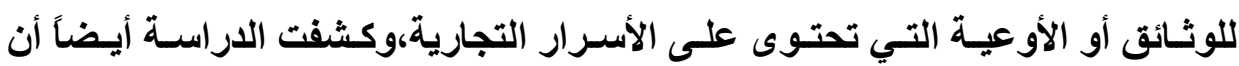

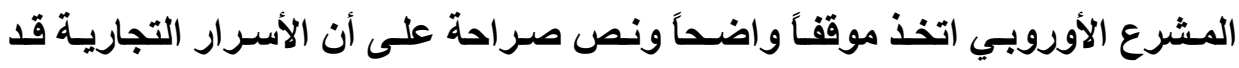

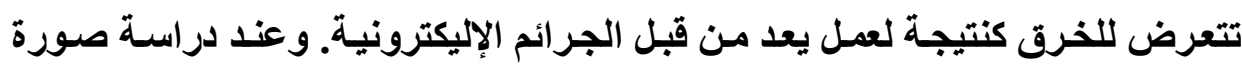

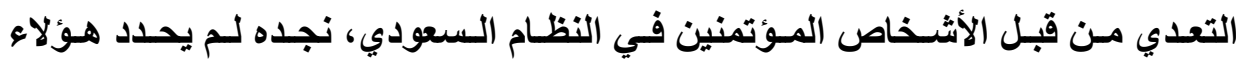
الأثخاص وترك المجال مفتوحاً أمام الفقه لتحديد ذلكت وفي نفس السياق تميز القانون

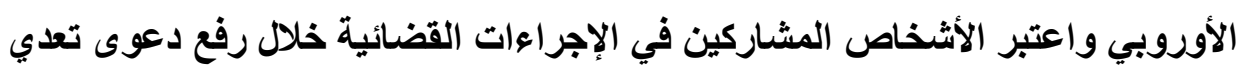


على الأسرار التجاريـة ومنهم أطراف الدعوى والمحامين وممثلي الخصوم والشهود من قبل الأثخاص المؤتمنين على الأسرار التجارية محل النزاع. اما فيما يتعلق بصورة التعدي غير المشروع عن طريق الإخلال بالعقود، فقد

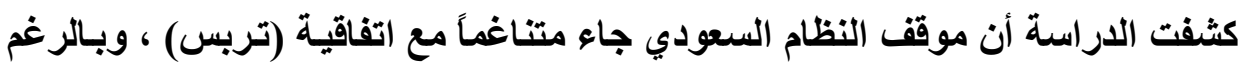

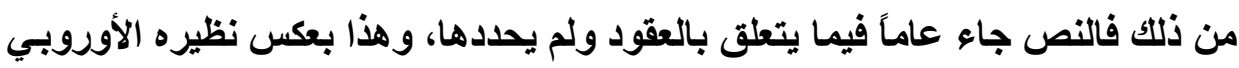

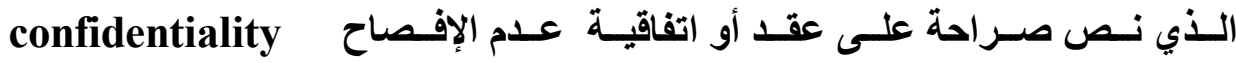
agreement

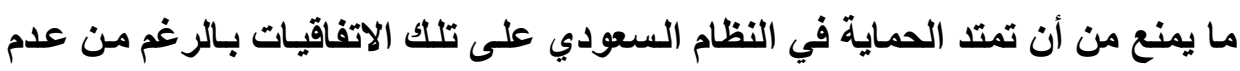

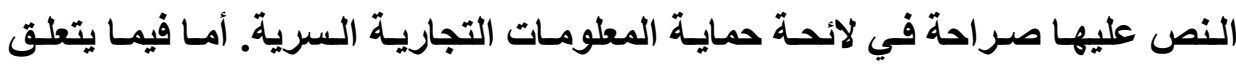
بصورة التعدي على الأسرار التجاريـة من قبل الغير فقد وجدت الاراسـة أن النظام السعودي يحصرها في عملية الحصول على المعلومة بعكس القانون الأوروبي الذي

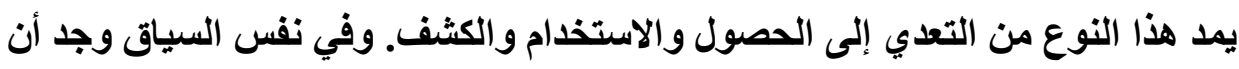

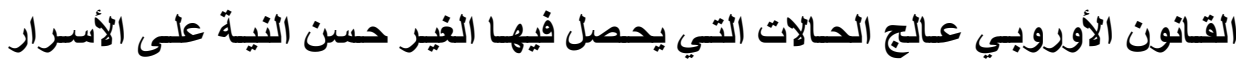

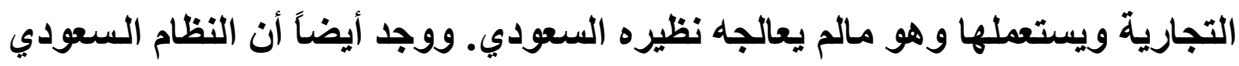
أغفل معالجة السلع المخالفة (التي جاءت كنتيجة لتعدي على سر تجاري محمي) سواء

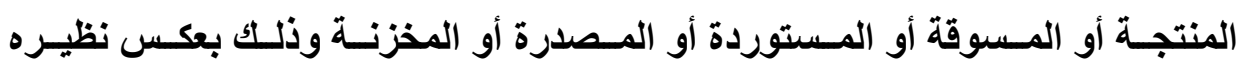
الأوروبي الذي عالجها بشموليه بما فيها الحظر والإتلاف والمصادرة.

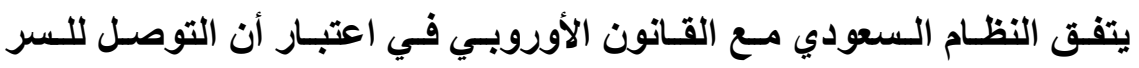

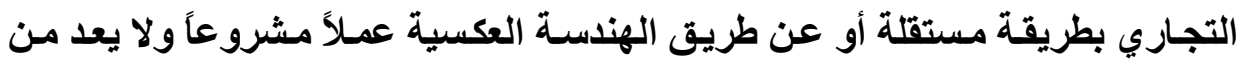
صور التعدي غير المشروع على هذه الحقوق بمـا يعني أن كـلا النظامين لا يقران

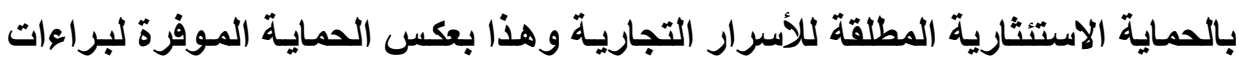

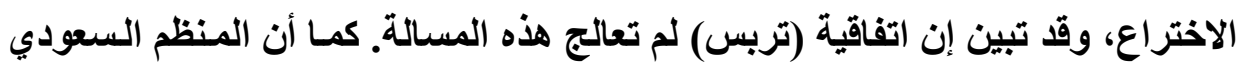


أغفل صورة التوصل للأسرار التجارية عن طريق الملاحظة أو الاراسة أو التفكيك أو

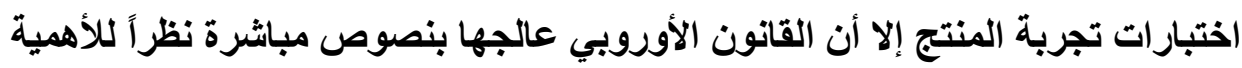

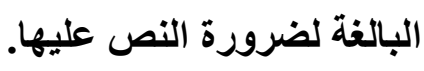
أغفل القانون الأوروبي معالجة اشتراط الإفصاح عن الأسرار التجارية للجهات الحكومية بهاف تسويق المنتجات الدوائية والزراعية الكيميائية الجديدة بالرغم أنها

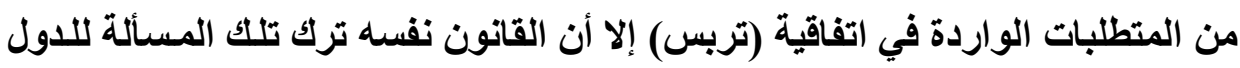
الأعضاء لتنظيمها ولكن دون النص صراحة على تلك المنتجات. أمـا النظام السعودي

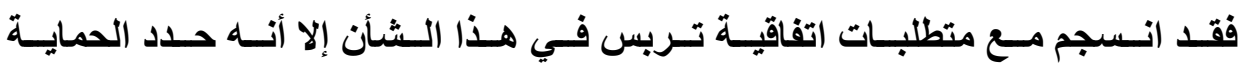

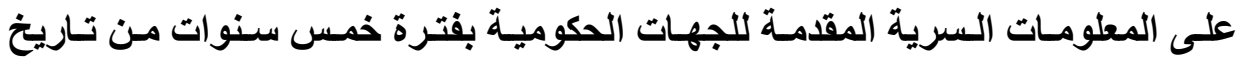

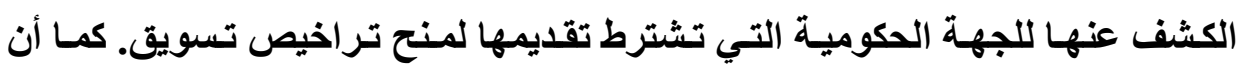

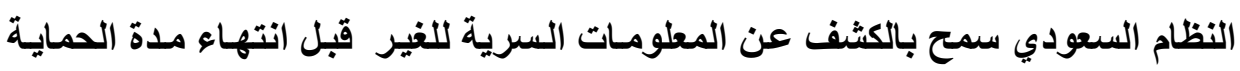
وذلك لأغراض البحث والتجارب في حالة كون تكرارهـا يتسبب في أضرار لإنسان

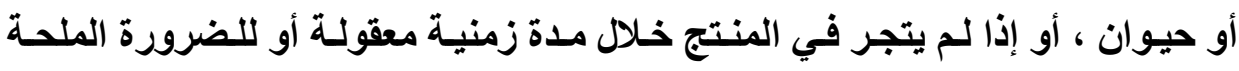
وكذلك ألزم الجهة الحكومية المختصة بحماية هذه الأسرار وعدم كشفها إلا في حالة

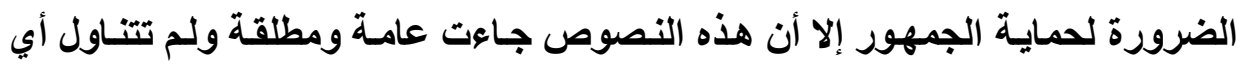

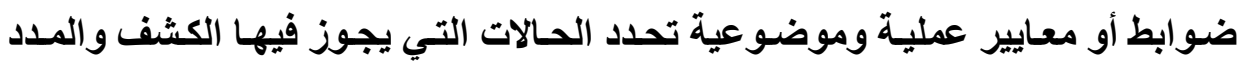
المتعلقة كحالة عدم الإتجار أو ضـوابطومعايير تقدير الضرورة الملحة التي تدعو للكشف عن السر التجـاري. وفي المقابل لم يعالج القـانون الأوروبي هذه المسائل

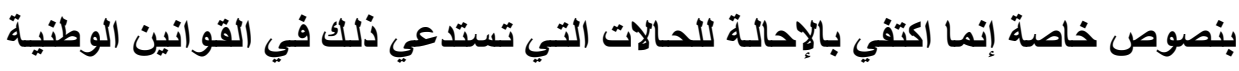

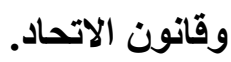


ثانياً:التوصيات

بصورة مجملة بالرغم من توافق لاتحة المعلومات التجارية السرية مع المعايير الدولية إلا أن الضرورة لازالت قائمة لتبني قانون (نظام) يحكم حماية الأسرار التجارية لإية وفقاً لأحثث التطورات القانونية العلمية بما يحقق للمملكة مكانة اقتصادية تسودها روح المنافسة والإبداع وتسهم في جذب الاستثمارات الأجنبية، وفيما يتطق بالجانب الذي

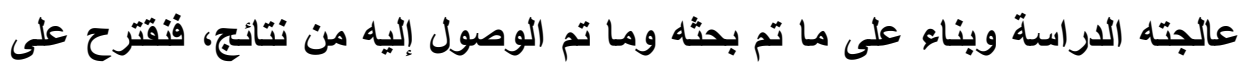
المنظم تبني التوصيات التالية:

1. النص صراحة على تعريف للأسرار التجارية يتصف بالثمولية، ويتسنى ذلك

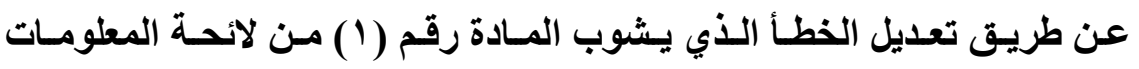

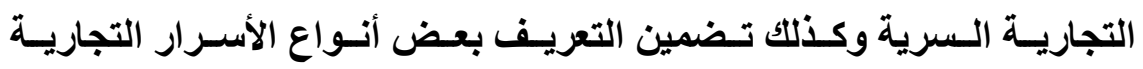

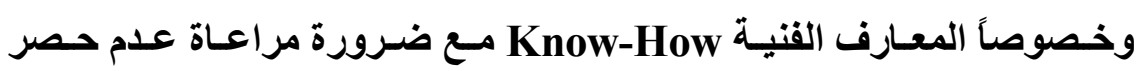
أنو اعها والنص على قابلية تلك الأنواع للقياس عليها.

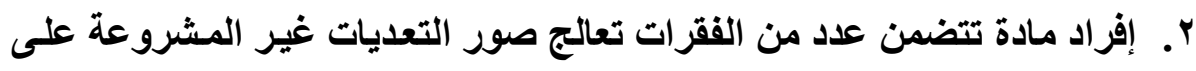

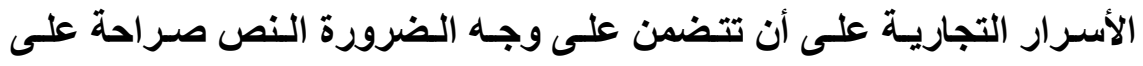

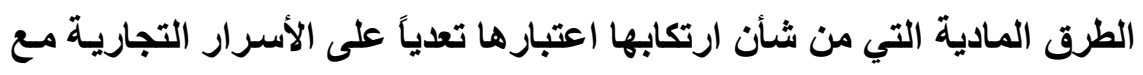
ضرورة تضمينها طرق التعدي عليها بأساليب لها علاقة بالئا بالجرائم الإكترونية.

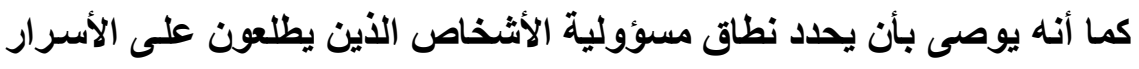

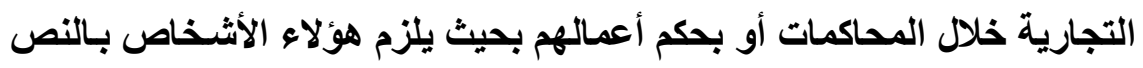

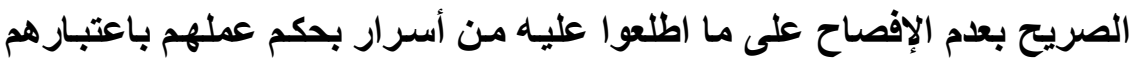

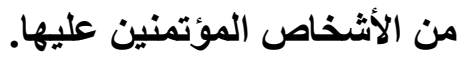




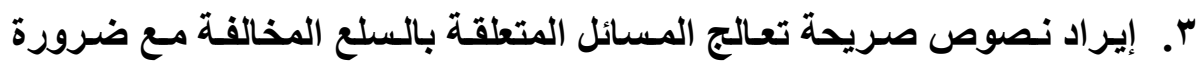
النص على حظر بيعها أو عرضها للبيع أو تخزينها أو استيرادها أو تصديرها كما أن ذلك يتطلب أيضاً تنظيم طرق اتلافها وسحبها من الأسواق ومصادرتها.

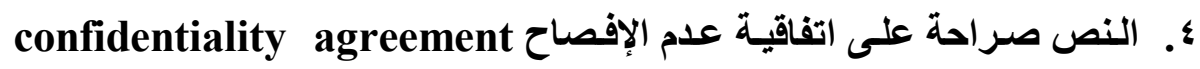

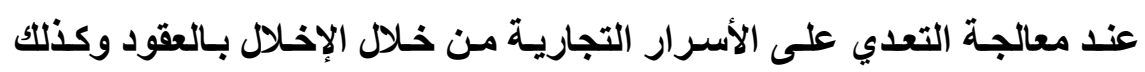

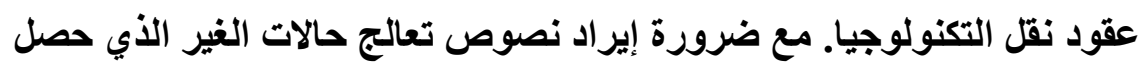

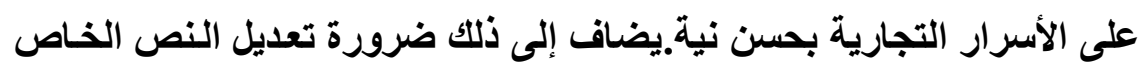

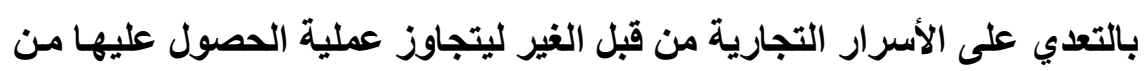
قبل الغير إلى الغير الذي يكثفها أو يستعلها.

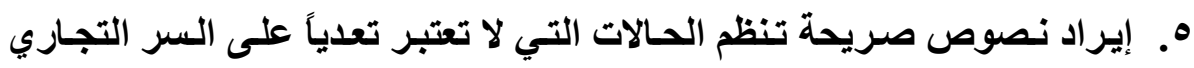

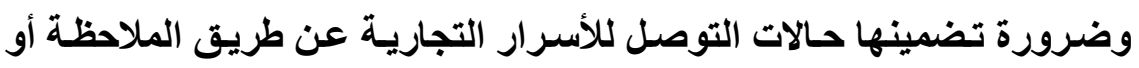

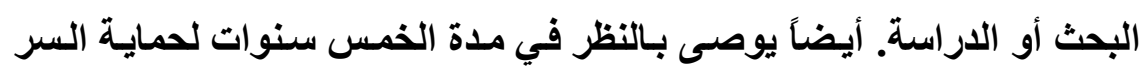

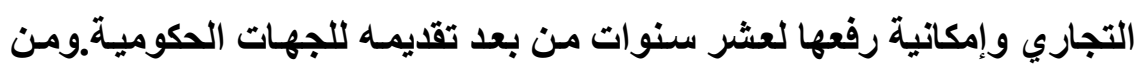
الضرورة بمكان تقييد صلاحيات الجهة الحكومة وسلطتها التقديرية في امكانية

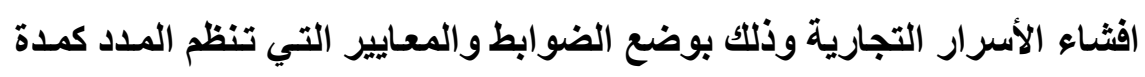

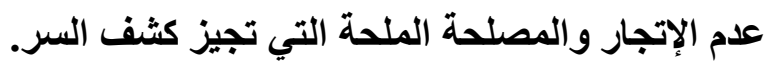
7. نرى ضرورة تضمين النظام نصوصاً خاصة بالحمايـة الجزائية للسر التجاري

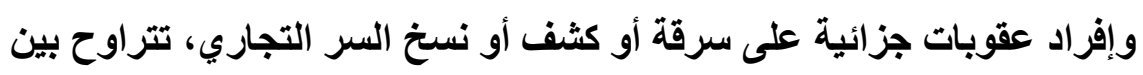

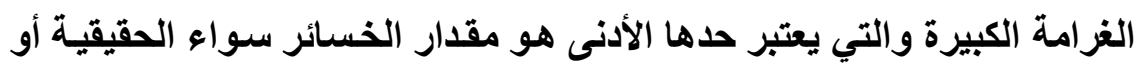

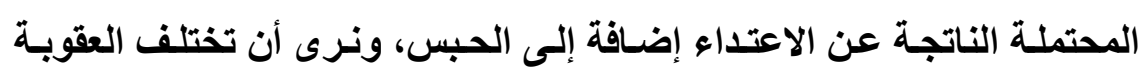

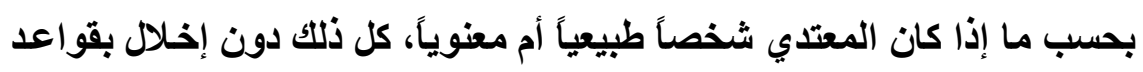

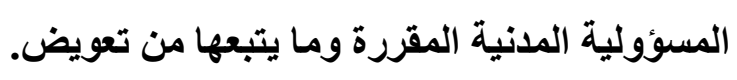




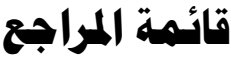

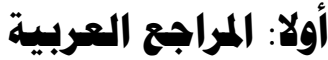

1. أبو العلا علي النمر، الالتزام بالمحافظة على الأسرار في عقود نقل التكنلوجيا،

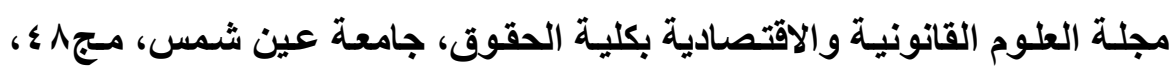

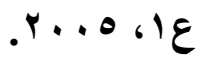

r. أنور طلبة، حماية حقوق الملكية الفكرية، المكتب الجامعي الحديث، الإسكندرية ،

$$
r+11
$$

r. أمسين مصطفى محمد، الحمايـة الجنائيسة لحقوق الملكيـة الصناعية في ضـوء

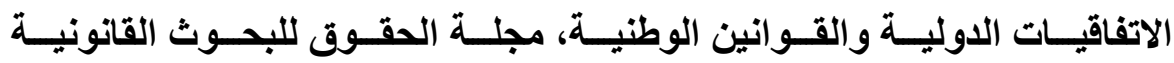

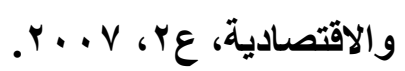

؛. إبراهيم أحمد إبراهيم، حمايـة الأسرار التجاريـة والمعرفـة الفنية، مجلـة العلوم

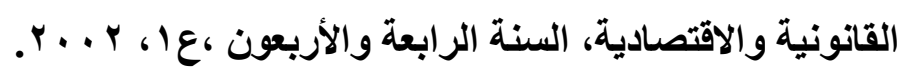

•.إبـراهيم محمد عبيدات، الأسـرار التجاريـة، المفهوم والطبيعة القانونيـة وآليـة

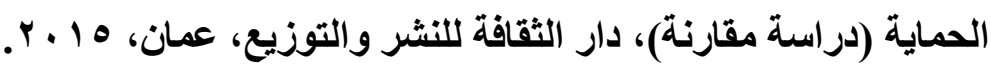
7. احمد عبدالرحمن المجالي، حماية الاسرار التجارية في القانون السعودي، مجلة

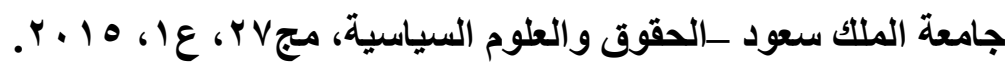
V . أمسين مصطفى محمـ، الحمايـة الجنائيسة لحقوق الملكيـة الصناعية في ضـوء الاتفاقيات الدولية والقوانين الوطنية، دار الجامعة الجديدة، الإسكندرية، ـ 1 + r. 
^. جلال وفاء محمدين، الحمايـة القانونية للملكية الصناعية، وفقاً لاتفاقية الجوانب

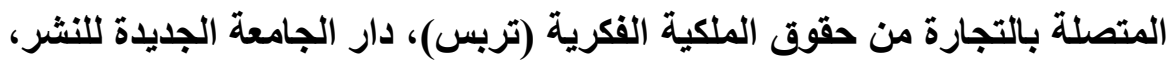

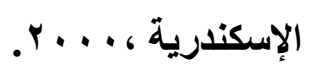

9. جلال وفاء محمدين، فكرة المعرفة الفنية والأساس القانوني لحمايتها (دراسة في

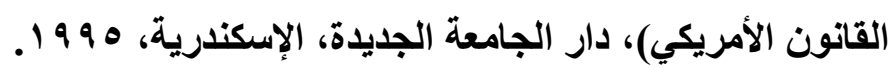

• 1.حسام الدين عبدالغني الصغير، حماية المعلومـات غير المفصح عتها والتحديات التي تواجه الصناعات الاوائية في الدول النامية، دراسة لاتفاقية الجوانب المتصلة

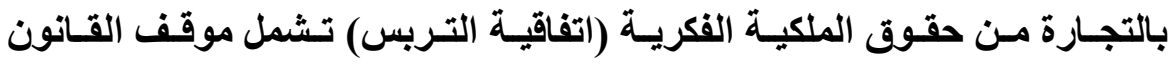

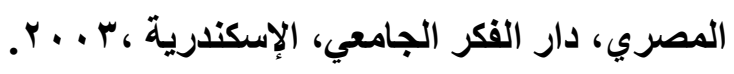

11.حسام الاين عبدالغني الصغير، حمايـة المعلومـات غير المفصح عنها في اتفاقية

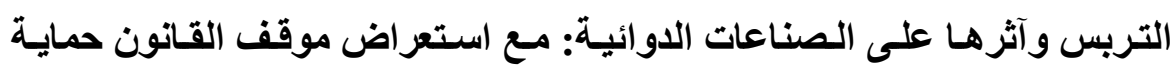

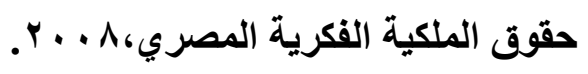

r ا ـحسام عيسى، نقل التكنولوجيـا (دراسـة الآليـات القانونيـة للتبعيـة الدوليـة، دار

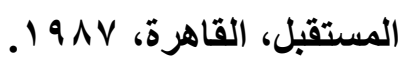

با ا.خالا ممدوح إبراهيم، حقوق الملكية الفكرية (الملكية الصناعية ـ الملكية الأدبية

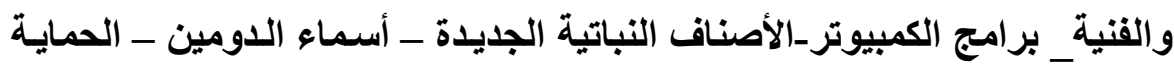

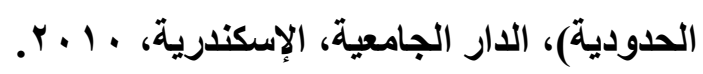

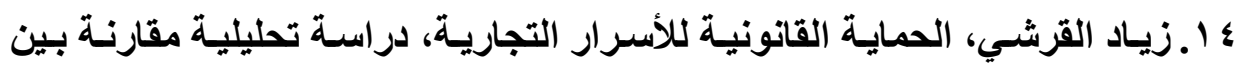

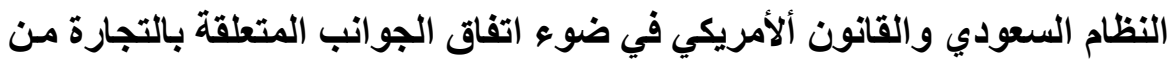

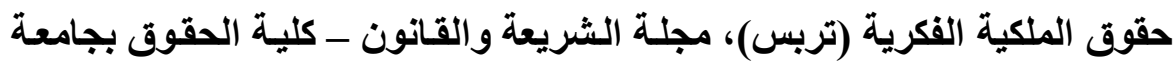

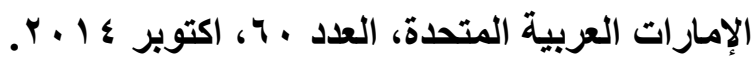


ه ا ـميحة القليوبي، الملكية الصناعية (براعات الاختراع، نماذج المنفعة، التصميمات التخطيطية للاوائر المتكاملـة المعلومـات غير المفصح عنها، العلامـات، البيانـات التجارية والمؤشرات الجغرافية التصميمات والنماذج الصناعية الأصناف النباتية، الاسـم التجـاري، وفقًا لأحكام قانون حمايـة حقوق الملكيـة الفكريـة رقم ب ب لسنة

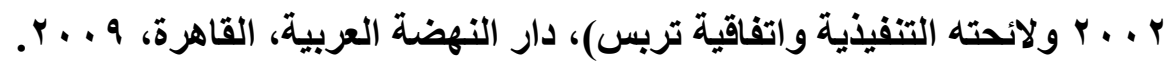
17 ـ عبدالهادي محمد الغامـدي، الملكيـة الصناعية، وفقـاً لأنظمـة الملكيـة الصناعية السعودية واتفاقيتي باريس والتربس، مكتبة الثقري، الرياض، ع ب ع أهـ. V ا ـعـيم مغبغـب، بـراة الاختـراع، ملكيـة صـنـاعية وتجاريـة (دراسـة فـي القـانون

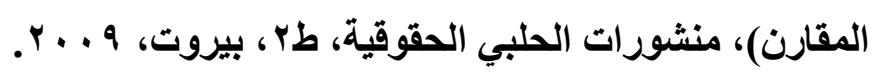

1 ا ـــوري حمــ خـاطر، شـرح قواعد الملكيـة الفكريـة ـ الملكيـة الـصناعية، الطبعـة

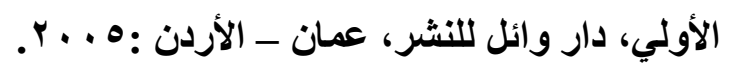

9 ا.رضوان عبيدات، حمايـة الأسرار التجاريـة في التشريع الأردني والمقارن، مجلة

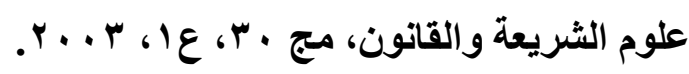

• r. رياض أحمد عبدالغفور، الحماية القانونية للمعلومـات غير المفصح عنها دراسـة مقارنة في ضوء قوانين واتفاقيات حقوق الملكية الفكرية وأحكام القانون المدني،

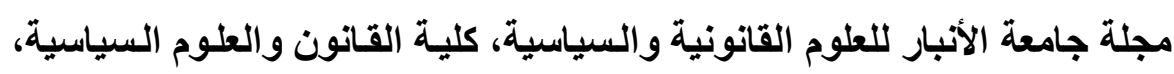

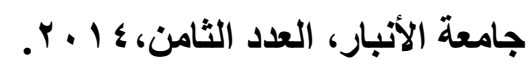
ا ب. عماد حمد الإبراهيم، الحماية المدنية لبراعات الاختراع والأسرار التجارية: دراسة مقارنة، رسالة ماجستير قدمت لكلية الدراسات العليا في جامعة النجاح الوطنية في

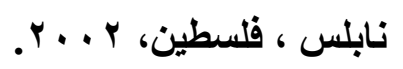


Y Y. عمر كامل السواعدة، الأساس القانوني لحماية الأسرار التجارية (دراسة مقارنة)،

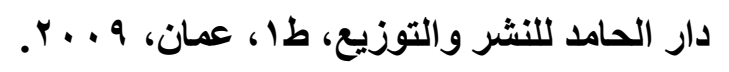

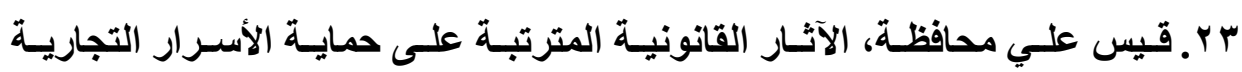

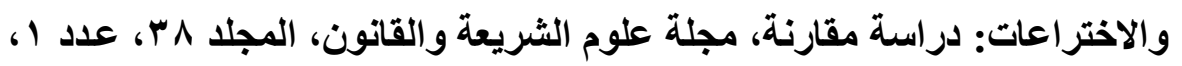

צ r. محمد يوسف الفاعوري، الحماية القانونية للأسرار التجارية في التشريع الأردني،

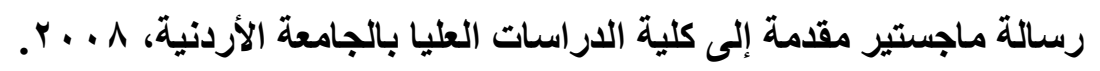

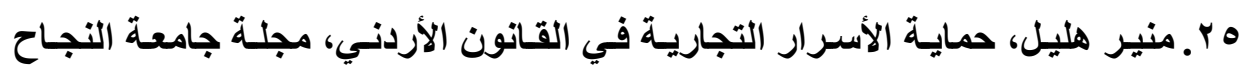

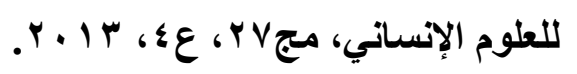

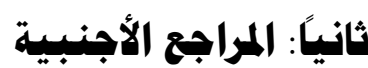

1. Aplin, T.; Bently, L., Johnson, Ph. \&Malynicz, S., Gurry on breach of confidence: The protection of confidential information, 2nd ed., oup, 2012.

2. Aplin, Tanya, Reverse Engineering and Commercial SecretsCurrent Legal Problems 66.1 (2013).

3. Brian T. Yeh, Protection of Trade Secret: Overview of Current Law and Legislation, Congressional Research Service, 7-5700, (2016).

4. Carlos Correa , Trade Related Aspects of Intellectual Property Rights: A Commentary on the TRIPS Agreement (Oxford Commentaries on GATT/WTO Agreements, (OUP 
Oxford , 2007).David T. Keeling, Intellectual Property Rights in EU Law Volume I: Free Movement and Competition Law: 1 (OUP Oxford, 2004)

5. Cleveland, Joseph F, Jr., Preventing Trade Secrets Theft under the New Trade Secrets Law,Computer and Internet Lawyer, 33.9 (2016), p16.

6. Coleman, A., The legal protection of trade secrets, Sweet \& Maxwell, 1992.

7. Daniel Gervais, Intellectual Property and Trade and Development, (Oxford University Press; 2 ed., (2014).

8. Dogra, Rahul; Dhiman, Vijay; Gupta, Nipun, Intellectual property rights (ipr) and mechanisms for intellectual property protection (ipp): a review,International Journal of Pharmaceutical Sciences and Research 3.11, (2012).

9. Dr. François Dessemontet, Protection of Trade Secret and Confidential Information "Protection of Trade Secrets and Confidential Information", Intellectual Property and International Trade: The TRIPs Agreement, (Kluwer Law International, La Haye, 1998). 
10. Fitzpatrick, William M; DiLullo, Samuel A., International Trade Secret Protection: Global Issues and Responses, Competition Forum 11.2 (2013).

11. Gervais, D., The Trips Agreement: Drafting history and analysis, 4th ed., Sweet \& Maxwell, 2012.

12.Halling, R Mark, Weyand, Richard F., The Economic Valuation of trade secret, Journal of internet Law, Feb. (2006),

13. Justin Malbon, Charles Lawson, Mark Davison, The WTO Agreement on Trade-related Aspects of Intellectual Property Rights: A Commentary, (Edward Elgar Publishing, 2014)

14. Marco AlexandreSaias ,Unlawful acquisitionof trade secretsbycybertheft:betweentheProposedDirectiveonTradeSe cretsandtheDirectiveonCyberAttacks, JournalofIntellectualPropertyLaw\& Practice, Vol.9,,No 9(2014).

15. Michael L. Rustad, The Negligent Enablement of the Trade Secret Misappropriation, Technology Law Journal, 22, 3, Mar (2006). 
16. Nuno Sousa Silvia, What exactly is trade secret under the proposed directive?, journal of Intellectual Property Law \& Practice, Vol 9, No. 11, (2014).

17. Tanya Aplin, A critical evaluation of the proposed $\mathrm{EU}$ Trade Secrets Directive, King's College London Dickson Poon School of Law Legal Studies Research Paper Series, paper no. 2014-25.

18. Torremans, Paul L. C, The road towards the harmonisation of trade secrets law in the European Union,Revista La PropiedadInmaterial, Issue 20, (2015)

19. Wes Anson, Donna Suchy, Fundamentals of Intellectual Property Valuation: A Primer for Identifying and Determining Value, (American Bar Association (2005)

$$
\text { ثالثًا: التشريعات والمعاهدات والتقارير }
$$

20. Agreement on Trade-Related Aspects of Intellectual Property Rights, The TRIPS Agreement is Annex 1C of the Marrakesh Agreement Establishing the World Trade Organization, signed in Marrakesh, Morocco on 15 April 1994. 
21. Baker \& Mackenzie, Study on Trade Secrets and Confidential Business Information in the Internal Market, MARKT/2011/128/D (2013) (B\&M Report).

22. Defend Trade Secrets Act of 2016 (18 U.S.C. § 1839)

23. Directive (EU) 2016/943 of the European Parliament and of the Council of 8 June 2016 on the protection of undisclosed know-how and business information (trade secrets) against their unlawful acquisition.

24.Hogan Lovells International, Study on Trade Secrets and Parasitic Copying (Look-alikes), MARKT/2010/20/D: Report on Trade Secrets for the European Commission (2012) (Hogan Lovells Report).

نظام براءات الاختراع والتصميمات التخطيطية للارات المتكاملة والأصناف النباتية و النماذج الصناعية لعام هץ ؛ أهـ لائحة المعلومات التجارية السرية لعام كب؟ الهـ لهـ

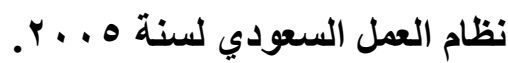
قانون المنافسة غير المشروعة والأسرارالتجارية الأردني لسنة ... . . . قانون حماية الملكية المصري لسنة ب ... بـ. قانون حماية الأسرار التجارية القطري لسنة هـ ـ. r. قانون الأسرار التجارية البحريني لسنة ب. ..

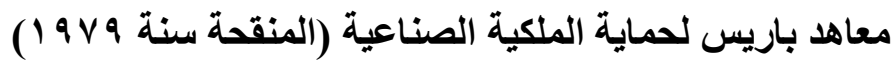

